\title{
Addressing the Problems of Access: Protecting Sources, While Giving Users Certainty
}

ABS Series No. 1

Jorge Cabrera Medaglia and Christian López Silva

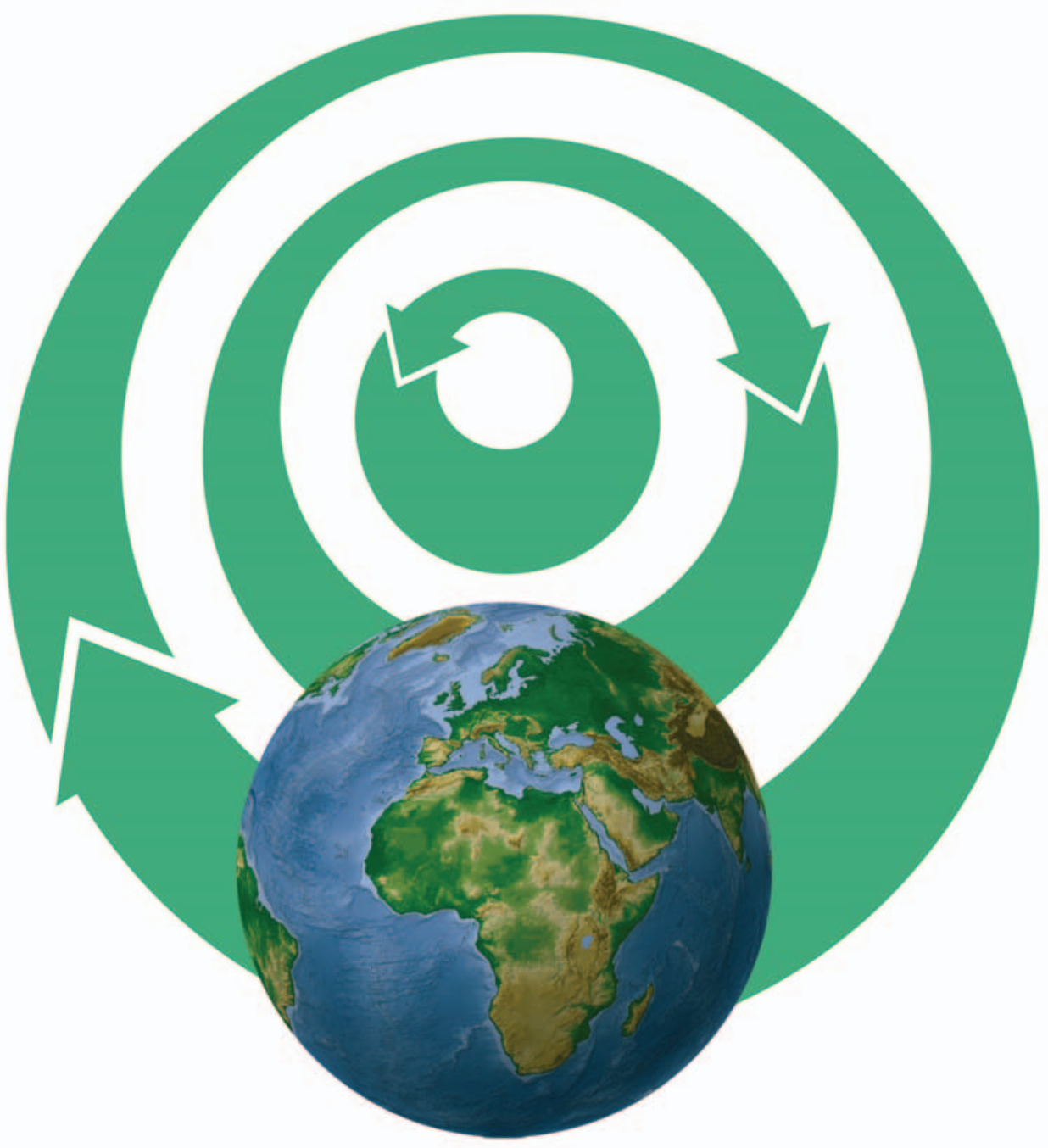



Addressing the Problems of Access:

Protecting Sources, While Giving Users Certainty 



\section{Addressing the Problems of Access: \\ Protecting Sources, While Giving Users Certainty}

Jorge Cabrera Medaglia and Christian López Silva

IUCN Environmental Policy and Law Paper No. 67/1 
The designation of geographical entities in this book, and the presentation of the material, do not imply the expression of any opinion whatsoever on the part of IUCN or the German Federal Ministry for Economic Cooperation and Development (BMZ) concerning the legal status of any country, territory, or area, or of its authorities, or concerning the delimitation of its frontiers or boundaries.

The views expressed in this publication do not necessarily reflect those of IUCN or BMZ.

This publication has been made possible in part by funding from BMZ.

Published by:

IUCN, Gland, Switzerland in collaboration with the IUCN Environmental Law Centre, Bonn, Germany

Copyright:

(C) 2007 International Union for Conservation of Nature and Natural Resources

Reproduction of this publication for educational or other non-commercial purposes is authorized without prior written permission from the copyright holder provided the source is fully acknowledged.

Reproduction of this publication for resale or other commercial purposes is prohibited without prior written permission of the copyright holder.

Citation: $\quad$ Cabrera Medaglia, Jorge and Christian López Silva (2007). Addressing the Problems of Access: Protecting Sources, While Giving Users Certainty. IUCN, Gland, Switzerland. xiv $+77 \mathrm{pp}$.

ISBN:

$978-2-8317-0979-6$

Cover design by: $\quad$ IUCN Environmental Law Centre

Cover image: $\quad$ Beverly Lorenc

Layout by: $\quad$ magoodesign $•$ Markus Kahlenberg

Produced by: $\quad$ IUCN Environmental Law Centre

Printed by: $\quad$ medienHaus Plump, 53619 Rheinbreitbach, Germany

Available from: $\quad$ IUCN Publications Services

Rue Mauverney 28

1196 Gland

Switzerland

Tel +41229990000

Fax +41229990010

books@iucn.org

www.iucn.org/publications

A catalogue of IUCN publications is also available.

The text of this book is printed on Novatech $90 \mathrm{~g} / \mathrm{m}^{2}$ paper made from raw materials originating from responsibly managed forests. 


\section{Contents}

Foreword

Series Editor's Preface

About the Series

Acronyms

\section{Chapter 1 Introduction}

1.1

Some facts and issues

1.2 Open issues and concerns

1.2.1 The use of CBD definitions

1.2.2 The application of traditional property regimes (over tangible assets) to "genetic resources"

1.2.3 Public domain

1.2.4 Contractual enforcement

1.2.5 Reliance on source country law

1.2.6 Lack of incentive-based approaches

Characteristics of national regime construction

1.4

Purpose and structure of this book

\section{Chapter 2 Setting the Stage}

2.1

\subsection{1}

2.1.2

2.1.2.1

2.1.2.2

2.1.2.3

2.1.2.4

2.1.2.5

2.1 .3

2.1.3.1

2.1.3.2

2.1 .4

2.1 .5

2.1.6

2.1 .7

2.1 .8

2.1 .9

2.1 .10

2.2

2.3

2.4

2.5

2.6

2.6.1

2.6.2

2.7
Construction of access regimes

Main objectives of ABS legislation

Frequent criticisms of access legislation to date

Extent of scope and coverage

Cumbersome application process

Difficulties involving prior informed consent

Complexity of institutional mechanisms

Contractual expectations and benefit sharing

Definitions, scope and exclusions

Definition issues

Precise scope

Ownership of genetic resources

Mechanisms to control utilization

Restrictions on access for specific uses and third party transfer

Legislative interpretation of access and benefit-sharing obligations and their relationship

Monitoring and legal remedies

Restrictions imposed for environmental purposes

Support for conservation

Different treatment for agricultural genetic resources and ex-situ collections

Regulatory complexity: double permissions

IPR-related issues

Legal certainty

Functionality and consistency in the ABS legal frameworks

General considerations

Functionality and consistency of ABS systems

Brief reflections on the implementation of $A B S$ laws vii

ix

xi

xiii

\section{1}

2

3

3

3


$\begin{array}{lll}3.1 & \text { The conceptual aspects } & 27\end{array}$

3.1.1 Refining the concept of genetic resources 28

3.1.1.1 The utilitarian approach

3.1.1.2 Genetic resources as the "utilization of genetic information" 34

3.1.1.3 The permanent access criteria 35

3.1.2 An access-based (source country) view of the issue of derivatives 38

3.1.3 The utilization issue 39

$\begin{array}{lll}3.2 & \text { Property rights in genetic resources } & 40\end{array}$

3.2.1 Applying existing law of property to genetic resources 40

3.2.2 Property rights issues generally 41

3.2.2.1 National law on the property interest in genetic resources 41

3.2.2.2 Applying conventional property law to genetic resources 42

3.2.2.3 Public domain $\quad 43$

3.2.2.4 The example of Costa Rica 43

3.2.2.5 Open questions 44

3.2.3 Avoiding the property-definition problem 45

3.2.4 Recommendations 46

3.3 Differentiating between basic and commercial research $\quad 46$

$\begin{array}{lll}3.3 .1 & \text { Legislative approaches } & 48\end{array}$

3.3.2 Recommendations 49

$3.4 \quad$ Prior informed consent (PIC): making it operative and certain 50

3.4.1 National PIC measures $\quad 50$

3.4.1.1 Insight into PIC from user countries $\quad 51$

3.4.1.2 Bonn Guidelines: recommendations for PIC implementation 51

$\begin{array}{lll}3.5 & \text { Conclusions: pathways to effective legislation in source countries } & 51\end{array}$

Chapter 4 Enforcement, Tracking, and the Need for Incentives and Other Approaches 53

$4.1 \quad$ Preliminary considerations - inefficacy of mandatory measures 53

4.2 Controlling and monitoring the utilization of genetic resources 53

4.2.1 Direct national monitoring and oversight

4.2.2 Facilitating/mandating transboundary monitoring and oversight $\quad 54$

4.2.3 Contractual mechanisms

4.2.4 Case study: tracking and monitoring at INBio 56

4.2.4.1 External transfers for bioprospecting 56

4.2.4.2 External transfers for biodiversity inventory 56

4.2.4.3 Costs of tracking resources through INBio $\quad 57$

4.2.4.4 Overall analysis: practical aspects of INBio's tracking system 57

4.2.4.5 Legislation where there is less infrastructure

$\begin{array}{lll}4.3 & \text { Source-based incentives for compliance } & 57\end{array}$

4.3.1 Role of incentives in source-country legislation 60

4.3.2 Recommendations regarding monitoring and oversight 60

$\begin{array}{lll}4.4 & \text { Additional concerns: flexibility and law } & 61\end{array}$

$\begin{array}{lll}4.5 & \text { Flexibility through governmental reciprocality } & 61\end{array}$

4.6 Case study: reciprocality in the Seychelles' draft ABS Law 62

$\begin{array}{lll}4.7 & \text { Enforcement and guarantee } & 63\end{array}$

$\begin{array}{lll}4.8 & \text { Trade concerns } & 63\end{array}$

$\begin{array}{lll}\text { Chapter } 5 \text { Conclusions } & 65\end{array}$

$\begin{array}{ll}\text { References } & 67\end{array}$ 


\section{Foreword}

It is my pleasure to present this book Addressing the Problems of Access: Protecting Sources, While Giving Users Certainty, written by Jorge Cabrera Medaglia and Christian López Silva, which is published as IUCN Environmental Policy and Law Paper (EPLP) No. 67/1. This book represents an important contribution to the body of ABS scholarship currently available, and is provided at a critical time in the development of ABS as a functional concept. The IUCN EPLP series dates back to 1972, and has through 35 years maintained a high standard of legal scholarship and quality outputs.

The ABS Series, which includes this book, is the first "sub-series" within the EPLP series, designed in this way to maximize the usefulness and accessibility of these writings to the broad range of participants addressing the ABS challenge at both national and international levels. We believe that this Series offers a real contribution that will enable progress on an issue which has, to now, been stymied both by its complexity and by its controversial nature. It is only through the understanding of those complexities that consensus and useful compromise can be attained that will resolve the controversies and enable a functional system for achieving the all-important equity objective of the Convention on Biological Diversity.

\section{Dr. Alejandro Iza}

Director

IUCN Environmental Law Centre

June, 2007 



\section{Series Editor's Preface}

In the course of The ABS Project, IUCN's Environmental Law Centre has taken a central position in promoting researched and balanced analysis of critical components of the current discussions of the international regime on access and benefit sharing under the CBD. The ABS Series provides the culmination of these efforts, enabling recognized experts to undertake intensive research and present detailed, balanced and reasonable analysis. It operates as a counterpoint to the growing numbers of authors whose work in ABS issues is sometimes more focused on advocacy than research. With this Series, we are trying to take a very different approach and to achieve a very different objective. Simply put, we hope to provide a deeper understanding of the legal, economic, practical and factual issues affecting the debate, and to build our analyses and recommendations on intensive legal research.

I have the pleasure of offering this brief introductory comment, in introduction of the first book in The ABS Series, by Jorge Cabrera and Christian López: Addressing the Problems of Access: Protecting Sources, While Giving Users Certainty. Like all books in the Series, it presents professionally skilled work from among the most able and well recognized legal experts working in the $\mathrm{ABS}$ area, in conjunction with rising experts in the field. In selecting the author, The ABS Project called on recognized international expert Jorge Cabrera and invited him to develop a collaborative team. He selected Christian López Silva, a young lawyer who has already gained extensive international experience in genetic resource issues (ABS and GMOs) through collaboration with key international law experts in IUCN, UNU, and the Sheffield Institute of Biotechnological Law \& Ethics.

This book represents an effort to provide a balanced and researched analysis of the facts and law relevant to the development of national legislation by which countries provide the authority and rules for utilization of genetic resources over which they have sovereign rights recognized under the Convention on Biological Diversity.

This book, and indeed the entire ABS Project, owe a great debt to our primary financial supporter, the German Federal Ministry for Economic Cooperation and Development (Bundesministerium für wirtschaftliche Zusammenarbeit und Entwicklung or BMZ), and especially to Julia Kaiser, Andrea Laux and Frank Schmiedchen - without whom this work could not have been completed. Numerous other partners and collaborators have also made important and sustaining commitments for which we are very grateful.

Finally, on behalf of all of the authors of this title, I express our gratitude for the support and foresight of Dr. Alejandro Iza and the IUCN Environmental Law Centre. It was through Dr. Iza's efforts that The $A B S$ Project became a reality, and his understanding of the difficulties in its implementation as well as his support and the unstinting assistance of the staff of the Environmental Law Centre, including especially Legal Officer Daniel Klein, Project Assistant Ann DeVoy, Senior Information and Documentation Officer Anni Lukács, Documentation Officer Andrea Lesemann and Documentation Assistant Monica Pacheco-Fabig. Collectively, these individuals have been a primary reason that the Project could finish its work and that outputs throughout the term of the project have achieved the level of legal excellence expected of the IUCN Environmental Policy and Law Papers, among which The ABS Series has been included.

Tomme Rosanne Young

Series Editor and Project Manager, The ABS Project June, 2007 



\section{About the Series}

The ABS Series represents a response to two realities: First, the ABS issue is controversial, and technically and legally complex. Because of the constant international concern over controversial policy and political issues, primary focus of all writing on $\mathrm{ABS}$ has been focused on political positions and advocacy, even where the expressed purpose of a particular document is "practical legal advice." Lack of a rigorous body of ABS analysis has been one part of this implementation problem. Many professional inputs are characterized by opinions that are unsupported, or supported only by citations to the opinions of other experts or random references to or excerpts from laws and policy instruments, taken out of context.

To IUCN's Environmental Law Centre, it has become clear that the complexity and the controversiality are linked problems. Solutions to the international $\mathrm{ABS}$ controversies are currently stymied by the lack of credible, non-biased technical analysis of the elements and issues of national implementation. Serious in-depth analyses are needed concerning not only the few $\mathrm{ABS}$ examples, but also the kinds of legal options that are available and the manner in which they function. Simply put, one cannot build a structure without the right tools - and having the tools is meaningless without knowledge of what they can and cannot do.

The second "reality" faced by this project is the fact that, despite the long-extending international negotiations, genetic resources are being taken, studied, developed and utilized every day. Countries do not have the luxury of waiting for international negotiations to answer their questions, before taking action. It is consequently urgent for all parties (users, source countries, source communities and resource owners, user countries, researchers, middlemen and others) to have some basis for taking these actions. More important, they need to have some certainty that this basis will be robust enough to protect his/its rights, even after international negotiations provide some guidance or assistance to all or part of the ABS issue. Even where national laws and practices exist, they are proving inadequate to this objective, in some measure owing to the lack of technical help, as described above.

Consequently, The ABS Series focuses on national implementation and the legal and legislative issues that must be addressed, rather than advocating or addressing a particular side or position in the international negotiations. Through this process, The ABS Series seeks to create the best possible basis of researched information on the practical application issues. It is thus not only a tool for national decisionmakers but also for implementers. While it is not always possible to be certain that one has been unbiased, we have made an effort, at minimum, to note the existence of other credible positions on the issues discussed, and to give some reasons why these positions were not more fully expounded.

As of this writing, the international process for development of the ABS regime is still ongoing. While not intended to "influence" that process, The $A B S$ Series has been designed and written in the hope that a better knowledge of the realities of ABS will enable the negotiators to develop the regime as a functional and effective tool of conservation, equity and international development. As such, we believe that the books in this Series will continue to be primary works of scholarship and professional analysis on which the architects and implementers of the ABS regime will rely long after the negotiations have concluded. In addition, it is hoped that the authors in the Series (or a team of similarly qualified experts) will be engaged to update relevant books from the Series, when the time is right.

Target Audiences: Writing for a broad audience can sometimes be challenging for lawyers. In The ABS Series, however, we recognize that our primary audience includes national decision-makers, NGOs and others, as well as lawyers and economists. We have endeavored to present our research in an accessible way, without doing harm to our absolute standard of legal correctness. Although many readers would 
like a "simplified" pamphlet-style analysis of the ABS issue, which can answer all of their questions in a few pages, this is not possible - the only simple fact about ABS is that it is not simple. The ABS Series provides summaries of the complexities in the issue that legal specialists must grapple with, but at the same time attempts to avoid "legalese" and its companion "econoese." In this way, we feel that The ABS Series provides both clarity and understandability for the non-lawyer, who may obtain a thorough grounding in the ABS issue through reading these books. For the legal or economics professional, however, these books also provide resources and information that will enable their deeper understanding of $\mathrm{ABS}$ issues.

The future: The ABS issue is still evolving. After the commencement of The ABS Project, the CBD entered on a groundbreaking process of re-evaluating ABS and attempting to develop the necessary tools, consensus and understanding (e.g., a clearer and more functional "international ABS regime") that will enable progress toward achieving the goals of the CBD. With this decision, The ABS Project underwent its first evolution. It had begun as a project aimed at helping national governments to find some positive steps to enable them to try to achieve the fixed language of CBD Article 15. In 2004, it necessarily expanded that focus - embracing the goal of informing all participants and interested persons (at national, regional and international level) regarding the options, instruments, practices and processes that can enable the $\mathrm{ABS}$ regime to become a functional mechanism for achievement of the CBD third objective. Only time can decide how far the international negotiations will go toward assisting and supporting ABS implementation. The team of professionals who have worked to provide The ABS Series hope that a useful and innovative result is quickly obtained, and that we will all have the opportunity to extend the work of this Series and to guide, analyze and promote the new regime components that will be developed. 


\section{Acronyms}

ABS
TRIPS
CBD
COP
IPR
ITPGRFA
MAT
PIC
TK
WIPO
WTO

access to genetic resources and benefit sharing

WTO Agreement on Trade-Related Aspects of International Property Rights Convention on Biological Diversity

Conference of the Parties to the CBD

intellectual property rights

International Treaty on Plant Genetic Resources for Food and Agriculture mutually agreed terms

prior informed consent

traditional knowledge

World Intellectual Property Organization

World Trade Organization 



\section{Introduction}

This book is intended to address the "Access" component of the Access and Benefit Sharing (ABS) legal analysis, in detail. Specifically, this book does not aim to provide a comprehensive listing of particular provisions by country, ${ }^{1}$ or engage in country-by-country analysis. Rather, it is focused on substantive issues of Access law, seeking to achieve three divergent objectives:

- To identify the particular elements of "access" that must be addressed by each country that is or may be a source of genetic resources for use in another country (in the words of Article 15, that may be a "country providing genetic resources");

- To explain several primary legal concepts (enforceability, the problems of ambiguity and vagueness, etc.) in a way that is accessible to non-lawyers (international delegates, legislators, government officials, and involved civil society groups). Here the objective is to be very clear about why there are problems, why they have not been solved by existing national approaches, and (possibly) what

\subsection{Some facts and issues}

A number of issues are clear. For example, many of the most significant legal impediments to functional ABS legislation cannot be solved at the level of a single country. Some countries have tried to address key problems, but found that their solutions cannot be functional in the absence of generally agreed understanding regarding the legal principles underlying ABS. Other countries, although recognizing options that could make ABS law effective, have avoided those options, fearing that any decision to use language or concepts not found in the CBD could have the effect of narrowing their rights or legal protections.

A number of the standard statements about why might be the options for solving these problems;

- To use these concepts:

o to explain why earlier "assumptions" about the legal process of implementing ABS were incorrect; and

o to enable understanding of the nature of the legal impediments that must be addressed and the kinds of issues and solutions that can function legally as tools of ABS implementation.

Although it cannot exist without its partner - the "benefit-sharing" component - the access element of the law of the source country, and the contents of any "ABS Agreement" negotiated in that country are the primary legal foundations on which the rest of the "international regime on ABS" will be built. Hence it is essential to create a systematic analysis of the requirements of that law, both the Convention on Biological Diversity (CBD) requirements and the basic requirements of enforceable legislation, which are often not considered in analysis of access legislative issues.

ABS is not working appear to be false - for example, in the negotiations of the Bonn Guidelines, it was consistently stated that overly complex national legislation and institutional arrangements, and high transaction costs were the primary factors that prevented companies from involvement in ABS. There are certainly situations in which legal problems have gotten in the way of $A B S$ negotiations. However, preliminary analysis of contracts and legislation suggests that a country with a very simple ABS law is no more likely to gain an ABS contract than one with very complex requirements. Companies' confidence in the individuals and agencies they are dealing with may be a much more significant factor.

\footnotetext{
Tables of then-current national ABS legislation were provided in an interim publication under this series - Cabrera Medaglia, 2004, A Comparative Analysis. That initial paper, and the tables within it, may be accessed on the IUCN Environmental Law Centre's website at www.iucn.org/themes/law
} 
Key legal issues that have a significant impact on enforceability of ABS Agreements are not addressed in many countries. One such issue relates to the definitions of "genetic resources," "biological resources" and "utilization of genetic resources." If the parties, the judge or other enforcing person/entity cannot objectively verify whether a particular transaction involves "genetic resources" or the "utilization of genetic resources" then the agreement may well be considered to be "vague" and the court will refuse to decide any legal issue relating to it. Many countries try to avoid this problem by writing their law so that $A B S$ provisions apply to all "biological resources;" however this only compounds the problem, since under such a law, every market transaction involving agricultural products would be an "ABS transaction."

Other key legal issues affecting implementation and enforcement include:

- Application of (tangible and intangible) property law to genetic resources;

- Clear understanding of the concept of "public domain" over genetic resources and its legal consequences on the rights transferred to the users;

- Difficulties in drawing the line between commercial and non-commercial ABS projects;

- Difficulties in obtaining Prior Informed Consent (PIC);

- Reliance on unenforceable "assurances" regarding what will happen after the resource has left the country; and

\subsection{Open issues and concerns}

This paper is intended to address the legal issues that can be appropriately applied in "source country" legislation - the need to, on one hand, properly protect national interests in genetic resources while, on the other hand, providing sufficient "user certainty" and other types of legal (market) confidence, to encourage
- Lack of incentives for users to affirmatively seek the relevant permits and agreements.

At least one question has so far not been seriously asked - the ability of the provider country to tie the access agreement to compliance by the user country. Specifically, it is clear that "access" provisions are only half of the required legislation. To be properly covered by law, each "access" arrangement can involve two types of legal instrument:

(1) the "access" instruments (laws, agreement, license, etc.) in the source country, and

(2) the "measure to secure benefit sharing and compliance with the terms and conditions under which access was granted."

Similarly, it is only possible to impose an access requirement where both provider country and user country adopt measures requiring it. User countries undermine the ability to apply ABS, wherever they fail to adopt legislation requiring the companies and institutions in their country to enter into access arrangements for every case in which they are using genetic resources from another country. ${ }^{3}$

In this regard it is equally important to address the legal ability of the source country to condition access on the use of resources only in (or under the jurisdiction of) countries that have adopted sufficient "user measures."

users (research and commercial entities) to incur the time and expense of complying with the "access" 4 component of $\mathrm{ABS}$.

The legal systems for ABS were created without a clear and consistent understanding of certain critical

2 In this connection, it is important to remember that, in the CBD, ABS is entirely focused on cross-border situations. Domestic uses of the country's own genetic resources are not covered. This does not mean that the source country cannot regulate domestic uses, however, only that they are not directly part of the CBD's requirements.

3 These issues are discussed in Tvedt and Young, 2007.

4 It seems useful to divide the ABS process into "access" and "benefit-sharing." 
themes necessary for the systems to be (legally) consistent and functional. Elements of existing legal frameworks (contracts law, property rights regimes, etc.) were utilized with the idea that they would be applicable

\subsubsection{The use of CBD definitions}

In the provisions discussing access, the terms "genetic resources" and "biological resources" are used as defined by the Convention without clarifying their scope. This has made it difficult to clearly determine a key without modification or explanation to transactions related to genetic resources.

Among the elements and mechanisms utilized for the construction of ABS systems are:

aspect of the access systems, such as their scope, and the activities or resources covered by the ABS laws and regulations. ${ }^{5}$

\subsubsection{The application of traditional property regimes (over tangible assets) to "genetic resources"}

Depending on how "genetic resources" is defined, the Convention on Biological Diversity can be considered as the starting point for the creation of a new property right (and consequently a right of commercialization) over these resources. Nevertheless, in contrast to other natural resources (wood, petroleum, minerals), the exercise of property rights (including control) over genetic resources presents difficulties that have not been adequately considered. The Convention intentionally leaves countries the freedom of determining their own systems of property rights over genetic resources, which is correct in terms of the overall convention (which consists predominantly of provisions which call for the development of national legislation), but at the same time, the lack of guidance from the $\mathrm{CBD}$ has been an impediment to the development

\subsubsection{Public domain}

Related to the foregoing, the legal consequences of applying the regime of public domain to genetic resources, as occurs in some legal systems, especially

\subsubsection{Contractual enforcement}

The application and the sufficiency of the contractual processes as a means of guaranteeing the conditions of access and the mutually agreed terms, including the benefit sharing, is still unresolved. In this sense, the of legal analysis of whether traditional systems of property rights could be applicable to genetic resources. For example, in Roman-Germanic systems, an essential aspect of the property right is the ability to exclude others. Regarding genetic resources, physical control over the property does not prevent others from the ability to extract, test or take other actions involving the genetic resource contained in other existing samples. Like the shared nature (even among countries) of the genetic resources themselves, ${ }^{6}$ this fact presents questions regarding ownership and dominion. Likewise, in some countries a distinction has been made between genetic resources (owned by the State) and biological resources (owned by private parties) which contain the genetic resources or components.

with respect to the rights conferred to the user over the samples (extracts, fractions, etc.) needs to be addressed.

principal instrument that the $\mathrm{CBD}$ has considered for the realization of its Third Objective has been the use of bilateral mechanisms (contracts). ${ }^{7}$ Not surprisingly, a body of literature dealing with "bioprospecting

$5 C f$ Caillaux and Ruiz, 2002. In this paper, they affirmed that the access legal framework "must be thoroughly unambiguous with regard the definitions especially with respect to what is really meant by access. The legal regime that controls access must be also very clearly defined in terms of its scope and boundaries. (Does it apply to medicinal plants? Does it apply to taxonomic research? Do the same rules apply to nationals and foreigners?) The success of an access regime will largely depend on these variables."

6 See regarding the transboundary nature of genetic resources, Aguilar, 2004.

7 A quick analysis of the ABS measures, like the 391 Decision of the Andean Community, the Biodiversity Law of Costa Rica and the Provisional Measure of Brazil, among others, shows how contracts are an essential instrument for the ABS systems. See Gartforth et al., 2004. 
contracts" has been developed, ${ }^{8}$ but little formal or official legal interpretation (court decisions and other applications) has actually been generated. At minimum, the application of contract rights alone can be insufficient to protect provider countries or areas,

\subsubsection{Reliance on source country law}

The creation and application of national laws, and the established mechanisms of monitoring and control, have been considered to be sufficient to ensure compliance with the conditions of the permits and access contracts. Essentially, however, these laws and compliance

\subsubsection{Lack of incentive-based approaches}

The regulatory framework and policies of the ABS have not adequately considered the design of incentives to encourage the compliance of users (companies, universities, etc.) with the ABS regulations. The difficulties of applying traditional concepts of property, control, and monitoring to genetic resource uses have not promoted the establishment of incen- especially due to the fundamentally transnational character of the relations of the ABS and the ease of reproducing genetic information contained in the samples.

mechanisms base their ability to determine compliance solely on the user's reports regarding his progress, including indirect reporting (under which the source country's awareness of these results is obtained by screening, patent applications, etc.).

tives for compliance with access procedures, in a way that would make it "good business" for commercial and scientific users to follow the rules. As will be mentioned later, on occasion, the ABS systems have appeared to "penalize"9 those who want to follow the legal procedures. ${ }^{10}$

\subsection{Characteristics of national regime construction}

As conceived in this book, the development of national ABS regimes has over time displayed the following characteristics:

1. Legal/legislative development has occurred mostly in developing countries (that can be qualified as providers of these resources) considering the pioneering experience of the Philippines and the Andean Community. ${ }^{11}$

2. The existing regimes were designed without international guidelines or consensus on how to construct them. ${ }^{12}$
3. It was thought that the existing legal instruments (national laws, systems of property, and systems of contracts) were adequate without modification to establish operative ABS systems. The understanding of some concepts particular to access to genetic resources has impeded, in some degree, the realization of the objectives of the establishment of the ABS regimes. The legal instruments that the countries have utilized to construct ABS systems (such as contracts, procedures to grant permits for use of natural resources, etc.) are developed and regulated under the various national legal systems (i.e., not under a single unified international system).

\footnotetext{
See for instance, Downes, 1994; Gollin, 2002; Cabrera Medaglia, 2004, “Elementos básicos ...”; Rosenthal, 2003; Sampath, 2005 ; CBD, 1998. Young, 2006.

0 For instance the bioprospecting initiatives which became public in Mexico, see Larson et al., 2004.

1 On the legislative process in the Philippines, see Benavidez (in Carrizosa), 2004.

12 Later, the CBD adopted the Bonn Guidelines on Access and Benefit Sharing in 2002. See Decision VI/24. However, the Guidelines do not provide orientation on certain key issues (practical definition of genetic resources; what is utilization, etc.) but have focused on well known concepts like mutually agreed terms, examples of benefit sharing, etc. The Guidelines were based on the previous work of the Expert Panel created by Decision IV/8 para. 3. Before the Panel was created the CBD activities on ABS were limited to gathering information on national measures, good practices on ABS, etc.
} 
Nevertheless, some existing difficulties for the effective application of the ABS laws are due to the lack of understanding (or creating) of what can be called "legal concepts specific to access to genetic resources."

For example, the ABS legislation to date has relatively easily encompassed, in general terms, the following aspects: objectives of the system; definitions (from the CBD); scope of application; competent authorities at different levels; procedure for obtaining prior informed consent; procedure for negotiating the mutually agreed terms (MAT) and the fair and equitable sharing of benefits (using contracts); and requirements that MAT must include mechanisms for monitoring and control and sanctions for non-compliance, including penal, civil, and administrative measures. ${ }^{13}$

As Young affirms, ${ }^{14}$ however, "After 12 years legislative draftsmen and agencies are still attempting to grapple with complex legal problems that hinder the effective $A B S$ implementation. $A B S$ is in some ways 'unique,' particularly in its merger of very new concepts of commercial law and science with the goals of conservation, sustainable use and equity. New legal concepts and tools are needed, as well as new uses of existing tools. Legal innovation, however, is not an easy process."
Equally, it is not possible to address the issue of legal certainty (for provider entities as well as users) without considering the difficulties that users (nationals and foreigners, academics or companies) confront due to the difficulties of knowing how to obtain the prior informed consent and to have certainty with respect to the access procedure. ${ }^{15}$

Initially, it is important to note a critical point: Despite their importance, some of the questions that this study seeks to answer have not been addressed systematically by the specialized doctrine of the $\mathrm{ABS},{ }^{16}$ by the national authorities, or by the decisions of the Conferences of the Parties, with significant exceptions. ${ }^{17}$ These difficulties have not been recognized as obstacles to the effective application of the access laws, except for some specific studies. ${ }^{18}$ For example, studies explaining how to formulate legal frameworks regulating access, although valuable, frequently do not identify the critical elements nor offer any actual assistance with them. ${ }^{19}$ There are studies of legislation that have addressed some of these elements, ${ }^{20}$ but this book will not repeat them. Rather, it intends to explore conceptual aspects and to propose workable options. Nevertheless, when necessary, it may refer to provisions that illustrate the aforementioned concepts. ${ }^{21}$

13 These basic elements have been suggested by authors like Glowka, 1998; and Mugabe, 1997.

14 Young, 2004, "The International Regime from an implementation perspective...”.

15 This issue will be addressed later on. With regard to the private sector difficulties in obtaining prior informed consent, see Columbia University, 1999; Ten Kate and Laird, 1999.

16 However, Young has emphasized the importance of addressing these issues, see, among other articles of the author, 2005, "Gaps and Obstacles...".

17 See for instance Decision V/26 para. 12 adopted at the V Conference of the Parties, which identified the need for more information on issues like: incentive measures, clarification of definitions, market for genetic resources, etc. Likewise, see Decision VII/19 adopted at the VII Conference of the Parties related to the Use of Terms or Definitions (Section A) and the "Measures in User Countries" (Section E). Lastly, Decision VIII/4 A adopted at the VIII Conference related to property rights on genetic resources.

18 Some limited analysis is presented in Cabrera Medaglia, 2004, A Comparative Analysis.

19 See Glowka, 1998; Mugabe et al., 1997; Seiler and Dutfield, 2001; Barber et al., 2002.

20 See Cabrera Medaglia, 2004, A Comparative Analysis. See also the study of the Pacific Rim Countries carried out for Carrizosa et al., 2004, which identifies as a problem for the ABS implementation, among others: "the broad scope of access and benefit sharing policies. Most of them cover genetic (DNA and RNA), biological (specimens or parts of specimens) and biochemical resources (molecules, combination of molecules and extracts) found in both in situ and ex situ collections. Monitoring of bioprospecting activities has proven to be a difficult, expensive and resource-consuming task and no Pacific Rim Country has established a monitoring system," etc.

21 Among other sources, the author reviewed the following documents or studies: Cabrera Medaglia, 2004, A Comparative Analysis; Gartforth, 2004; Nnadozie et al., 2003; and the ABS measures data base of the CBD www.biodiv.org etc. 


\subsection{Purpose and structure of this book}

This book seeks to address the most relevant legal issues to provide certainty for users of genetic resources and at the same time safeguarding the rights of the providers. Up to now, the efforts to develop an international regime of access to genetic resources and benefit sharing have not addressed this aspect in a systematic manner, despite its relevance in terms of satisfying the necessities behind the negotiations of the Regime. ${ }^{22}$

For this reason, the book has been structured in the following manner:

- In Chapter 2, a basic overview of the primary approaches to "access legislation" at the national level is provided;
- In Chapter 3, this book goes into more depth in consideration of several principal aspects that are considered essential for the construction of functional and operative ABS laws, also considering the concepts of legal certainty and functional consistency of the access system;

- Chapter 4 addresses the efforts of provider countries to find ways of enforcing their ABS laws in the country where the users are located. ${ }^{23}$ This mechanism is perceived to be of paramount importance, and the difficulties of monitoring and compliance (and resulting lack of enforceability) is cited as the reason underlying the call for a "binding regime" on ABS.

22 Some authors have suggested the relevance to include these aspects in the work of the ABS Working Group. See Young, 2004, "The International Regime...;" and Dross and Wolff, 2005.

23 See on the concept of User Measures Decision VII/19 Section E. See also Barber et al., 2003, and Tvedt, "Elements," 2006. See also Loufi, 2006. 


\section{Setting the Stage}

Before turning to the authors' analyses of particular controversies, it is important to briefly introduce a

\subsection{Construction of access regimes}

This section provides a basic summary of the components of an "access regime" - that is, of those elements of $\mathrm{ABS}$ legislation that are directed at ensuring that the country is aware of, and able to receive a share of benefits derived from, the use of genetic resources from that country. It is based primarily on work published by IUCN in an earlier interim publication in this series - Cabrera Medaglia, J., A Comparative Analysis of Legislation and Practices on Access to Genetic Resources and Benefit Sharing (ABS): Critical Aspects for Implementation and Interpretation. It will not restate this detailed analysis, but will briefly describe the components of national access legislation, as considered there.

Following the Convention's entry into effect, ABS very quickly became highly controversial, ${ }^{24}$ beginning with the promulgation of the Philippines Executive Order in 1995, the first specific legislation centered on the regulation of $\mathrm{ABS}$. Later, the first regional framework, Decision 391 "The Common Regime for Access to Genetic Resources" of the Andean Community, too was intensively discussed. Numerous studies, seminars, publications and discussions have been generated on this subject. Nonetheless, in spite of the time elapsed and of the accumulated experience, difficulties still continue to arise in the negotiations at the core of the $\mathrm{CBD}$, and, what is even more worrying, a series of obstacles persist which impede the effective enforcement and implementation of these initiatives and measures. ${ }^{25}$ few critical objectives of the ABS regime relevant to the rest of this discussion.

To date, numerous different studies and researches, on the efforts of promulgating and implementing legal frameworks on access and benefit sharing at the national and international levels, have been completed. ${ }^{26}$ These studies can be characterized basically according to their approach to four main issues:

- the design of the laws and regulations;

- the participation of stakeholders in the national or regional processes of drafting $\mathrm{ABS}$ laws and policies and, eventually, in the negotiation of contractual agreements and other arrangements relative to ABS;

- contracts, agreements and other arrangements on $\mathrm{ABS}$; and

- aspects relating to the implementation of the legal provisions.

However, even more recent studies, which refer in some degree to aspects of implementation and interpretation of ABS regimes in general, lack any legal or institutional analysis that emphasizes the needs which the regulation on access to genetic resources imposes on legal systems. This last has become more imperative, in consideration of the fact that at least 15 countries have some legislation on $\mathrm{ABS}$ and more than forty are in some phase of design or are considering introducing new legal rules to regulate the access to genetic resources and benefit sharing.

24 Caillaux and Ruiz, 2002.

25 Caillaux and Ruiz, 2002.

26 For example, even though the scope, methodology, objectives and geographic range of the studies vary, the following documents can be mentioned to guide the design of ABS legislation: Glowka et al., 1994; Glowka, 1998; Mugabe et al. (eds) 1997. From other perspectives it is also possible to mention: Seiler and Dutfield, 2001; Bass and Ruiz (eds), 2000; Swiderska, 2001; Columbia University, 1999; Crucible Group II, 2001; Secretariat of the Convention on Biological Diversity, "Case studies...”, 1998; UNEP-WIPO, 2000; and Svarstad, and Dhillion, 2000. 


\subsubsection{Main objectives of ABS legislation}

It is generally stated that $A B S$ systems must encompass, in general terms, the following aspects, in the law and other relevant practices and systems of source countries:

- objectives of the system;

- definitions;

- resources encompassed or scope of application;

- competent authorities at different levels (including the designation of a "national focal point" for $\mathrm{ABS})$;

- procedure for obtaining prior informed consent (PIC);

- procedure for negotiating the mutually agreed terms and the fair and equitable sharing of benefits (using contracts);

- mechanisms for monitoring and control; and

- sanctions for non-compliance, including penal, civil and administrative measures. ${ }^{27}$

\subsubsection{Frequent criticisms of access legislation to date}

Before proceeding to a discussion of the specific elements of national access legislation, however, it is useful to briefly canvass the primary criticisms that have been leveled at these laws, generally by the commercial and academic sectors. At some points in the various ABS negotiations, these factors have been cited as the "reasons that ABS is not working." More recently, however, most writers and negotiators recognize that these points are less common than formerly stated, and that they represent only the perspective of users. Consequently, while interesting, they should be seen as a list of the concerns of only one side of the negotiations, recognizing that there are generally equal and opposite concerns expressed by other stakeholders with an interest in the ABS issue (governments, civil society, etc.).

[Note: The following comments were derived originally from a list based on the experience of the
As a practical matter, of course, most of these elements are relatively straightforward legislatively, and do not require significant guidance: most countries can designate focal points, apply and/or extend their standard public participation practices, apply their standard contract laws (PIC and mutually agreed terms), and draft sanctions without external aid. The problems for most countries arise because the basic international design of the ABS concept is not completed or expressed in a way that enables practical implementation. Consequently, this chapter will provide only a summary of most of the above "elements" - leaving for later chapters the discussion about the more difficult problems of the overall ABS structure.
Philippines, under its Executive Order No 247 (EO), as implemented by the Department Administrative Order 96,28 two documents which have since been de facto amended by the newer Wildlife Act.] ${ }^{29}$

\subsubsection{Extent of scope and coverage}

The scope of the access provisions are frequently too broad due mainly to a vague definition of the term "bioprospecting" - a newly coined term which is often informally used, and sometimes legislatively equated with "access." Objectors noted that the term "prospecting" means "to explore" or "to look for," but that the law (in this case the Philippine EO) covers more than just "looking for," extending to almost all kinds of collection, research, and utilization of biological and genetic resources, including conservation research that many scientists, academic institutions, and NGOs undertake and which have nothing to do

27 These basic elements have been suggested by authors like Glowka, 1998; and Mugabe et al., 1997.

28 Petit et al., 2001; Benavidez, in Carrizosa, 2002.

292001 Wildlife Law, discussed in Benavidez, in Carrizosa, 2002.

30 "Determining the coverage of the EO was from the start the most difficult issue" (Antonio La Viña, cited in Benavidez, in Carrizosa, 2002). 
with prospecting. While this is entirely true, it is not legally or practically incorrect - all legislation defines some key terms, as shorthand ways of specifying the coverage of the act or particular provisions.

\subsubsection{Cumbersome application process}

The period from filing of the application to final approval of the agreement is another point of concern. In the Philippines (one of the more expedited processes), it is estimated to require at least five months. For most local scientists and researchers, the process is cumbersome, costly, and considered a deterrent to research, growth and development.

\subsubsection{Difficulties involving prior informed consent}

The PIC requirement is usually seen by applicants as administratively tedious, burdensome and a cause of much delay - for example, the EO specified a 60-day period before PIC could be certified as complete. However, it is the cost of securing the PIC certificate that is the source of most complaints from the bioprospectors' point of view. For example, in the Philippines (as in many other countries), PIC responsibilities are delegated to the individual communities. Hence, if the research required utilization or collection of resources from 12 regions of the Philippines, the collector would have to go to 12 sites to secure 12 PIC certificates. Each community could impose different demands, terms and conditions on that process. Indeed, even the identification of which community should give consent is often problematic, given the range of species and the fact that many species populations are pelagic or migratory.

\subsubsection{Complexity of institutional mechanisms}

Many of the most well-developed systems involve the use of an inter-agency body consisting of representatives of various agencies of the government and other sectors. This approach is thought to be advantageous because of the multi-disciplinary nature of the issues relating to bioprospecting. However, an inter-agency approach has many inherent problems as well. It is difficult to get a quorum of the members; resolution or decision-making takes a long time because of irregular attendance of members; and coordination between member agencies is difficult.

The contrary approach of broadly disseminating ABS obligations among the various ministries and sectors has become a common alternative, but places users in a different situation, in which it is difficult or impossible to know which agencies govern a particular application. At some points, both approaches are used, multiplying the administrative complexity.

At the international level, these concerns have instigated the requirement that each country designate an "ABS Focal Point," who could undertake the regular activities which would not really need the involvement of the inter-agency committee, and could serve as a purveyor of information about which agencies and requirements apply. Ultimately, however, while most countries have designated ABS focal points, few such designees have been able to effectively address the above-listed complaints.

\subsubsection{Contractual expectations and benefit sharing} One of the most common complaints relates to the level of demand imposed under benefit-sharing legislative requirements. Often particular percentages may be stated as "generally applicable" components of the "mutually agreed terms." In some cases, other kinds of benefit-sharing provisions are often seen as too demanding, particularly when imposed on researchers, given the possibility that they will compromise the confidentiality of information developed by these researchers. 


\subsubsection{Definitions, scope and exclusions}

As noted above, in the past there have been criticisms regarding the lack of clarity of the term "genetic resource," and especially its implications in determining the scope of regulations for access to genetic resources. ${ }^{31}$ Particularly, the vagueness of the definition included in the Convention on Biological Diversity has been debated, which has been criticized for its lack of precision. In the same way it has not always been clear when access to genetic resources occurs, in opposition to the access to biological resources, nor when the utilization of genetic resources takes place and if this constitutes a different phase altogether. Predominantly, in most of the legislation about access to genetic resources, even though those terms are defined, in practice, it has not always been so simple to establish which activities constitute access to genetic resources and which access to biological resources. It is also difficult to know which mechanisms are available to the State to find out whether there is access and utilization.

\subsubsection{Definition issues}

The Convention on Biological Diversity defines genetic resources as follows (Art. 2 Use of Terms): "Genetic material of actual or potential value." Additionally the Convention defines biological resources and genetic material, but does not actually clarify what it means by "access to genetic resources," or "utilization of genetic resources." It further states:

"Genetic material" means any material of plant, animal or microbial or other origin containing functional units of heredity.

"Biological resources" includes genetic resources, organisms or parts thereof, populations or any other biotic component of ecosystems with actual or potential use or value for humanity.
The implications of this definitional uncertainty in national laws on access have been easily perceived in practical application. Some requests have been presented, either in exclusively taxonomic terms or for the commercial utilization of biological resources, without clarifying the status of genetic or biochemical properties contained in the samples. ${ }^{32}$ In other cases, especially in applications dealing with the use of medicinal plants, nutraceuticals and botanicals, legislation in many countries excludes these entire categories from the scope of access, even though they are important growth sectors at a worldwide level in the private sector, ${ }^{33}$ both as whole (biological) resources and as genetic and biochemical resources. Sometimes they are included, but only as to entities and practices at a higher level of industrialization another term that is not defined properly.

In general, the available legislation on access nearly always bases the definition of genetic resources on the above language from the Convention, with some modifications that do not alter its essence, or enable it to be practically applied. Additionally, definitions such as "bioprospecting" are often used to clarify national intention regarding the scope of ABS legislation.

One of the most troubling problems for practical application is the difference between the normal acquisition of biological resources and "access to genetic resources." In general, countries do not provide a clear indication of the difference between "purchase of biological resources" (the organic material) and "taking the genetic material (which is contained in the biological material)." The difference is typically thought to be based on intended or declared use: the search for genetic or biochemical material contained in the biological

31 CBD, First Report of the Expert Panel on ABS, 1999, reported in COP-5, Document UNEP/CBD/COP/5/8/; Ten Kate and Laird, 1999; Glowka, 1998.

32 Cf. Ruiz, 2000; Osama, 2003; Barber et al., 2002. For instance, according to the amended regulations (2001), of the Sarawak Access, Collection and Research, collection means "the removal or taking away of biological resources from their natural habitat or any place where they are found, grown, propagated, kept or stored, but does not include (article 2): a) the inspection or study, but without removal, of any biological resources at the place where the same are found, grown, propagated, kept or stored; b) the making of any graphic or written description or representation of such biological resources; or; c) the taking of any photograph of any biological resources." The amended regulations excludes a study, experiment, test or examination, carried out within Sarawak, of biological resources in connection with any educational course or syllabus conducted by an approved institution which does not or is not intended to lead to development and commercialization of the aforesaid properties, values and qualities.

33 Ten Kate and Laird, 1999; Rosenthal, 2003. 
specimen, for different purposes (basic research, bioprospecting, etc). Supposedly, in some countries, the taking of biological resources must comply with certain requirements, including the information provided by the applicant before granting removal. This information should contain details on the intended use and therefore if the proposed use implies access to genetic resources, the competent authority must refer the applicant to the appropriate legal body in charge of granting access in order to initiate the legal procedures for access and benefit sharing.

A related question applies to terms such as "utilization of genetic resources" and "access to genetic resources." These terms are of great importance practically, and are discussed in more detail in Chapter 3, and other books of this series. ${ }^{34}$

\subsubsection{Ownership of genetic resources}

One critical element of national law that is needed is to determine and legally acknowledge the difference between the owners of the land, from which the specimen is collected, the owner of the specimen, and the owner of the genetic resources. The current complexities of this issue are more completely discussed in Chapter 3, but the basic issues should be summarized here for completeness.

The Convention to Biological Diversity does not define a property right over genetic or biochemical resources. Its only input on ownership issues is to recognize the sovereignty of the States over their genetic resources. This recognition puts genetic resources on an equal footing with all other kinds of property (tangible and intangible) - specifically, that the rights of an individual "owner" of any property extend only to those matters that the national government says he

\subsubsection{Precise scope}

Questions of definition also affect the scope of access, of $A B S$ and of the international system being developed (both informally and formally) for ABS. The Convention on Biological Diversity in its article 15 refers only to genetic resources, without specifically using the term biochemical resources. Nevertheless, since "genetic resources" has no precise definition, one cannot tell whether the unique biochemical properties of a specimen are included in that term. In addition, the scope of Article 15 does not impede a country from deciding to extend the scope of its procedures of access to biochemical resources. ${ }^{35}$ The latter, owing essentially to the importance which biochemical resources hold for research and development in pharmaceutical industry, would be a substantial extension to some observers. ${ }^{36}$

may own - something that differs from country to country. Up to now, however, property systems and constitutions, with few exceptions, have not made reference to genetic resources. The fact that genetic resources are usually integrally included in biological resources (physical samples of a specimen or part) creates confusion. However, in the same manner, some legal systems differentiate between property rights in biological resources and the proprietary rights in genetic resources. ${ }^{37}$ Generally, the State is considered the owner of the genetic resources but the individual landowner or specimen owner who gives the biological resource containing the genetic resource, or authorizes the entrance to the land where the resource is located or to the ex-situ collection, is considered the provider of the biological resource.

The definition of the property rights is recog-

34 See especially Tvedt and Young, Beyond Access, 2007.

35 This is specifically stated in the Costa Rican Law, for example, while the Philippine EO, Decision 391 of the Andean Community, and many other laws include both biological and genetic resources. See Cabrera Medaglia, 2002.

36 Ten Kate and Laird, 1999.

37 The United States may be an exception, based on the fact that some national delegates have claimed that the owner of the land is equally the owner of the genetic resources located on it. This claim is based on national parks however, which are indisputedly the property of the federal government. Consequently, it does not clarify the question of ownership of specimen vs. sovereignty over genetic resources. See the document submitted by the Delegation of the United States to the fourth session of the Intergovernmental Committee on Intellectual Property and Genetic Resources, Traditional Knowledge and Folklore. The document is entitled "Access to Genetic Resources Regime of the United States National Parks." 
nized as one of the most complex issues related to ABS. ${ }^{38}$ The sovereignty concept is different from patrimony and from property; the latter is not approached by the Convention itself, giving each State the freedom to decide whether the genetic resources are private or public property. For instance, in Colombia, according to the sentence dictated by the C-977 State's Council, "the legal regime of property applicable to genetic resources with real or potential use is the one established for public domain goods, in generic terms in Decision 391 of the Commission of the Cartagena Agreement..." it means that genetic resources are the inalienable, unattachable and imprescriptible patrimony of the Nation. ${ }^{39}$

There are some sources of confusion even here, however. Decision 391, for example, specifically refers to the existence of different types of ownership. First there is a definition of "provider," which acknowledges

\subsubsection{Mechanisms to control utilization}

With regard to the mechanisms to enable a provider country to know when utilization takes place, there is much commonality among national systems, primarily because such mechanisms are illusory. In general, the country of origin only knows when utilization has occurred when there is a previous application for access wherein a mechanism has been established which informs about the future utilization of the resource. There is no system for monitoring the uses which imply access or utilization of the genetic resources. However, some countries are engaging in measures to attempt to address this, even if only in part. In the Philippines, for example, several references exist to training activities for controlling access to providers both of the biological resources and of the intangible component. As part of the application, an identification of the provider of the biological or genetic resources and intangible component is required (art. $26 \mathrm{~b}$ ). This distinction is also envisaged in the different access contracts: the annex for the intangible component (art. 35) and the accessory contract for the provider of the biological resource, the owner of the biological resource, the land, and the ex-situ conservation centre (as owner or custodian of the biological resources) (art. 41). According to this article, accessory contracts are those that are signed in order to carry out activities connected with the genetic resource or its by-products, between the applicant and the owner, possessor or manager of the land where the biological resource is located, the ex-situ conservation centre or the owner, possessor or manager of the biological resource containing the genetic resource.

genetic and biological resources and attempting to ensure that their export is in compliance with the access legislation.

One country, Costa Rica, has attempted to unilaterally impose a requirement for a "certificate of legal provenance" stating that this certificate is a previous requirement for granting IPR protection to the innovations related to elements of biodiversity. ${ }^{40}$ Unfortunately, owing to primary jurisdiction issues, this provision only applies to those who seek IPR protection under Costa Rican law, unless Costa Rica is able to bring a claim, under another country's IPR law, that the IPR application is a breach of contract.

\subsubsection{Restrictions on access for specific uses and third party transfer}

One of the most relevant issues in $A B S$ is related to the potential ability of the State or other provider of the genetic resource to impose limits on the further activities that can be developed by the user. These limits can (usually) consist of the following:

a) Prohibition of the use of the resource for purposes different than the ones requested. This applies in relation to obtaining the PIC as well as to the permit or contract of access itself. The Bonn Guidelines explicitly consider that the prior informed consent should be based on the specific

38 Columbia University, 1999.

39 See Hernández, 2000.

40 Articles 71 and 80 of the Biosafety Law. 
uses for which consent has been granted. While prior informed consent may be granted initially for specific use(s), any change of use, including transfer to third parties, may require a new application for prior informed consent. Permitted uses should be clearly stipulated and further prior informed consent for changes or unforeseen uses should be required (para. 34 on Specification of Use).

b) Restrictions for the transfer of the material to third parties. These restrictions pursue to avoid the risk that the third party will acquire the samples without the proper follow up and authorization of the State. Such transfer, however, could be necessary or convenient for different reasons. It is normal, in many cases, for companies to transfer materials to third parties under subcontracts for specific screening activities and researches that will be more profitable if outsourced than if conducted "in house." 41 Under these scenarios, the legislation can opt to require a pre-authorization for such transfers or can contractually establish the requirement of notice of such transfers as a mandatory provision in Material Transfer Agreements or other contractual $A B S$ agreements, to secure the rights of the provider and facilitate the monitoring of the transferred materials.

c) Restrictions on the users' ability to obtain (or file applications for) intellectual property rights over genetic resources. Options for a restriction or prohibition on IPR filings can range from a total moratorium (African Union Model Law) up to a previous authorization (India Biodiversity Law) or just requiring a previous notification (Bhutan Biodiversity Act). The important issue is to enable awareness of the commercial uses being undertaken and anticipation of the size and nature of possible benefits (milestone payments, etc.).

d) Commitments on the exclusivity of the access granted to a user. Even though there is little evidence of its use, it should be possible to establish such commitments. The need to clarify exclusivity of rights was a main element leading to the modification of the Western Australia (WA) law relative to ABS. The WA Conservation Act amended provides the possibility of certain exclusivity: according to article 33.6, the Ministry and the Executive Director may enter into agreement with another person to grant, issue or refuse licenses or permits to take or remove forest products or other flora in a manner that has the effect of conferring on the other person an exclusive or preferential right to take or remove forest products or other flora referred in the agreement. This exclusivity was applied in the case of the benefit-sharing arrangement between the Department of Conservation and Land Management of WA and AMRAD, an Australian pharmaceutical company. Exclusive rights were provided to AMRAD for the commercial development of a product derived from a WA flora. ${ }^{42}$

In essence, where one or more of these actions is restricted in the law or permit, the user can undertake that action only if he first returns to the provider country and obtains prior informed consent.

\subsubsection{Legislative interpretation of access and benefit-sharing obligations and their relationship}

There was a general view expressed by some legal ion that this is legally incorrect. authors in the early years following the adoption of the $\mathrm{CBD}$ that $\mathrm{ABS}$ is an exchange at the contract level, wherein access is the provision of genetic resources and benefit sharing is the payment for them. Increasingly a large number of experts share the opin-

Access refers to the ability to enter, bioprospect for, collect and/or remove genetic resources; while benefit sharing is an equitable construct - the obligation to fairly and equitably share the benefits arising from

\footnotetext{
41 See Ten Kate and Laird, 1999.
}

42 See Ten Kate and Laird, 1999. 
the utilization of genetic resources. This latter approach is based on the idea of utilization and means much more than just "payment" for access, as discussed in Chapter 3. However in most existing national $\mathrm{ABS}$ laws, including the ones analyzed in the Comprehensive Analysis, and from the point of view of the decision-makers, access and benefit sharing are considering two inextricable elements of the same

\subsubsection{Monitoring and legal remedies}

Two of the most relevant aspects on ABS, that present larger difficulties, are related to the monitoring of access and benefit-sharing conditions, and the existing legal remedies against non-compliance with the contract or permit. ABS legislation will always be difficult to enforce, due to the nature of genetic resources, particularly their wide availability and the ease of dissemination or replication. ${ }^{43}$

At present, national ABS legislation does not include adequate monitoring systems. Monitoring and evaluation of the agreements is in most cases weak or absent. ${ }^{44}$ This seems to be one of the main difficulties of the ABS regimes. To this, the difficulties derived from the characteristic of genetic resources as information, are added..$^{45}$ This characteristic has brought to evidence the inconvenience of applying the traditional monitoring instruments. Probably, as the Expert Panel on $A B S$ recommended, ${ }^{46}$ monitoring could be more effective with the participation of an institution or local counterpart. ${ }^{47}$ This system has been considered by diverse countries (Bhutan, Bolivia, etc). Regardless of utility of in-country participation, it must be acknowledged that research and development in their most advanced phases will normally be carried out outside the borders of the country of origin. For this reason, additional mechanisms to warrant the tracking of the materials, for example identification systems, process - or at least benefit sharing is always required in cases of access. Thus, access triggers the benefit sharing, but no law seems to specifically say that no benefit sharing will be required where the resources were obtained in other ways. This standard approach considers access as a first step for the utilization of the resources and does not separate - conceptually - access and the sharing of benefits, even if the latter occurs later.

must be explored. In the same way, mechanisms to oblige the users to present periodical reports, including reports on the applications for patents, together with the possibility of making audits to verify the compliance, are some of the indicated solutions. In general, countries do not have systems that allow them to practice audits to verify the compliance with the clauses stipulated on the contract itself.

In the individual $\mathrm{ABS}$ contracts, however, most of the countries seem to have given a particular emphasis to establishing appropriate monitoring systems for compliance with the mutually agreed terms,${ }^{48}$ although the effect of this work has not been to create clear and enforceable mechanisms. There are significant obstacles that generally prevent the effective exercise of legal remedies when contractual (MAT) or legal violations occur, particularly since most violations occur after the resources have moved from the provider country to another jurisdiction.

Here also, the question of penalties is very simple to insert in legislation, ${ }^{49}$ but the uncertainty about the meaning of key terms, as well as the inability to monitor or become aware of utilization, are a serious limitation preventing these measures from having any noticeable impact.

43 This issue is examined in detail in Ruiz and Lapeña, (eds.) 2007.

44 Columbia University, 1999.

45 Ruiz, 2000; Cabrera Medaglia, 2003.

46 First Report of the Expert Panel on ABS, par. 88.

47 Cf. Bonn Guidelines, par. 56.

48 Documented in Cabrera Medaglia, 2002.

49 Ibid. 


\subsubsection{Restrictions imposed for environmental purposes}

Another category of provisions that is easily drafted but nearly impossible to implement is the group of social and environmental-based restrictions on the uses to which genetic resources may be put. These restrictions are specifically authorized in the Convention, which limits the access requirement by calling on parties "to facilitate access to genetic resources for environmentally sound uses ... and not to

\subsubsection{Support for conservation}

Connected to the previous section is the question of how ABS laws support conservation and sustainable use objectives. One of the main criticisms of the ABS laws is that only a tenuous link exists between access and the conservation of biological diversity. In many cases this link exists only indirectly in term of technology transfer, reporting and submission of ecological data, etc. The Bonn Guidelines are not categorical enough about this link, but consider as one of the main objectives: "to contribute to the conservation and sustainable use of biological resources." ${ }^{50}$ At paragraph 22 (Overall strategy), it provides as well that the ABS system should be based on an overall access and

impose restrictions that run counter to the objectives of this Convention" (Article 15.2). Thus, national laws include provisions calling for decisions that take into account the criteria of public interest and the precautionary principle and the objectives of conservation, sustainability, the avoidance of environmental harms, and human health.

benefit-sharing strategy at country or regional level. This access and benefit-sharing strategy should aim at the conservation and sustainable use of biological diversity and be part of a national biodiversity strategy and action plan to promote the equitable sharing of benefits.

One of the most significant factors in ABS-related debates at sectoral, national and global levels is the fact that they spend little or no time addressing environmental and social matters, especially questions of conservation, sustainable use and equity.

\subsection{Different treatment for agricultural genetic resources and ex-situ collections}

Another of the criticisms of the ABS regimes is based on the fact that they attempt to treat the different sectors equally. ${ }^{51}$ In all the cases, the current national laws do not seem to recognize the particularities of genetic resources for food and agriculture. This is expected, given that the Convention on Biological Diversity does not distinguish among different categories of genetic resources whose conservation and sustainable utilization vary (according to whether they are wild, domesticated, microbial, etc.). ${ }^{52}$ The exchange and appropriation practices of food/agriculture resources differ, however, in terms of their distribution and availability, the level of difficulty in reproducing them, and the existence or non-existence of market mechanisms for their exchange (among other factors). ${ }^{53}$ In the same way, these resources can be conserved either in-situ or ex-situ, with each option presenting technical, economical and juridical particularities. For example, regarding the ex-situ collections, processes have been developed like the Common Principles of Access to Genetic Resources and Benefit Sharing for Botanical Gardens and Micro-Organism Sustainable Use and Access Regulation International Code of Conduct (MOSAICC).

With some exceptions (e.g., Brazil and Bhutan), there has not been any legislation which differentiates between the treatment of genetic resources for food and agriculture and those of other genetic resources. Differentiated treatment is expected in future legisla-

\footnotetext{
50 Bonn Guidelines, para. 11.a.

51 Correa, 2000.

52 Correa, 2000

53 Correa, 2000.
} 
tion, however, in connection with the implementation of the Treaty on Plant Genetic Resources for Food and Agriculture (PGRFA) of FAO in each member country. Broader extension of this Treaty's membership will probably increase the number of situations in which differentiated treatment is accorded for some agricultural species, held by some institutions.

In the same way, existing regulations do not always respond to all the particularities that ex-situ collections can present. The convention is very unclear about the status of genetic resources that are sampled from biological material collected before the entry into force of the Convention on Biological Diversity (December 29, 1993). This ambiguity coupled with the condition of the collections as users and providers of genetic resources; their nature as intermediary entities; the little information available about most of them; and the conditions on which the property or custody of the genetic resources can be transferred have created serious concerns regarding the manner in which those collections can be viewed in national and global $A B S$ regimes.

\subsection{Regulatory complexity: double permissions}

As noted above, a common complaint among bioprospectors focuses on the complexity of ABS laws, particularly the need to apply for different permits to obtain access to the samples and to remove them from the country. For instance, in many cases, additional permits to obtain biological resources are required by other institutions without establishing adequate coordinating mechanisms among the governmental entities to facilitate access to genetic resources for sound uses. From a government perspective, this situation was probably not intentional, but is the unintended result of adopting new legislation that regulates a different component (the genetic) contained in biological resources traditionally regulated by other laws. In addition, it is not

\subsection{IPR-related issues}

Finally, the relation between the IPR and access to genetic resources has been the subject of various analyses and studies and it is still a contentious issue. ${ }^{55} \mathrm{It}$ has been and continues to be the subject of enormous volumes of international academic and legal analysis, which will not be reproduced here. It is important to note that there are many other aspects to this issue. uncommon in other sectors, in most countries. ${ }^{54}$

The extent to which additional permits are needed (beyond the specific rules of "access to genetic resources") in order to gain access to the biological resource that contains those resources, has become another important legislative inquiry. In the event of different permits being necessary it is important to determine if coordination mechanisms have been established to avoid duplication regarding the permits and to prevent obstacles to the access to the resources for environmentally sound uses. One important co-existing requirement may be the Environmental Impact Assessment (EIA) or related instrument.

For example, as noted above, national legal regimes of provider countries sometimes seek to develop and apply mechanisms for securing and supporting the PIC and MAT by restricting the use of the IPR system, for example, by requiring the disclosure or certificate of origin of the genetic resources utilized in the claimed invention. ${ }^{56}$

54 See Young, Options and processes... 2002, regarding other situations in which commercial entities must obtain multiple permits in order to be able to engage in a particular activity.

55 See Dutfield, 2000; ICTSD, 2003; Report of the Commission on Intellectual Property Rights, 2002.

56 As noted above, the possibility of a Global proposal for such a certificate is discussed in detail in Ruiz and Lapeña, expected 2007. See also the VI Conference of the Parties of the CBD (Decision VI/24) which contains several references to the use of these mechanisms and, in general, to the role of intellectual property rights in the implementation of access and benefit-sharing arrangements. 


\subsection{Legal certainty}

Legal certainty is a characteristic sought by the users of genetic resources. ${ }^{57}$ This concern, as expressed by the users of genetic resources, is based on the lack of clear regulations regarding $\mathrm{ABS}$ in the country of origin of these resources and associated traditional knowledge, e.g., developing countries. As a response to this difficulty, the Conference of the Parties to the CBD has requested an analysis of the theme. ${ }^{58}$

In response to this request, a comprehensive study on "legal certainty" was presented in the III meeting of the ABS Working Group in Granada, Spain. ${ }^{59}$

In accordance with the Report, "a party would have legal certainty regarding an instrument if he was fully aware of all relevant laws and certain that they were consistently and predictably in force and enforceable. A narrow definition of legal certainty for users focuses on three elements:

- Process certainty: including the establishment and empowerment of competent national authorities, specifying rights and duties of others who may be involved; clarity regarding the procedures for applying for $\mathrm{ABS}$ rights; clarity regarding various deadlines for processing applications; and clarity regarding the appeal of the decision by the applicant or by others.
- Scope and nature of the grant: this factor enhances legal certainty by clearly defining the rights granted as well as enunciating the mandatory provisions and conditions that must be included within the mutually agreed terms.

- Legitimate expectations and vested rights: this kind of legal certainty can be supported in several ways, including clear and specific statutory requirements and limitations regarding subsequent challenges to the user activities after receiving $\mathrm{ABS}$ rights and clear limitation of the nature of government power to alter, cancel, repudiate, amend or suspend an ABS right, once it has been received." 60

The relevance of legal certainty is evident in the position of some countries. For example, the government of Australia has indicated that one of the advantages of investing in bioprospecting in Australia is the existence of legal certainty under the Australian ABS legislation. This is reflected in the legal regime of that country, by the adoption of clear and transparent regulations for the granting of permits, based on a stable system of commercial transactions and property rights (intellectual and physical). ${ }^{61}$

57 See Oxley and Bowen, 2006.

58 See CBD COPVII, Decision VII/19, part E. g.

59 IUCN-Canada, 2005.

60 The analysis covers: A. Process certainty: 1. Identification and empowerment of CNA. 2. Integration with other levels and processes. 3. Clear and transparent procedures. B. Scope and Nature of the Grant. 1. Nature of the Right Granted. 2. Clarity on the mutually agreed terms: the user obligations. 3. Restrictions on transfer and other rights. C. Legitimate expectations and vested rights. 1. Third Party impacts on the ABS agreements. 2. Claims of non-compliance. 3 Government alteration for other causes and the loss of a vested right.

61 See Australian Government. Department of Environmental Heritage, Genetic Resources Management in the Commonwealth Areas. Sustainable Access and Benefit Sharing, Canberra, 2005. 


\subsection{Functionality and consistency in the ABS legal frameworks}

This part briefly outlines some legal aspects that should be carefully established in national and inter-

\subsubsection{General considerations}

Certainly, legal impediments and obstacles exist that explain the limited implementation of ABS systems. Often, for example, countries may have assumed incorrectly - that legal mechanisms and institutions currently functional for conventional contracts and/or property transactions would operate in the case of transactions involving genetic resources without the necessity for adjustments or modifications. At the same time, there are other reasons behind the low implementation of ABS measures, which are no less important. These include both legal gaps ${ }^{62}$ and other problems (e.g., lack of awareness and misunderstanding). ${ }^{63}$

For example, one critical factor is the lack of capacity, knowledge, and skills to negotiate the complex terms of the bioprospecting contracts. The author has had the opportunity to confirm that this is an element as relevant as the functional difficulties previously mentioned. ${ }^{64}$ These are related to the issue of the potential liability of the Governmental Officers in charge of granting permits or negotiating $\mathrm{ABS}$ agreements, if a mistake is made during the process of negotiation.

Another key problem arises from frustration in source countries, due to the limited economic and non-economic benefits (monetary and non-monetary) national systems, with the purpose of ensuring that the regimes of access can function adequately.

perceived to be derived from the different bioprospecting projects and, in general, from the application of $A B S$ frameworks. ${ }^{65}$ Richness in biodiversity terms does not necessarily translate into commercial products such as new medicines, seeds, etc. In this sense, those who have asserted that bioprospecting would become a "green gold mine" have had to modify or moderate their observations. From this perspective, bioprospecting is a component of a more extensive strategy for the conservation and sustainable use of biodiversity, rather than the solution to immediate conservation needs.

Cases of illegal access, misappropriation or "biopiracy" that have occurred in countries and communities, especially in Latin America, Asia and Africa, have had frustrating, or even controversial results, suggesting a higher than expected level of difficulties in finding cost-effective legal solutions within the framework of national ABS legislation or in the context of industrial property law. ${ }^{66}$ Emblematic cases such as Maca in Peru or Neem in India, among many others, have frequently been mentioned as a rationale for undertaking modifications to the text or operation of intellectual property right systems (particularly patents, which are frequent causes of complaints being filed for misappropriation or biopiracy).

62 See those indicated by Carrizosa et al., 2004; and Nnadozie et al., 2003. See also SCBD, "An Analysis ... including identification of Gaps," 2004. Another author identifies five often closely related problems for implementing ABS laws: (i) misunderstandings with regard to the definition of "genetic resources," "sovereignty and benefit sharing," and "IPR;" (ii) lack of awareness of objectives and purposes of the ABS; (iii) failure to distinguish between sectors and the adoption of the relatively homogenised approach provided by the CBD framework; (iv) lack of information creating protectionist reactions; (v) dispersed capacity and lack of coordination; see Lettington, 2004.

64 The CBD has recognized this problem and has developed a Capacity Building Plan adopted by the VI Conferences of the Parties. For ongoing ABS capacity building projects see Gartforth et al., op. cit., and the $\mathrm{CBD}$ web site on capacity building initiatives.

65 The implementation of ABS regulations, and even the existence of concrete initiatives on bioprospecting, has not generated the huge benefits some had expected for the provider countries and the communities or indigenous peoples. Cfr Cabrera Medaglia, 2004, A Comparative Analysis and Cabrera Medaglia, "Biodiversity Prospecting in Practice," 2004. About the commercial value of biodiversity for the different industries and activities (not only using genetic resources but also biological resources) see Ten Kate and Laird, 1999. On the potential commercial value of genetic resources - especially from microorganisms - for the pharmaceutical industry, see Suzuki, 2005.

66 It is difficult to quantify the level of these activities due to the lack of legal certainty on the definition of biopiracy. For some, it consists of the acquisition of genetic resources and traditional knowledge without the consent of the country or holder of the resource or knowledge; when rules for fair and equitable benefit sharing are not established; when IPR protects innovations that are copies or cosmetic modifications of the genetic resources; or when IPR protects biotechnological innovations based on the genetic resources, whether or not prior informed consent exists, etc. On the topic of biopiracy and the difficulties of judging whether certain activities constitute misappropriation. Cfr, Dutfield, 2004; and Young, 2006. 
In addition, although the $\mathrm{CBD}$ requires the Parties to take measures to ensure fair and equitable benefit sharing (see particularly the provisions of article 15.7), it has mostly been developing countries that have issued regulations on ABS. ${ }^{67}$ Thus, the nations that are home to pharmaceutical, biotechnological and agricultural companies (mostly developed countries) have not effectuated the corresponding regulations to ensure benefit sharing - which are necessary if they are going to comply with their legally binding international obligations. The absence or limited presence of so-called "user country measures" has been criticized as one of the causes of high transaction costs and the highly controlling nature of current access laws. The need for "user country measures" ${ }^{68}$ has been stressed by those who have noted the transboundary nature of $\mathrm{ABS}$ in trade relations ${ }^{69}$ and the inadequacy of national regulations after the samples or information on the genetic resources leave the country that provided them. In this context, it can be stated that the ABS provisions in the countries of origin are incapable alone of creating an ABS system that is functional and consistent.

One of the common denominators of ABS is the lack of trust among the different actors involved or potentially involved in ABS transactions. ${ }^{70}$ This atmosphere is not appropriate to advancing negotiations, whether internationally, among countries, or in a more limited way, through contracts between providers and users of genetic resources.

\subsubsection{Functionality and consistency of ABS systems}

At the same time, some of the functionality difficulties mentioned by lead authors in this field are as follows: ${ }^{71}$

"Functionality is needed in any legal framework. It depends on the law maker's ability to weave laws, regulations, contracts, permits, institutions into a system satisfying five basic legal systematic requirements:
- legal consistency,

- clarity about what is forbidden, permitted, encouraged and or mandatory,

- mechanisms that protect and give legal certainty to all parties,

- practically implementable enforcement mechanisms, and

- consistency related laws, frameworks, systems and tools.

Regarding ABS, the Convention itself has hindered the creation of sufficient clarity, consistency and replicability."

A recent paper on $A B S$ functionality (developed under the ABS project) cites the following "elements to facilitate ABS implementation through consistency, legal certainty and clarity:"

- Certainty about what transactions and uses are covered by ABS: Knowing which transactions involve "genetic resources" (GR) requiring compliance with $A B S$ laws and which are biological resources (utilizing conventional markets and instruments);

- An effective legal means by which each source country can know of and protect its rights after genetic resources leave the country;

- Accepted indicators that can be used to "prove" that GR used in one country have come from a different country and that the user has obtained a valid right to use them;

- Key messages clarifying the meaning of GR and use: CBD negotiations opted not to negotiate clear provisions about what genetic resources are and how they are owned or transferred, leaving the

67 Cfr, the study by Gartforth et al., who describe current ABS measures and legislation. According to this study, approximately 25 countries have some kind of specific legislation on ABS. In many cases, however, the ABS elements of the laws identified include only general statements whose effective application requires additional regulations or laws to further develop the general precepts.

68 Cfr Barber et al., 2003.

69 Young, 2005; Cfr Young, "Genetic Resources ...," 2004.

70 IISD, Stratos, and Cabrera, A Guide..., 2005.

71 See Young, "Gaps and Obstacles...", 2004. 
clarification of these matters to national law. Negotiators left countries unguided;

- Operative clarity: Consistent understanding is the first issue here as well. Users-providers-agencies must know objectively if a genetic or biological resource or use of genetic resources is involved;

- Procedures for obtaining ABS permissions: Most countries' national legislation already contains procedural systems that can be models for PIC and MAT related procedures in ABS. National experience is the first and best guide to applying and implementing these requirements in its governmental, legal, cultural system;

- Remedies and controls relevant to ABS compliance: There are fewer existing mechanisms as templates for $A B S$ remedies in light of ambiguity of certain key concepts. With objective ABS standards, it could be possible to use existing tools for $\mathrm{ABS}$ compliance;

- Legal assurance: The system must provide certain protections for the Parties involved, including governments, applicants, property owners, middlemen, subsequent transferees, user institutions and other affected parties. This type of legal assurance is promoted where the legal framework clearly and objectively defines and protects the rights that the provider and user acquire by complying with the system;

- User protection: This component of legal assurance appears to require:

a) a clear distinction of the rights granted in the ABS agreement, the limits of those rights and the responsibilities associated to them;

b) assurance about how and when an ABS agreement becomes final;

- Provider protection: This component appears to depend on: a) the ability to monitor the user or to have certainty regarding post-access uses of the GR;

b) clear contractual statement of the source rights if the user violates;

c) access to legal processes and incentive mechanisms where the resources are used;

- Enforceability: Some of the challenges can be met through the regime negotiations, by the adoption of:

a) enforcement measures that deter both local and international parties from violating the law;

b) mechanisms for source countries to obtain jurisdiction over users and or access to justice in user countries;

c) accepted evidentiary requirements enabling source country officials to make their cases successful in user countries.

- Enforcement addressing two different kinds of actors:

o the user under an ABS agreement that is accused of violating that Agreement; and

o the biopirate who takes GR for commercial development without any ABS compliance.

Many enforceability issues will only be raised after the GR leave the source country. Current ABS monitoring seems to rely on reports from the user, raising the question of how does the country confirm reports?

- Integration with other relevant laws and processes. In this regard ABS presents interesting challenges, including their relationship with the following: laws on the marketing, purchase, sale, transport, and use of biological resources; the biosafety framework; protection of plant varieties, germplasm, food security, forest, etc.; the protection of local communities; national laws relating to ownership of and transactions involving tangible and intangible property; consumer protection and fairness in contractual/business negotiations and operations. ${ }^{72}$

72 This issue is not addressed in this book. In this regard, however, Cabrera Medaglia mentions the complaints - from a bioprospector's point of view - about the complexity of ABS laws related to the need to apply for different permits to obtain access to the samples. For instance, additional permits to obtain biological resources are required by other institutions without establishing adequate coordinating mechanisms among the governmental entities to facilitate access to genetic resources for sound uses. From a government perspective, this situation was likely not intentionally created, but it is the unintended result of adopting new legislation that regulates a different component (the genetic) contained in 
- Incentives: It can be difficult to find ways to enhance the motivation of users, source countries and others to comply with the system. Few incentives that are offered as mechanisms for promoting ABS meet these tests. The public relations benefits of ABS compliance are limited by the fact that few members of the public have even heard of ABS. Patent and other legal rights systems are currently interpreted in a way that does not allow the issuance of patents to require disclosure of origin or permission from the source country. The advantages of a good relationship with source countries, although certainly important, may be less valuable after the user takes genetic resources out of that country. There is no current indication that compliance with $A B S$ will protect against future lawsuits or make other legal processes easier. Currently the market incentives in the ABS as actually implemented are not clear or compelling. ${ }^{73}$

Following this line of argumentation it has been suggested that ${ }^{74}$ primary national implementation needs must be addressed if ABS and genetic resources systems are to function effectively. As such, the primary gaps in the framework above appear in the following categories:

- Recognition that ABS as transboundary commercial law cannot be implemented effectively by the source country alone and must be realized in user countries as well. Without user country measures, the efforts of source countries to uni- laterally control and regulate the full range of an ABS transaction, which is by definition a transboundary transaction, are almost meaningless. ... One of the most critical gaps in the implementation of Article 15 is user countries' near complete failure to provide a similar level of detail of guidance for user country obligations.

- An integrated set of consistent legal concepts, terms and mechanisms. The only operative provisions of $A B S$ create a new kind of property and call for a commercially oriented legal framework to oversee its equitable utilization. The CBD draftsmen, however, seem not to be aware of how unique these proposals were. They assume that existing national property and contract law systems would be able to regulate and implement ABS. As a result of this assumption, the legal parameters of an entirely novel legal right to utilize genetic resources were never specifically agreed. Even the most basic concepts such as the meaning of "genetic resources" and "utilization of genetic resources" are not concretely understood and legally settled.

- Real and sufficient practical incentives to motivate both countries and companies to create and utilize ABS systems. Current approaches to creating a functional $\mathrm{ABS}$ must be reoriented to provide commercial encouragements for compliance rather than seeking to compel compliance through lawsuits and policing.

biological resources traditionally regulated by other laws. For that reason, a major difficulty for securing the legality of access is reflected in the existence of legal frameworks that regulate and control, from different perspectives, the access to or research on biological resources. That is, to which extent additionally to the rules of access to genetic resources, to access the biological resource (containing the genetic resources) additional permits are required. In the event of different permits being necessary it is important to determine if coordination mechanisms have been established to avoid duplicity regarding the permits and to prevent obstacles to the access to the resources for environmentally sound uses, Cabrera Medaglia, 2004, A Comparative Analysis... .

73 See Young, 2004, "Gaps and Obstacles...".

74 Young, 2004, "Gaps and Obstacles...”. 


\subsection{Brief reflections on the implementation of ABS laws}

Finally, it is convenient to present the status of implementation of access legislation. ${ }^{75}$ Although there is a lack of fact development and analytic studies on this question, the state of implementation has been considered low and incomplete. ${ }^{76}$ Normand ${ }^{77}$ offers the following description:

... countries are at different levels of implementation of access and benefit sharing and have adopted different approaches to regulating access and benefit sharing, reflecting their national administrative structures, priorities, cultural and social specificities. While certain Countries have only adopted one measure, generally legislation, others have adopted a package of measures, including for example, a national strategy, legislation or regulations or guidelines. A number of countries are still in the process of developing their national systems and therefore the package is often incomplete. In addition, the national procedures and structures are diverse. For example some Countries have different levels of government responsible for regulating $A B S$ - at the nationall federal or at the statelprovincial level.

$A$ majority of Countries, with national measures included on the CBD database can be divided into three categories: The first category includes Countries which refer to $A B S$ in their national biodiversity strategy or their environmental or biodiversity legislation but have not yet regulated ABS in any detail. These measures generally provide for the developing of $A B S$ regulations and include some general specifications regarding elements to be addressed. The second category includes Countries that have a biodiversity or environmental law with some general provisions on ABS or access to biological resources, which may include a provision for the establishment of a regulation on $A B S$. The third category is those which have addressed ABS in greater detail. They have established competent national authorities, procedures for prior informed consent, procedures for the development of mutually agreed terms, including benefit sharing and compliance measures. The issue of IPR is also generally addressed in various manners and in varying degrees of detail.

With regard to the main features of their $A B S$ regimes, the provisions vary from one national system to another, although some general underlying elements may be highlighted:

- Competent National Authorities: in some cases the Competent National Authority is an organization already in existence, while in other cases a new organization is created by the ABS measure.

- Prior Informed Consent: In each Country some type of application for access has to be made in order to obtain access to genetic resources. These provisions also provide indications regarding specific information that the application should contain and the procedure leading to the approval or refusal. The majority of measures also require the PIC of the relevant authority/resource provider in the geographical area where the GR are to be accessed. Specificities of some measures include different requirements for access depending on the type of applicant and different requirements depending on whether access is granted for commercial and or non-commercial purposes.

- Mutually Agreed Terms: a majority of existing national systems provide that mutually agreed terms are to be set out in an agreement. Some measures also provide for different types of agreements depending on whether the genetic resources are being accessed for research or commercial purposes. The measures generally provide that the agreement is also to be approved by the National Competent Authority. Measures generally provide for BS with the competent authority or with indigenous peoples and local communities or resources provider and in most cases

75 An overview on the implementation of ABS measures is found in Gartforth, 2004.

76 Furthermore, experience of and documentation on such implementation is scarce. The information available indicates that the development of national measures has proven difficult for many countries due to a number of factors including a lack of technical expertise, budgetary constraints, weak government structures, and political support, local social conflict and conflict over ownership of genetic resources, see CBD, 2004.

77 Normand, 2004 
for both. Indications regarding the types of benefits to be shared vary depending on the measures.

- Compliance measures: the measures examined generally include provisions for compliance. Although few address monitoring and enforcement to ensure compliance with ABS measures, they generally provide penalties, sanctions for infractions or offences, such as infractions to the provisions of the legislation, regulation or guideline. These sanctions include fines, seizure of samples, revocation and cancellation of the permission to access, revocation of the agreement, a ban on future bioprospecting and imprisonment. $^{78}$
She concludes: "Developments are currently taking place in a number of countries, through national initiatives and capacity building projects, however there is still a lack of relevant awareness and capacity to address access and benefit sharing among relevant actors, in both developed and developing Countries." Ogolla adds to this description, ${ }^{79}$ noting that "Most measures require that a standard clause be incorporated in the contract. Some legislative measures appear to focus on non-monetary benefits such as the involvement of local institutions for research and development."

Table 1. Conventional legal mechanisms currently applicable to ABS systems

\begin{tabular}{l|l} 
Type of mechanism & Specific application \\
\hline Contract law & $\begin{array}{l}\text { Provides the means by which the mutually agreed terms are estab- } \\
\text { lished, and the possible use of contractual mechanisms to resolve dis- } \\
\text { putes. Contracts with terms concerning tracking and monitoring of } \\
\text { uses of genetic resources based on reporting obligations. }\end{array}$ \\
\hline $\begin{array}{l}\text { Law of tangible and } \\
\text { intangible property rights }\end{array}$ & $\begin{array}{l}\text { Direct application of property rights concepts, conventionally used for } \\
\text { other types of property, to genetic resource transactions. }\end{array}$ \\
\hline $\begin{array}{l}\text { Permit-based } \\
\text { administrative law }\end{array}$ & $\begin{array}{l}\text { Systems for the granting of prior informed consent, requiring provi- } \\
\text { sion of information (to the competent authority) before an authoriza- } \\
\text { tion is granted, and oversight of compliance (legal authority often lim- } \\
\text { ited to activities within the source country). }\end{array}$
\end{tabular}

ABS addresses IPR to varying degrees. A number of measures in the context of benefit sharing include specific requirements for disclosure of origin of genetic resources and traditional knowledge in IPR applications. Some countries have specific measures relating to consultations between national ABS authorities and national patent offices as well as the ex post facto review of IPR. Some developed countries have developed and revised their IPR law to accommodate a disclosure-oforigin provision, with some differences in scope (disclosure of origin only, or also evidence of prior informed consent). The issue of sanctions for noncompliance lies outside the patent law.

78 Normand, 2004.

79 Ogolla, 2005. 
In this regard, a study carried out in 2004 has found that ${ }^{80}$ relatively few cases exist in which a court or other official provided an interpretation/implementation of the regulations. In many cases, the interpretation/implementation can be deduced out of the omissions made by the authorities, for example, when considering whether an activity constitutes access or not. Nonetheless, leaving interpretation to be inferred from conduct can ultimately generate problems regarding the control and monitoring of those activities involving access to genetic resources.

On occasion, in spite of the existence of applications for access and (sometimes) access contracts or permits, it is difficult to establish which systematic interpretation the authorities have utilized. It is a difficult and uncertain task, when starting from the few experiences available, to arrive at general conclusions. In some countries there are only one or two documented cases of access through the course of many years. Even in these cases, from the analysis of the permits granted, it is not possible to draw conclusions of interest due to the fact that these are limited to applying the legal framework without making any interpretations on important aspects.

The available information on ABS applications or ABS contracts is not always public or readily accessible. There have been cases in which the access to the genetic resources is granted using general legislation enabling the grant of research or collection permits (under general laws on conservation of nature, forests, wildlife or the environment in general). In such circumstances, even if the bioprospecting agreements that are eventually adopted address access criteria and sharing of benefits, they generally have been negotiated and accomplished without considering a legal regime of access, suggesting that formal legal efforts to implement them may be difficult or impossible. ${ }^{81}$

The different studies carried out on the implementation of national ABS laws ${ }^{82}$ confirm the difficulties that are faced by provider countries in seeking to obtain or verify adequate compliance with the current legislation of the provider countries. In practice, the level of enforcement of these laws is relatively low. ${ }^{83}$ There are many possible causes of this. For example, agencies may have limited negotiating power to deal with applications, particularly those involving transnational companies. Often there is also significant opposition from sectors of civil society that consider many kinds of bioprospecting initiatives to be per se biopiracy. Most important may be the absence of detailed regulations on procedures to facilitate decisionmaking by government officials (and give them confidence that they are meeting the responsibilities of their office). At the same time, it has been observed that existing $A B S$ procedures are highly bureaucratic and based more on the premise of control ${ }^{84}$ than on promotion. This situation is probably caused, at least in part, by the need to control the flow of resources, due to the inadequacy of national regulations for monitoring the use of genetic resources, as well as to the lack of user country measures. This has generated a situation of legal uncertainty concerning access to genetic resources.

80 Cabrera Medaglia, 2004, A Comparative Analysis.

81 A 2002 study carried out on the Pacific Rim Countries (42 countries) concluded that since 1992, 29 access projects have been approved in that region under ABS laws (Carrizosa, pers. comm.). Carrizosa concludes that "More than other natural resource policy, ABS has been the target of misconceptions, politics and negative publicity. Biopiracy claims, poorly defined ownership rights over genetic resources, the patenting of life, the protection of traditional knowledge and equity issues have thwarted access initiatives and have also contributed to the cancellation of bioprospecting projects." Carrizosa, 2004.

82 See, in particular, Cabrera Medaglia, A Comparative Analysis, 2004; Gartforth et al., 2004; Carrizosa, 2004.

83 Nevertheless, some improvements are starting to be seen in the application of the legal ABS frameworks, such as in Brazil, for example, where the number of permits has grown steadily in the last few years, mostly having to do with non-commercial applications. For example, in 2005 there were almost 100 access applications for basic research and 20 for bioprospecting and technological development. See www.mma/port/cgen

84 Cfr Barber et al., 2002. They suggest that there are only two approaches to be taken into account in building and applying the ABS regulatory frameworks: (i) controlling access through extremely restrictive legal provisions; and (ii) seeking to facilitate or promote access through flexible regulations that are more coherent with the user's reality. 
Despite the foregoing, some countries have been able to apply the legislation - at least in a limited form. This is the case in Costa Rica, ${ }^{85}$ in the system being visualized and operationalized in countries such as Brazil ${ }^{86}$ and in others to a lesser extent. ${ }^{87}$

In summary, as one commentator concludes: ${ }^{88}$

Despite the apparent clarity of the objectives, the record of implementation is very poor. A growing, but still limited, number of Countries have passed legislation and those that have done so are finding it difficult to implement, only a limited number of contracts has been approved under new legislation. ... This situation is due to the lack of recognition of the need of an integrated regulatory approach in which both provider and users of genetic resources take action to enforce provisions of the CBD. This situation was in fact created by a limited recognition of the realities of biotechnological research and development as well as the lack of coordination mechanisms across jurisdiction. ... Some form of documentation of the genetic resources such as the certificate of origin, could play [a role] in fostering the CBD objectives in an economically and efficient manner.

85 See Cabrera Medaglia, 2004, "Costa Rica: legal framework and public policy."

86 See presentation of the Brazilian experience made at the COP VIII in Curitiba, "Implementación de la legislación de acceso y distribución de beneficios en Brasil," Ministerio de Ambiente, March 2006.

87 Some developments have taken place in Malaysia ( Sarawak) and in Venezuela. See Cabrera Medaglia, 2004, A Comparative Analysis...,; and Febres, 2003.

88 Fernández, 2005. 



\section{Key Issues for Functional and Operative Certainty in Access Regimes}

This chapter presents some of the most relevant legal concepts of access, whose proper interpretation/clarification/application is necessary for constructing functional and operative ABS systems.

The elements that have been considered particularly relevant are the following:

- Conceptual notions: genetic resources, biological resources, utilization, derivatives.

- Systems of property rights and their application to genetic resources: implications of the concepts of public property (public domain) over the

\subsection{The conceptual aspects}

This section seeks, by means of an integrated focus on the concepts "genetic resource," "derivative" and " utilization of genetic resources" to suggest some recommendations that would permit:

a) improvement of the legal certainty for the applicant for access and the successive acquirers (which would allow the granting of certain protection against claims of misappropriation of genetic resources); and

b) improvement of the rights of the provider by putting legal mechanisms in place that can control the phase of utilization of the genetic resources.

One of the main problems in the establishment of ABS regimes derives from the lack of clarification of three key aspects which can be referred to as "conceptual aspects of the ABS." These conceptual elements cannot be analyzed separately because it is necessary to be clear on each one of them and on the manner in which they interact and complement each other to allow the operation of functional ABS systems. functionality of ABS regimes.

- Distinction between basic research and commercial purposes, including the consequences of this distinction on legal certainty and the rights of the provider.

- Processes for obtaining Prior Informed Consent.

- Incentives to motivate compliance.

- Monitoring of (i) the flow of genetic resources and (ii) compliance with the conditions of access, noting the insufficiency of contractual provisions to ensure the monitoring of the use of genetic resources in processes of research and development carried out in foreign jurisdictions.

Generally, the majority of countries with ABS legislation have focused on regulating access to genetic resources, based on the definitions contained in the CBD ${ }^{89}$ Nevertheless, the direct use of this terminology from international instruments in national laws presents practical difficulties that impede legal certainty with respect to the scope of the ABS systems. In many cases, these definitions have been adopted without consideration of the implications of these concepts.

Additionally, as was mentioned earlier, there are practically no decisions of the $\mathrm{COP}^{90}$ that call for this clarification. Some recent studies of the implementation of access laws mention, as one of the problems with the efficiency of this legislation, the confusion with respect to the activities regulated. As examples, it has been pointed out:

The scope of most ABS policies covers non-human genetic, biological and biochemical resources found in ex situ and in situ conditions. This broad scope

89 Cf. Gartforth et al., 2004; Cabrera Medaglia, 2004, A Comparative Analysis....

90 Decision V/26 had indicated the need for gathering more information on definitions. The Executive Secretary convened an Expert Group on the Use of Terms, which limited its work to exchanging information about national practices. Decision VI/ 24 requests the ABS Working Group to study, among others, the use of Terms and Definitions. Finally, Decision VII/19 B invites Parties, organizations and stakeholders to submit information on the following terms: access to genetic resources, commercialization; derivatives, etc. It also requests the Working Group to continue working on the use of terms not defined by the CBD. 
has caused confusion among users and providers of genetic resources about the type of activities that should be regulated by these policies. ${ }^{91}$

In the same sense, Dross and Wolff mention: ${ }^{92}$

It has been noted that a broad range of terms are either not defined in the Convention or even if defined in the Convention are not clear enough and can thus be interpreted differently by the Parties. One of the consequences is the invitation in the COP Decision VII/19 to submit information on existing national definitions on a number of terms including access to genetic resources, benefit sharing, commercialization and derivatives.

In general, the confusion with respect to activities that involve access remains. Such is the case with access requests in certain countries which supposedly deal with activities related to biological resources.
Box 1. Selected examples of access applications which involve conventional uses of biological resources.

- Petition for access to genetic resources for camelids and llama in Bolivia. The goal of the project was the marketing and live exportation of camelid livestock (llamas and alpacas) for the marketing of their meat in the Middle East.

- Collection, inventory and preparation of an Atlas of Wild Peanut were carried out as a proposal for access to genetic resources. ${ }^{93}$

- Formation of a Germplasm bank of the species "xenophiles." 94

- Project on the sustainable use of Cohune Palm in Guatemala for supply of processing oil.95

- Harvesting and selling of Prunus Africana (barks per kilo).

- In some countries (Ecuador) the term derivatives has been interpreted to cover medicinal plants as such. ${ }^{96}$

\subsubsection{Refining the concept of genetic resources}

In the past there have been criticisms of the lack of clarity of the term "genetic resource," and specially its implications in determining the scope of regulations for access to genetic resources. ${ }^{97}$

Particularly, the vagueness of the definition included in the Convention on Biological Diversity has been debated, which has been criticized for its lack of precision. In the same way it has not always been clear when access to genetic resources occurs, in opposition to access to biological resources, nor when the utilization of genetic resources takes place and if this constitutes a different phase altogether. Predominantly, in most legislation addressing access to genetic resources, even though those terms are defined, they have continued to be unclear in practice. In particular, even with statutory adoption of these definitions, it is not simple to establish which activities constitute "access to genetic resources" and which are "access to biological resources." Few States' ABS laws provide the mechanisms to determine whether their genetic resources have been accessed and/or utilized.

As noted in Chapter 2, neither the Convention nor national law have provided usable practical definitions of key terms. Even those terms which are defined in the Convention are not defined in a way that enables implementation. Thus concepts like "genetic

91 Cf. Carrizosa et al., 2004.

92 Dross and Wolff, 2005.

93 Ministry for Sustainable Development, 2004.

94 Febres, 2003.

95 Cfr Dross and Wolff, 2005. See of these authors other examples which might found under the category of biological resources in Cabrera Medaglia, 2004, A Comparative Analysis..., at Annex 4, Comparative Table of ABS Agreements.

96 Ruiz, 2000.

97 Ten Kate and Laird, 1999; Glowka, 1998. 
resources," "genetic material of actual or potential value,"98 utilization of genetic resources and other basic matters are not defined or not sufficiently clear. ${ }^{99}$ Little attention has been paid to the need to precisely define a number of terms, whose inclusion in the international ABS Regime ${ }^{100}$ would improve the effective application of national ABS systems.

These are concepts which the IR could help to clarify in order to create consistent and functional legal frameworks. There have been important incidences of legal difficulties arising due to a lack of understanding regarding the difference between biological resources and genetic resources. ${ }^{101}$ Young reports ${ }^{102}$ five uncertainties regarding the application of ABS principles to a particular claim of misappropriation, including the nature of genetic resources. "One area of uncertainty regarding the application of $\mathrm{ABS}$ principles related to whether the claim is in fact addressing ABS rather than some other kind of legal concerns.... Unfortunately this is not a simple matter to determine whether a claim involves genetic resources or not because it is not possible to know with legal certainty what a genetic resource is.... More than half of the public cases [of misappropriation] examined involved direct uses of either natural products and essences or remedies using such products and essences and naturally or traditionally derived varieties already being used for conventional agricultural purposes....".

This question goes to the heart of the CBD discussions. From the earliest CBD negotiations, it was clearly expected that $\mathrm{ABS}$ should not alter existing functional markets and market activities in biological resources. To create an ABS system without disrupting conventional markets in biological products, however, it was necessary to separate the concept of biological resources (traditional biological commodities) from genetic resources (the genetic and biochemical information which can become the basis for non-conventional uses).

The boundary between activities involving access to genetic resources and those that, to the contrary, make use of biological resources is not always clear. ${ }^{103}$ In effect, it has been noted that the CBD definitions of biological and genetic resources are, strictly speaking, functionally identical so it is not possible to clearly distinguish between the two. ${ }^{104}$ Cabrera, commenting on the implementation of ABS laws mentions:

98 CBD, Art. 2 Use of Terms.

99 The drafting history of the CBD does not present any particular help to clarify this issue and how some critical issues were not addressed at all or were addressed in a manner that does not provide enough guidance to policy makers and ABS practitioners. See Glowka, 1994.

100 Decision VII/19 had already mentioned the need to continue working on certain definitions. However, from the point of view of the international regime, more than being a matter of simple conceptual clarifications, this has to do with essential aspects that are needed to give the ABS systems legal consistency and functionality.

${ }^{101}$ For example, the difficulties in analyzing cases of "misappropriation" or "biopiracy" of genetic resources and traditional knowledge, given the lack of clarity about which activities constitute access to genetic resources (and which would consequently be required to follow the respective rules) and which, on the other hand, constitute the use of biological resources. Cfr Young, 2006. As noted above, numerous claims have been based on direct utilization of oils, flours, grains or other extracts milled or taken in conventional ways using naturally occurring or traditionally derived subspecies or varieties. These actions use the variety in the same way that commercial trade in fruit juices used the property of the fruit, but do not require special genetic-based research or activities. Other claims focus on normal kinds of plant breeding (cross pollination, hybridization, etc.) or animal breeding. Many such claims are adequately regulated under other laws, suggesting that they do not need to be covered by ABS law. Likewise, a report on 36 cases of biopiracy in Africa, recently distributed during the Meeting of the Working Group in Granada, presents some examples in which there are at least well-founded doubts about whether a genetic or biological resource was involved. Cfr Edmond Institute (undated).

102 IUCN-Canada, 2005.

103 Cfr Dross and Wolff, 2005. Young notes that "Few concrete mechanisms have been suggested for determining which activities are normal commercial use of biological resources and which are utilization of genetic resources. Some have suggested that genetic resources law applies to new and unconventional uses of biodiversity in which a user may often need only a relatively small amount of biological material. Once the material has been brought into the user country, it can usually be reproduced whether chemically or biologically. As a consequence it is not possible to control the movement of genetic resources from the source country, the only way to prove a violation of ABS principles is to prove that someone has utilized genetic resources. Legal certainty and binding enforcement of ABS agreements will depend on whether the distinction between biological and genetic resources is clear, unambiguous and instantly recognizable by governments and all other involved parties in all countries." Young, 2004, "Genetic Resources...".

104 Young, 2004, “Genetic Resources...”. 
"Neither does the Convention define what is to be understood as access and utilization. This has implicated that on the implementation and interpretation of the laws on access, requests have been presented to access biological resources with exclusively taxonomic purposes or for the commercial utilization of biological resources, without the existence of access to genetic or biochemical properties contained in the samples. In other cases, especially where dealing with the use of medicinal plants, nutraceuticals, botanicals, etc., the majority of legislation tends to exclude them from the scope of access, even though it is considered an important growth sector at a worldwide level and that there is an increased interest in botanicals from the private sector. ${ }^{105}$ Sometimes they are included, but only where there exists a larger level of industrialization - another term that is not defined properly.

In general, the studied legislation bases the definition of genetic resources on the one provided by the Convention, with some modifications that do not alter its essence. Additionally, the laws define access to genetic resources and eventually some of the activities that represent access, such as bioprospecting. ..... it is unclear to what extent the use of a whole medicinal plant, herbal plants, or nutraceutical food is an activity which involves access. " 106

Typical approaches include:

- Legislation that repeats the definitions of genetic resources, genetic material and/or biological resources of the CBD: examples include the Philippines, Andean Pact, Bhutan, Uganda, ${ }^{107}$ etc.

- Access legislation that includes all biological resources in general: The India Biodiversity Law, and The Model Law of the African Union Countries.

- Legislation of access that applies to biological resources in general but qualifies the activities by means of the definition of access or bioprospecting: India, Venezuela, ${ }^{108}$ Australia (federal), ${ }^{109}$ South Africa, etc.

- Access legislation that defines genetic resources the same as the $\mathrm{CBD}$, but specifies the meaning of access, or establishes exceptions for such uses as "conventional," "traditional" or as an "organic resource:" Andean Pact, Sarawak (Malaysia), Costa Rica, Philippines, Uganda, Australia (Federal) etc.

- Access legislation that defines genetic resources the same as the CBD and adds biochemical resources: Costa Rica, Australia (Queensland), Bhutan. ${ }^{110}$

- Legislation that contains definitions of genetic resources that differ from the CBD: Brazil. ${ }^{111}$

The confusion increases because even in cases of conventional uses of biological resources, benefit-

105 Ten Kate and Laird, 1999.

106 Regarding this issue, Glowka points out "For example if the blossoms of a plant were harvested as a bulk or biomass commodity for direct use in an herbal tea or a cosmetic and not for their genetic or biochemical informational value in a technological application, would harvesting and export trigger the prior informed consent and mutually agreed terms provisions under the legislation? The supplier of the blossom more than likely has or will negotiate a supply agreement with the users. This presumably reflects a mutually agreed price to supply a certain quantity of the blossom at a particular price... Benefits therefore will accrue without creating a new regulatory regime....However if for example, cells from the blossoms or seed from plants were used as the basis for a cell culture or farm cultivation to mass produce an active ingredient, then they are being used as a genetic resource." Glowka, 1999.

107 In these cases, access or bioprospecting is sometimes also defined.

108 The Biodiversity Law of Venezuela is not clear. The scope of the access provisions refers in some cases to biodiversity resources and in others to genetic resources.

109 Environment Protection and Biodiversity Conservation Amendment Regulations, 2005.

110 These legislations also define access, bioprospecting or biodiscovery.

111 The Provisional Measure of Brazil defines Genetic Heritage as follows: “information of genetic origin contained in the samples of all or part of plant, fungal, microbial or animal species, in the form of molecules and substances originating in the metabolism of these living beings or from extracts obtained from in situ or ex situ conditions...". The Biodiversity Law of Costa Rica and the Access Norms (regulations) defines separately genetic resources and genetic elements, the genetic resources concept is based on the idea of some degree of human intervention. 
sharing provisions in line with the CBD have been developed. For example, the BioTrade Initiative of UNCTAD, which focuses only on extracts and natu- ral ingredients, includes detailed provisions for compliance with national $\mathrm{ABS}$ requirements. ${ }^{112}$

\section{Box 2. Benefit sharing and the BioTrade Initiative of UNCTAD ${ }^{113}$}

The objective of the BioTrade Initiative of the UNCTAD is to contribute to the implementation of the three objectives of the CBD by means of the promotion of trade and investment in products and services of BioTrade. Based on the experience of the National BioTrade Programs, a set of principles of BioTrade have been developed, that are agreed upon between the Initiative and the Programs. One of them (principle 3) refers to the fair and equitable sharing of benefits derived from the use of biodiversity. Eventually these Principles and Criteria could be verified and certified with the aim of differentiating products derived from BioTrade.

Among the products selected by the Initiative or the National Programs and supported by the BioTrade Facilitation Program ( BTFP) are:

- Alligator meat and hide (caiman and yacare);

- Cacao;

- Ecotourism;

- Tropical flowers and foliage;

- Wild fauna for pets;

- Natural ingredients for the food, cosmetic and pharmaceutical industries;

- Ornamental and comestible fish.

The natural ingredients include: colorants for the cosmetic and food industries; essential oils for the cosmetic and food industries; vegetable oils for these industries; powdered fruit pulp for the food industry (supplements and additives); vegetable extracts for the phyto-pharmaceutical and food industries. The market for natural products encompasses: fresh or dehydrated medicinal plants; fruits, pulps, fruit oils; herbal extracts; vegetable oils; essential oils; natural colorants and many ingredients of this nature for which demand has been increasing.

A variety of options have been developed ${ }^{114}$ that countries can consider as ways of clarifying the concept of genetic resources/biological resources for the purposes of their national legislative systems. These include:
Option 1: Determining whether the law will recognize any difference between biological and genetic resources, keeping in mind the intrinsic difficulties involved in control-

\footnotetext{
112 It is noted that some important initiatives, especially the BioTRADE initiative of UNCTAD (see www.biotrade.org), are designing specialized programmes which apply the principles of ABS, in an abbreviated form, to the use of natural extracts (that is, of "biological resources"), especially in cosmetics and other consumer products. See the Informal Expert Workshop on Practical Guidelines for equitable sharing of benefits of biological resources in BioTrade Activities, Meeting Report, September 2006. BioTRADE joins a number of other actors who feel that the need for and importance of benefit sharing extends not only to genetic resources but to all components of biodiversity. The Addis Ababa Principles and Guidelines for the Sustainable Use of Biodiversity, for example, adopted by the Seventh Conference of the Parties of the CBD, include several references to this idea.

${ }^{113}$ Cfr www.biotrade.org. See the Informal Expert Workshop on Practical Guidelines for equitable sharing of benefits of biological resources in BioTrade Activities, Meeting Report, September 2006 which indicates "... equitable benefit sharing also arises in the context of the second objective of the CBD: the sustainable use of biodiversity. In this context, the need and importance of benefit sharing extends not only to genetic resources but to all components of biodiversity. The Addis Ababa Principles and Guidelines for the Sustainable Use of Biodiversity, for example, adopted by the Seventh Conference of the Parties of the CBD, include several references to this effect."

114 Young, 2004, “An Implementation Perspective...”.
} 
ling conventional uses of biological resources within the framework of $A B S$ systems.

Option 2: Considering genetic resources to be a more specialized type of material, as compared with the general category of biological resources; for example, a genetic resource might be a particular type of material taken in a specific way, such as prepared dry materials.

Option 3: Setting the distinction based on the intended use on the part of the applicant at the time of access, for example, whether access to the materials is sought for conventional purposes or with the intention of utilizing them for their genetic or biochemical characteristics.

Option 4: Deciding that "genetic resource" refers to genetic information, independent of physical access to it.

Option 5: Deciding that genetic resources could be best understood as the "right to use genetic information." 115

No solution is simple. Considering the international and transboundary nature of $\mathrm{ABS}$ relations and the need for consistency and legal certainty, ${ }^{116}$ it is hoped that the International Regime should provide the countries with some guidance on this matter.

The following discussion section explores some approaches to applying the different options or criteria to clarify this critical issue.

\subsubsection{The utilitarian approach}

According to some, the definition of genetic resources (in the $\mathrm{CBD}$ ) is relatively clear. For them, the ques- tion is simply establishing an agreed distinction between genetic material and genetic resources. They do not recognize any physical distinction: "a genetic resource is a genetic resource rather than a genetic material because we perceive it as a resource, that is, we attach value to it."

In essence, if one adopts a physical approach to defining these terms, genetic resources and biological resources are synonymous; if one adopts a utilizationbased conceptual approach, then perhaps the terms can be distinguished. This suggests the CBD intends Parties to the Convention to adopt a conceptual or utilitarian rather than physical or natural view of genetic resources. However, the language of the CBD definitions and other articles does not indicate how a utilitarian approach should or could be constructed, and especially, how it can be applied.

Numerous examples can be cited to illustrate the legal importance of line-drawing - that is, of making it clear which resources are "biological resources" (not governed by $A B S$ ), and which are genetic ( $A B S$ applies). For instance, is the seed or tuber of an agricultural crop, a genetic resource or a biological resource?

Under the utilitarian approach, the purpose in collecting a particular seed or tuber of an agricultural crop would define whether it was considered to be either a genetic resource - and thus regulated under ABS law - or a biological resource - and thus unregulated. It is at this point that the construction of the utilitarian approach becomes important. The genetic resource does not lie in the properties of the species, (color, taste, etc.), per se, but in the possibility that they may be multiplied, propagated, transferred into other varieties or species or synthesized for use in some scientific or industrial purpose (although it is not clear if there should be a limit on its application for scientific purposes). Ensuring that this is reflected in a regulatory regime is purely a question of recognizing

\footnotetext{
115 This definition makes it possible, at least theoretically, to deal with the issue of access to information that is available electronically, such as that deposited in data bases. The same information generated by genomic and proteonomic projects, for example, may gradually substitute physical access to samples, conceived as part of the normal or traditional collection process of ABS projects. Curiously, the international regime negotiators have not paid much attention to the impact of these technologies and the means of generating information on ABS proposals and systems, perhaps due to their technical complexity and the lack of analysis of their legal implications. Cf. on the topic, Oldam, 2005.

116 Cfr Young, 2004, "Genetic Resources...”.
} 
the problem and carefully drafting accordingly.

A problem that must be considered in the development of an utilitarian approach is the possibility of dishonesty on the part of the applicants for access to genetic resources. Once the resources are out of the jurisdiction of country of origin, it is not possible to control these resources and therefore not possible to know of and ensure a share in the associated benefits. Cabrera, after the analysis of most ABS laws in place, concludes that: "In general in most of the cases studied, there is no provision to differentiate the taking of biological resources (the organic material) from the taking of the genetic material contained in the biological material. The difference should be based on the intended or declared use: the search for genetic or biochemical material contained in the biological specimen, for different purposes (basic research, bioprospecting, etc.). Supposedly, in some countries the taking of biological resources must comply with certain requirements, including the information provided by the applicant before granting removal. This information should contain details on the intended use and therefore if the proposed use implies access to genetic resources, the competent authority must refer the applicant to the appropriate legal body in charge of granting access in order to initiate the legal procedures for access and benefit sharing...."

"It can be concluded that utilization of genetic resources is not defined. In general terms, the practice is based on the intended use of the biological resources, as a source of genetic information. For this reason, the only way to control the use of organic resources not as genetic information for different purposes (bioprospecting, scientific research, etc.) is looking at the information submitted by the applicant of the permit and whether it states that the access to the biological resource is for different purposes other than for its genetic composition. The intended use is the key aspect for knowing when a person is seeking access to genetic resources."

In accordance with this line of thinking, the difference between access to genetic resources and biological ones is the "intended use," that is, the declared purpose for which the applicant indicates that he desires access to a sample of a material. If this purpose is the search for new biochemical compounds for the creation of medicines or similar uses, the activity would involve access to genetic resources. If, for example, the purpose is to collect specimens only for taxonomic identification, this activity would not be considered access. ${ }^{117}$

However, the utilitarian approach faces some difficulties. ${ }^{118}$ "One theoretically clear understanding of 'genetic resources' is use of biological material for certain intentions or purposes. This defining criterion could link the scope of access legislation to the "purpose or intention" of the person or company having access to the biological material. This, however, implies a challenge for access legislation: As functional units of heredity are present in biological material also when sold for the purpose of commodities, the scope of access legislation would solely have been depending upon the purpose or intention of the one seeking to move biological resources across a border. The genetic resources could be said to cover certain intended uses of biological or genetic material.

"The primary intention of the use of biological

117 For some, this is the most appropriate solution. Cfr Dross and Wolff, 2005. Others believe that this would involve considerable legal difficulties in determining the legality of access. The difficulties mentioned include problems in objectively determining the applicant's intention; the possibility of his later being granted a different use of the collected materials by a third party - and possibly some time after the original collection was made, etc. Cfr Tvedt, 2006; and Young, 2004, "Genetic Resources...,".

118 With regard to the intentional approach, Young criticizes: "There is no objective way to distinguish these actions from obtaining access to genetic resources. The only difference is the intention of the person taking the action. In ABS, it can be particularly complicated having so many different persons, actions, and intentions between the original collection of a biosample and the point when its genetic resources are utilized commercially. It is not objectively clear whether access to genetic resources occurs at the time the biological specimen is collected from the wild or the farm or at the time the genetic resources material is first intentionally studied, extracted or otherwise utilized in commercial or other development. Moreover there are many possible situations in which the relevant genetic and biochemical information can be transferred without collection of physical material. A gene sequence or a biochemical formula may be expressed on paper and sent to a researcher in another country by mail. In 2005 , it is thought to be too difficult and costly to build genetic material into products solely from a gene sequence without a sample reference. That scientific capacity is expected to be developed substantially during the next decade." Young, 2004, "Genetic Resources...,". 
material typically changes over time. The purpose of the use typically changes after the genetic material has left the country. When the original intention is altered, access legislation targeting the primary intention will not be robust enough to capture the value created later. This constitutes a major obstacle and perhaps implies that it is impossible to control and reserve all exports or "access" to genetic material by this criterion.

"The intention is not manifest in any objective manner at the point in time of access. It is hardly possible to overview the intention of each individual transfer of biological material containing functional units of heredity. To control the intention of each exporter of biological material is not at all easy for the provider country. To base a court case or enforcement mechanism upon a criterion as subjective as the intention that the exporter originally had is close to impossible. To prove that the original intention was another than using the biological material in bulk is not an easy task before a court.

"Choosing intention as criterion will also not create the predictable situation for research and industry: Such an understanding of the concept 'genetic resources' will not easily meet the call from industry for a clear and stable legal situation. Choosing intention as the defining criterion will not establish a clear and predictable situation for researchers or industry receiving biological material. Both researchers and industry need to be faced with a clear legal status for the genetic material that they bring to laboratory for research and developmen."119

In synthesis, although the majority of legislation appears to have indirectly adopted the intentional criterion, this presents legislative and administrative problems relating to the determination of the existence of access, a legislative element that depends on the collector's intent at the time of collection, limiting the possibility of judging objectively whether the applicant truly intends to conduct activities of access. It makes it difficult for the administrative or judicial authorities to make an objective determination of compliance or of potential non-compliance with legislation regulating access to genetic resources, limiting the legal certainty of the provider, the user, and subsequent acquirers of the samples. Moreover, the intentional approach does not permit adequate control without the existence of measures that allows the source to know "utilization" of genetic resources has taken place.

\subsubsection{Genetic resources as the "utilization of genetic information"}

With regard to this potential solution Tvedt affirms that: ${ }^{120}$

"To understand what is meant by 'genetic resources, ' there is a need to look closer at the [phrase] 'of actual or commercial value, in the definition of genetic material." This qualifier establishes a distinction between genetic material and genetic resources, establishing the latter as a specific type of natural resource. The distinction focuses on certain types of value from biological/genetic material. The difficult question is which types of value that the CBD seeks to capture by the definition of genetic resources. The term 'actual or potential value' can be understood as the value of the biological material when it is used by taking advantage of the functional units of heredity. If this understanding of the legal concept is applied, the concept 'genetic resources' will be geared towards uses of biological material for certain purposes or categories of uses.

[It will then be clear that] Article 15 seeks to capture the value created from taking advantage of the genes (the functional units of heredity) in the biological material. Thus functional units of heredity (genetic material) - present in all biological material, even when used for bulk purposes - could potentially be used in breeding or replicating that specimen. Therefore, to control access by regulating export of genetic material is not at all possible or probably not even preferable. The vast majority of biological commodities contain genes and thus have potential to be used for their genetic material. Only small quanta of biological samples can be sufficient to capture the interesting genetic material. A necessary precondi-

\footnotetext{
119 Tvedt, 2006, and see detailed discussion of this issue in Tvedt and Young, 2007.

120 Tvedt, 2006.
} 
tion for effective access legislation to create benefitsharing, would require prevention of unauthorized access. As there are major obstacles related to controlling export of genetic material such exclusive control will not be possible. Therefore, the defining criteria for genetic resources need to be further explored."

As a possible solution, it has been suggested that the term "actual or potential value" associated with genetic resources should be understood in the context of the CBD. In this way, the obligation of benefit sharing has its origin in "the benefits arising out of the utilization of genetic resources" and "the results of research and development and the benefits arising out of the commercial or other use of genetic resources" (art. 15.7). From this perspective, the term "genetic resource" should be understood to be all activities that result in capturing the real or potential value of genetic resources. Thus, it is suggested that instead of focusing on the intention of the party requiring access, the concept of genetic resources should be linked to specific uses. This would also lay the groundwork for user countries to issue measures in their territories, based on certain categories of utilization. ${ }^{121}$ (This approach is further discussed under the general heading of "the utilization issue, "at 3.1.3, below.)

\subsubsection{The permanent access criteria}

A different approach uses a more objective consideration. If the sample is re-used (more or less directly - that is, as a whole specimen, direct extract, etc., without scientific/genetic alteration) as an ingredient in the production of commercial goods, it is not considered to be access to genetic resources, but the utilization of biological resources for conventional uses. Nevertheless, although this distinction can be used for the definition

of genetic resources, without the establishment of measures that permit control over the utilization of the resources, it would present the same problems enumerated in the case of the utilitarian approach. However, it lends certainty to the moment of access and over legal procedures to follow, according to whether it is access to genetic resources or conventional uses of biological resources.

\section{Box 3. Excerpts (Definitions) from the Seychelles Draft Law on Access to Genetic Resources ${ }^{122}$}

\section{Substantive scope/definitions:}

"Biological resources" includes organisms or parts thereof, populations, or any other biotic component of ecosystems with actual or potential use or value for humanity;

"Genetic resources" means biological resources, including parts and components, with the exception of:

- any biological resource for which the intended purpose does not involve cultivation or reproduction by means of any natural or artificial technique, including biological resources for conventional uses, and

- any other biological resource or use of such resource the Minister may prescribe in regulations;

"Parts and components" includes functional units of heredity, DNA sequences, chemical compounds, secondary metabolites, biochemicals and other similar material and transcriptions of information describing any of the above in terms of structure or similar technical details;

121 Cfr Tvedt, 2006, who calls this the "catalog approach."

${ }^{122}$ Lettington and Dogley, 2006. NOTE: As of this writing, this bill has not been adopted. 
Explaining the meaning of those definitions the authors point out:

First, the main element of the definition of parts and components to note is the word 'include', which is used to clearly state that the following list of examples is not exclusive. Equally, the items in this list are not necessarily mutually exclusive. For example, a DNA sequence might be considered a functional unit of heredity or a secondary metabolite might be considered a chemical compound. The key point to note is that the list is not trying to be scientifically precise: it is actually a political, rather than scientific, list and the aim is to ensure that it is understood that the definition clearly intends to include any possible element of a genetic resource.

Second, the reference to transcriptions of information is intended to ensure that rights are being claimed to any written source, or some other form of communication, describing the basic characteristics of a genetic resource. This is increasingly important as the details of materials' genetic or chemical structure can be unraveled and then sent by email, fax etc. ever more rapidly. Finally, the term 'parts and components' could have been added to the definition of biological resources with equal effect, genetic resources being a subset of biological resources. However, the placing in the context of the definition of genetic resources is intentional, as a means to emphasize its role within the context of the legislation.

... the CBD definition of genetic resources only highlights the fact that countries should define the term in a utilitarian (as opposed to a natural or physical) manner, but does not actually provide a definition itself. This issue is, therefore, subject to national interpretation.... The approach taken in Seychelles is based on the same basic structure that can be found in the CBD, namely the identification of a general group and then of a subset of this group. The general group can be found in the definition of biological resources, which is intended to cover all biological material. This matches the CBD definition of the same term, with one exception, which is that the reference to genetic resources has been deleted because it was not felt that this added anything substantive to the broad scope of the definition and created a risk of confusion.

The development of the definition of genetic resources was one of the most thoroughly discussed aspects of the development of the legislation, due to its central role in determining which activities would fall within the scope of the legislation and which would remain outside.

The most obvious exclusion was one for commodities, such as fish for consumption and other foodstuffs. This exclusion operates at a range of levels from a need not to burden Seychelles' significant fish processing industry all the way down to the question of household shopping. In a more specific context a range of other activities, including taxonomic research, the production of essential oils and the collection of wild materials for household use, were considered and, to varying degrees, proved controversial. For the purpose of establishing a generally applicable principle... the basic line between what use of a biological resource should make it a genetic resource and what use shouldn't (i.e. the line between uses regulated by the legislation and those not provided for) could be drawn on the basis of whether the intended use focused on the commodity nature of a resource or on some other property. The main strength of this approach is that it automatically excludes the majority of foodstuffs and other directly extractive and consumptive activities.

The basic solution that was developed is the text of subsection (a) of the definition, which focuses regulation on activities that involve cultivation or reproduction, i.e. that mean that the recipient of material is not dependent on the source in Seychelles after the initial collection. Where the recipient of material will continue to be dependent on the source in Seychelles, i.e. commodity transactions, this is not regulated by the legislation on the understanding that such situations are most effectively regulated by traditional natural resource extraction systems. Such systems typically con- 
sist of a price set according to the volume of material and the known uses of that material. To avoid the regulation of generally accepted uses that might fall within this definition of genetic resources the concept of conventional uses, discussed below, is introduced as an exception. .... To allow for situations that might not reasonably fall within the description of conventional uses, but that it might not be deemed appropriate to regulate as access to genetic resources, subsection (b) of the definition was introduced to provide the authorities with future flexibility to make exclusions as necessary. This follows the basic principle clearly established by stakeholders: an inclusive approach to regulation with exceptions to be established as necessary.

Supplementary scope definitions:

"Conventional uses"123 means widely practiced and accepted uses such as -

(a) The local collection of wild genetic resources for cultivation in home or kitchen gardens and intended primarily for domestic use,

(b) the sale or exchange of agricultural produce for food or feed purposes,

(c) traditional fermentation techniques,

(d) the saving, using, exchanging or selling of farm-saved seed or propagating material among farmers, or

(e) any other use the Minister may prescribe in regulations.

Explanation from the author:

The term "conventional uses" is different from "parts and components" in that, rather than clarifying the definition of genetic resources, it creates an essential exception to its scope. As mentioned earlier, the broad issue relates to what might be considered as generally accepted uses of biological resources that Seychelles deems it unnecessary or counter-productive to regulate through access to genetic resources.

Subsection (c) was probably the most controversial of the specific conventional use exceptions. Discussion covered distillation, both for alcohol and essential oils, and other similar activities as well as fermentation. As with subsection (b), the focus of the genetic resources definition on cultivation and reproduction might be seen to render this exception redundant. However, some activities, particularly fermentation, do involve the reproduction of biological resources. In addition, the fact that some stakeholders feel that the regulation, and taxation, of this kind of activity is currently inadequate suggests that access to genetic resources might be seen as a means to capture benefits. The conclusion, based on a majority opinion, was that fermentation, as an indicative example, should be excluded and that the other related forms of activity, particularly distillation, should also be excluded, as they are not really issues of access to genetic resources. If there are problems based on the perception that, in their commercial form, distillation or fermentation profit from the biological resources of Seychelles in a manner that is inequitable in terms of individual versus national benefit then this could be more effectively addressed through taxation or licensing.

As is suggested by the discussion of subsection (c), above, the list of specific examples of conventional uses is not intended to be exhaustive. It is primarily intended to provide an interpretative guide for use by the authorities.

${ }^{123}$ In a similar approach, the Draft Biological Resources Bill of the Northern Territories in Australia lists activities that do not constitute "bioprospecting:" fishing for commerce, harvesting of wild flowers, taking wild animals or plants for food, collecting peat or firewood, taking essential oils from wild plants, collecting plant reproductive material for propagation, and commercial forestry. 


\subsubsection{An access-based (source country) view of the issue of derivatives}

Another conceptual issue relevant to legal certainty is the concept of derivatives. Since the negotiations surrounding the Bonn Guidelines, and particularly in the COP 6 in The Hague, one of the most controversial topics has been that of derivatives and products and their relationship to access PIC and MAT. This discussion eventually resulted in the inclusion of "derivatives and products" in the Bonn Guidelines' discussion of benefit sharing. Thus, paragraph 44 of the Bonn Guidelines presents a list indicating the mutually agreed conditions included under point $\mathrm{i}$ : "provisions regarding the sharing of benefits arising from the commercial and other utilization of genetic resources and their derivatives and products." Likewise, with regard to the procedures for obtaining prior informed consent, the Guidelines indicate in paragraph 36 (l) (in mentioning the information to be presented) the "kinds/types of benefits that could result from obtaining access to the resource, including benefits from derivatives and products arising from the commercial or other utilization of the genetic resource."

According to their terms, the Bonn Guidelines are entirely "voluntary" (meaning in this case that countries have complete discretion as to whether to apply them); and in some cases, such as their provisions on the contents of PIC and MAT, and the lists of benefits and benefit sharing, they are doubly or triply voluntary, since these provisions are expressly made optional and expressed in non-mandatory language. ${ }^{124}$ While the topic of derivatives is also included in the International Regime negotiations ${ }^{125}$ (in fact, this discussion promises to be one of the most difficult due to the strong interest developing countries have shown in including derivatives and products in the International Regime), ${ }^{126}$ it is also a matter of national legislative concern for source countries.

In order to fully understand the issue, it is necessary to explain a few premises that may in some way contribute to advancing international negotiations on this subject. A number of national laws contain definitions of "genetic resources" that are much broader than the CBD's, applying access procedures equally to derivatives. ${ }^{127}$ In similar fashion, some national regulations extend the coverage of their access regimes by including "biochemicals" within the definition. ${ }^{128}$ Also, it may be possible to interpret the CBD language itself as including derivatives, if it is accepted that the object of $A B S$ regulations is to share benefits from the use of "genetic information" rather than tying them only to the material in a physical sense.

On this basis, one might wonder if it is necessary to regulate access to derivatives per se or if, on the contrary, it is more appropriate to clarify that they are covered in regulations on access to the genetic resources from which they are derived. If the second option eases the concerns of developing countries, it is undoubtedly preferable, as long as it allows the derivatives to be subject to PIC and mutually agreed terms, including those related to benefit sharing (through access to genetic resources). In this way, the benefits arising from the genetic resources can be identified and monitored through mechanisms that should be incorporated in the international regime, such as the certificate of origin/source/legal provenance, the disclosure of origin in IPR applications, and contractual arrangements on which access is based, as well as their monitoring clauses. ${ }^{129}$

It is equally important to recognize that the term "derivative" itself is not entirely clear. Glowka already noted concerns in 1998 in mentioning that

\footnotetext{
124 See generally paragraph 7 of the Bonn Guidelines as well as the above cited sections.

125 In the discussions and negotiations, both within the ABS Working Group and in the VII and VIII Conferences of the Parties, there have been recurring disagreements regarding the inclusion or not of derivatives and products. See Annex to COP VIII, Decision VIII/4, UNEP/CBD/COP/8/4, for example, to note how the references to derivatives and products are bracketed in the paragraphs where they are mentioned.

${ }^{126}$ From the commercial point of view, it must be accepted that derivatives or biochemicals - if they are accepted as equivalent - are very valuable for the pharmaceutical industry. Cfr Battig in this respect, cited by Wolff and Dross, 2005.

127 See Cabrera Medaglia, A Comparative Analysis, 2004.

128 See, for example, the Biodiversity Law of Costa Rica, articles 4, 6 and 7.

129 See in a similar sense, Tvedt, 2006.
} 
There are two contexts in which the term derivative applies. In the first, derivatives may be described as non-modified chemical components other than DNA or RNA, but formed by the organisms' metabolic processes. As in the case of DNA or RNA, these components exist in samples of biological materials obtained under ex-situ or in-situ conditions. Derivatives in this context, for example, may constitute active biological components found in the collected plant material, but that have yet to be modified and used in technological applications. In the second context, derivatives can consist of chemical components that are modified and created or synthesized from materials originally obtained from insitu or ex-situ sources. The resulting end products may be a hybrid seed, a traditional medicine or the synthetic version of a biochemical extract. Thus, they are products that are derived or synthesized from genetic or

\subsubsection{The utilization issue}

On this basis, it seems obvious that there is a need for clarification on the issues of utilization. This suggests a problem for source-oriented legislation, since utilization typically happens in another country. While it is hoped that the International Regime negotiations might resolve the concept involved, it will almost certainly not substitute for national legislation, nor will it be finished and implemented quickly. The task of national implementation will also be eased if those negotiations should address relevant criteria or a catalogue of uses that would be relevant for confining the user obligation.

In the meantime, however, the need for national legislative and administrative approaches in source countries remains critical. There may be a need (or advantage) in this process for reformulation of source country (access) legislation, to coincide with a benefit-sharing approach based on the idea of the use or utilization of the GR. In this connection, it is notable that the concept of "access to genetic resources" has not been defined either. biochemical resources through human intervention. Access legislation may be extended to derivatives in the first context. However, it would be very difficult to extend it in the second context in that this would be a matter of regulating access to technologies. ${ }^{130}$

Casas coincides with this view when he states that The international regime should not only cover genetic resources, but also their derivatives, understood as natural molecules that do not contain genetic information, but have resulted from a genetic resource. That is to say, they are compounds, extracts or secretions that occur as a natural expression of the genetic material and are the result of a metabolic process. ${ }^{131}$

If "access" means the ability to collect samples, then benefit sharing and/or utilization of genetic resources may not necessarily be based on access to genetic resources. ${ }^{132}$ Both the CBD (article 1) and the Johannesburg Plan of Action refer to the need to share the benefits arising out of the utilization of genetic resources, but do not tie this to the fact that such resources have been "accessed." The catalogue approach (listing activities that constitute genetic resources utilization) is primarily a tool of useroriented legislation, but could be a useful tool for access legislation as well, if (after) user countries have adopted it. Particularly where the country defines "genetic resources" or "access" based on intended use of the resources, it will be necessary to determine which intended uses require $\mathrm{ABS}$ compliance. Such legislation must include a list of activities or intentions.

In any case, it should not be forgotten that the principal purpose of such a legislative reformulation would be to provide certainty - both for users and for

130 Glowka, 1998. Likewise, according to Burton, the problem of derivatives is due to there being two interpretations or uses of the term derivatives. On the one hand, there are those who refer to derivatives as products or innovations originating from biological materials; their underlying concern is to control the commercialization or utilization of genetic resources in order to obtain a share of the benefits. Conversely, others address the topic from the perspective of the inadequacy of the CBD definition of genetic resources in not including the organisms' components, the interaction of genes and the biochemical compounds they express. Cfr Burton, 2004.

131 Casas, 2004.

132 The Annex to Decision VIII/4 contains some references to the use of the financial mechanism in cases in which the countries of origin of the genetic resources and derivatives cannot be identified. 
the source country. With this in mind, independently of the criteria or lists to be used, the national laws and international negotiations - should establish clearly the scope of the activities covered by the laws of access

\subsection{Property rights in genetic resources}

As noted above, the Convention on Biological Diversity has created a new system of property and commercial transactions for a specific material: genetic resources. This new property right was developed with the implicit understanding that the application of the property right to tangible property would be adequate and sufficient in the case of genetic resources, but that approach did not consider several circumstances.

For example, the assignment of exclusive rights to the physical property (rights to keep it, hold or change it, to exclude others, etc.), is based on the possibility of exercising physical control over the property. In the case of genetic information, its access and use cannot be controlled by means of the exercise of traditional (physical) property rights.

Another problem is the need to describe property, and which are excluded. At the same time, to give functionality to the system, it would be desirable that these criteria were harmonized by means of international decisions. ${ }^{133}$

in order to exert rights to it. How it is possible to describe with sufficient clarity, the intangible component of genetic resources in order to permit the creation of property rights over genetic information? ${ }^{234}$ The notion of genetic resources as natural or inherent information has been suggested by diverse authors. ${ }^{135}$

Here also, there is some reason to hope that the international negotiations may provide assistance in these matters, however, the basic property law issues development of new property systems or adaptation of traditional and conventional property systems to this new kind of property - will always be clearly matters of national governance, so that national legislative solutions, which are urgent now, will still be necessary and relevant, if any part of the international negotiation result provides critical agreements on supporting points.

\subsubsection{Applying existing law of property to genetic resources}

In general, the application of the traditional rights over tangible property to genetic resources can be difficult, raising, it has been affirmed, "Key questions of property ownership ... ABS created a new kind of commodity that is either intangible or possessed of a very complex legal status. No existing law is clear about who holds such rights." 136 In this connection, a study done in the Pacific Rim countries indicates the following: ${ }^{137}$

Evidently the information component of genetic resources is the most valuable for bioprospectors.
However, no State has created a property rights system for this component. Therefore, Countries still rely on the physical component (e.g., organisms or their parts) to define the legal status of their genetic (and biochemical) resources.

In legal doctrine, a general classification of property as tangible, corporal, or intangible has been established. In the case of genetic resources, there may be a basis for distinction between the rights over the physical entity (physical property) and over the genetic information that the resources contain (intangible property). This

\footnotetext{
133 E.g., clearly regulate that bulk use of biological resources as ingredients in commercial products, herbal medicine, cosmetics, does not constitute access.

134 Cfr Glowka, 1998.

135 See Vogel, 1998.

136 Young, 2004, “An Implementation perspective...".

137 Carrizosa et al.
} 
last represents the real value of the resources, and where the judicial problems are particularly complex. ${ }^{138}$

The material and geographic aspects of genetic resources pose an extraordinary challenge because most living organisms reproduce and disperse naturally, irrespective of restrictive measures that policy makers wish to lay on them, carrying out into the world

\subsubsection{Property rights issues generally}

The issue of property rights is very complex, ${ }^{139}$ raising questions and concerns relating to sovereignty, heritage and property - three very different legal issues. Of these, the latter is not addressed by the Convention, leaving each State free to decide if genetic resources are private or public property and under what circumstances. This issue is not fully clear in comparative law, because, in general, prior to 1992 (and indeed up to the present) most national property systems and constitutions, with few exceptions, have not made reference to genetic resources.

\subsubsection{National law on the property interest in genetic resources}

There are, however, a few legal systems that do make a property-based distinction between biological resources and genetic resources. Generally, the State is considered the owner of genetic resources (and mobile the very qualities (genetic resources) that bioprospectors and users are seeking rights in, and source countries are seeking to control. This biological fact is compounded by the elusive nature of information as valued added: information, even when derived from biological resources, is intangible and therefore requires a special property regime.

biological resources), although the owner of the land must be contacted to gain permission to collect the biological resource containing the genetic resource or authorizes the entrance to the land where the resource is located or to the ex-situ collection which is considered the provider of the biological resource.

The issue of property rights over genetic resources is very important in the ABS legislative context for two reasons:

- It is critical for determining the right to participate in the decision-making processes of $A B S$ and be beneficiary of the potential benefits.

- It can be a source of limitations on private action, derived from the concept of genetic resources as public property.

138 Cfr Febres, 2002.

139 Concerning legal certainty, one of the most pertinent aspects to be studied regards the definition of physical property rights to genetic resources, as recognized by the COP 8 when it requested the Parties to provide information to the Secretariat. CBD COP VII, Decision VIII/4, $\mathrm{UNEP} / \mathrm{CBD} / \mathrm{COP} / 8 / 4$, part A. 
Table 2. Examples of different approaches to property rights on genetic resources in selected countries

\begin{tabular}{l|l} 
Country & Approach to property issues
\end{tabular}

Costa Rica, Nicaragua, Andean Community
The legislation establishes specifically the property rights over genetic resources and establishes a system of public domain.

Wild flora or fauna and natural resources in general are considered the property of the state, but not expressly mentioned. In some countries (USA, Nigeria), the genetic resources located, for example, in national parks are considered property of the state, but this fact is not mentioned expressly in the national laws, and not clear in other situations.

There are no specific regulations over property, but the state has the right to control or authorize the use of genetic resources.

Countries in which there are private property rights over genetic resources, but the state preserves a limited power to control (species in danger of extinction, etc.).

Relationship between state property and the common and indigenous rights is not clear.

\subsubsection{Applying conventional property law to genetic resources}

Tenure and ownership systems are not uniform across the countries nor are they clearly defined in any given country. Based on their own legislative heritage and legal cultural traditions, countries exhibit a mixture of ownership arrangements that range from traditional common tenure to state-enforced private rights to land and resources, including the broad diversity of biological material. ${ }^{141}$ Analysts have identified a few general categories among countries' legal systems, which are quite useful for purposes of discussion, but should not be considered to imply national similarity among countries within each category:

- Common Law Systems: In these countries, natural resources are frequently viewed as primarily "private property," however the legal fact is that the state retains powers to regulate them or to control, limit or even prevent their use.

- Roman-Napoleonic Systems: Systems founded on Roman Law include concepts of private property, but usually recognize natural resources as property of the State, or patrimony. A number of these countries have directly regulated genetic resources, providing that they are public property and/or in the domain of the State. ${ }^{142}$

- Other legal systems: There are basically three other categories of legal system - religious law, customary law, and central-plan-based law. Under these

\footnotetext{
${ }^{140}$ See Note 36 above, the US information is based on a permit system that was adopted for collection of specimens in national parks. It is not clear that this limited statement embodies the USA's law on genetic resources, since it (i) was made by one agency (ii) applies to less than $4 \%$ of the country's land area and (iii) applies to only one property owner out of the millions of property owners.

141 Columbia University, 1999.

142 Cfr Pérez, 1997.
} 
three, private property concepts may not exist, or may involve a much stronger level of primary oversight and control.

While most countries believe themselves within one of these categories, the practical reality is that a mixed approach applies in virtually all countries.

\subsubsection{Public domain}

Many countries have specifically determined that a special status of ownership-related rights applies in the case of genetic resources. For example, in the case of Colombia, the Council of State determined in Decision C-977 that "the legal regime applicable to genetic resources of real or potential utility, is that which is established in general terms in the Political Constitution for public domain goods....", that is, genetic resources are inalienable, unattachable and imprescriptible, and the Nation's heritage. This is generally how the concept of the public domain is characterized. Most countries' legislations define other resources possessing such attributes, such as water, minerals, wildlife, hydrocarbons, and the maritime land zone, in the same way.

\subsubsection{The example of Costa Rica}

In a number of countries, national legislation declares (or treats) genetic and biochemical resources as goods of public domain. One example relevant to this discussion is the legal regime in the Costa Rican system.

The public domain goods (goods that may be considered as belonging to a public body) are linked to public utility purposes, therefore, they are subject to a special administrative regime of protection and use of goods. Thus, characteristics of the goods of public domain are three: (1) ownership to a public body; (2) public utility purposes; and (3) under a special administrative regime of protection and use of goods.

The public domain, in this case, reflects a grade of public purposes, which is so high that it excludes all other property relationships. Thus, when property or resources are in public domain a special administrative title "of intervention" (i.e., a title exercised only in order to prevent inappropriate use) applies, which must be considered as a res extra comercium. Property in the public domain is thus more than a special type of property - the State exercises a special protection based on powers (and competences) regulated by Public Law, whose mandatory focus is to guarantee the compliance and coherence with the purposes to which these goods are linked.

In this system the importance of linking public domain goods for public utility purposes is clear. This is reflected in the constitutional jurisprudence, which has specifically upheld the view that goods in the public domain are extra comercium goods, whose destination must be the public use and satisfy public interest. For this reason they are subjected to a special legal regime.

The classic paradigm for use of public domain goods is, without doubt, the assignment to a public use or utility. These are out of the trade, non-susceptible to private appropriation - the State's administrative title of intervention guarantees that the only uses of these resources will be for public purposes satisfying State scrutiny. There is, therefore, a special legal system of Administrative Law dedicated to identifying and applying standards for the legal characteristics of goods in the public domain such as non-assignability, non-applicability, immunity from seizure, etc. But, also, the application of this regime necessitates the use by the State of different means of guardianship and protection for public domain properties, as compared with the means available to a private owner when protecting private property. This has been pointed out by the Constitutional Chamber which noted that:

IV. (...) Characteristics of these goods, are non-assignability, non-applicability, immunity from seizure; they cannot be mortgaged neither can they be susceptible of obligation in Civil Law and other administrative action except for injunctions for recovering the domain. Since they are out of the trade, these goods cannot besubject to possession. Although a utilization right can be acquired, no property right may. ${ }^{143}$

143 Constitutional Chamber of the Supreme Court of Justice. Award No 2306-91 of November 6, 1991. 
However, the prohibition to alienate the public dominion of the State does not generally exclude its disposal by means of administrative law - through concession, lease, grant, authorization, and in general public or administrative contract. Once the resources have been delivered by an appropriate legal mechanism (concession or permit) the holder has a right of property, except where the authorizing title stipulates otherwise. For example, fauna is public domain, but the hunting and fishing permits allow the complete appropriation of individual specimens, including their destruction. Also, the concessions of water, minerals and hydrocarbons allow particular minerals, water and hydrocarbons to be sold, given, granted or destroyed.

The characteristics of non-assignability, non-applicability, and immunity from seizure, which apply to resources of public domain, cease to apply once resources such as petroleum, gold or water have been appropriated by individual users.

\subsubsection{Open questions}

The consequences of this legal nature (public domain) for the content (rights and obligations) of ABS agreements still need to be studied. As noted above, this question of ownership of property is considered to be almost exclusively a matter of national law. Even in cases in which property of foreign citizens has been "nationalized," international law has not generally contained the authority for other states or international bodies to intervene. Consequently, addressing the rights granted to those who are involved in prospecting of the materials is a crucial topic.

Given that users are acquiring these rights (or concluding that they have these rights) every day, the matter has a high degree of urgency. According to some, for example, the state concedes, upon permitting any type of physical access to biological resources, custody of the material for purposes of research and development. ${ }^{144}$

What rights would the receiver-user then have?
And especially, what rights to transform it and protect it - for example, by means of rights of intellectual property - are taken away (i.e., the source country no longer has the right to dispense it)? Can it protect the improved material or an invention stemming from it if they contemplate the genetic dedicated component? Can one isolate and characterize a gene and its function and the invention be patented with corresponding future uses? From the point of view of the user, restrictions in the use of the genetic resource via intellectual property can determine whether a company decides to bioprospect or not.

What implications must be considered for the genetic resources of public domain, with regard to the work of preparing and delivering samples, extracts and fractions, etc.? Would it be possible (would a company accept) for a country to require that extracts and fractions are delivered to the user "in custody" (in other words, extracted and prepared by the source country, so that the entire genetic resource remains the property of the source country)? If so, is there any limit on future acquisition of these property rights (physical) by third parties, since they are only granted in custody? Would this approach alleviate the property law concern? And if so, would it simply transfer the problem to another branch of law (for example to criminal law, which would have to find a basis for action against those who take and use genetic resources without any permission)? The restrictions in the use of the materials must be specified. What is the degree of restriction on these extracts or fractions that may practically be imposed?

For example, Casas (speaking of the law of Colombia) indicates that the applicant for access should consider the utilization of the genetic resources as part of the rights that he is applying for, but that this right of utilization does not transfer a property interest in the resources, because they have an unalienable character. Eventually rights on the intellectual intangible property resulting from the investigation and development of the genetic resources are usually claimed by means of IPRs. ${ }^{145}$

\footnotetext{
144 Casas (2004) suggests that the system should recognize custody rights to the person in physical possession of the samples, which entitles them to provide PIC and receive benefits.

145 Cfr Casas, 2004.
} 


\subsubsection{Avoiding the property-definition problem}

One way to address the difficult questions raised by the creation of this new kind of property right is to avoid addressing it. ABS issues are addressed contractually by many countries that have not described the right granted, but focused on the performances required. As has been indicated: ${ }^{146}$

One of the key requirements of user certainty is that user and the granting or source country share a mutual understanding of the exact nature of the rights granted by the $A B S$ agreement. In this connection it is interesting to note that none of the [national legislative] measures examined describes or considers $A B S$ rights from the perspective of the user, by stating in effect that the grant of $A B S$ rights entitles the user to the following.... In general terms, the nature of the positive rights granted by the $A B S$ decision is expressed in terms of limits. Apart from these, the nature of the grant is somewhat determinable by considering the activities that are strictly forbidden unless an ABS right is obtained.

Thus, for example, one possible solution would be to limit the permit-holder's or contract-holder's claim to the sample as delivered, or, in legislation simply to assure the free availability of the genetic material. Although it does not prevent any user from undertaking modification or from applying for IPRs on the modification of that resource, it at least provides a basis for holding that only new inventions and novel organisms (obviously including the genetic component of the organism) can legally be claimed in this way.

Table 3. Laws or regulations restricting uses of the genetic resources ${ }^{147}$

\begin{tabular}{l|l} 
Type of control/ country/law & Example \\
\hline $\begin{array}{l}\text { Restriction on patent or other } \\
\text { IPR - India/Biodiversity Law }\end{array}$ & $\begin{array}{l}\text { No person shall apply for any form of IPR by whatever name } \\
\text { called in or outside India for any invention based on research or } \\
\text { information on a biological resource obtained from India with- } \\
\text { out the previous approval of the National Biodiversity Authority. }\end{array}$ \\
\hline $\begin{array}{l}\text { Restriction on transfer of research } \\
\text { results - India/Biodiversity Law }\end{array}$ & $\begin{array}{l}\text { A separate approval from the National Biodiversity Authority will } \\
\text { be required for any transfer of the results of any research relating } \\
\text { to biological resources occurring in or obtained from India. }\end{array}$ \\
\hline $\begin{array}{l}\text { Restriction on patent or other } \\
\text { [ABS - African Union/Model Law on }\end{array}$ & $\begin{array}{l}\text { No person may apply for Intellectual Property Rights on life } \\
\text { forms. }\end{array}$ \\
\hline $\begin{array}{l}\text { Restriction on research-related } \\
\text { cultivation or multiplication - } \\
\text { Malaysia/Access Agreement }\end{array}$ & $\begin{array}{l}\text { The Access Agreement prohibits the researcher to germinate, } \\
\text { propagate, breed or cultivate any biological resources without } \\
\text { prior approval of the Sarawak Council. }\end{array}$ \\
\hline $\begin{array}{l}\text { Restriction on patent or other IPR - } \\
\text { Malaysia/Access Agreement }\end{array}$ & $\begin{array}{l}\text { The researcher shall not file any applications for patents, either } \\
\text { inside or outside Sarawak, without the prior concurrence in writ- } \\
\text { ing of the Council. }\end{array}$ \\
\hline $\begin{array}{l}\text { Restriction on transfer of resources - } \\
\text { Bhutan/Biodiversity Act }\end{array}$ & $\begin{array}{l}\text { Applicant shall not transfer the resources to any Third Party } \\
\text { without the authorization of the Competent Authority. }\end{array}$ \\
\hline
\end{tabular}

\footnotetext{
146 IUCN-Canada, 2005.

${ }^{147}$ It has been said that "a critical element of user certainty in the context of the nature of the rights granted relates to the question of whether additional permits or permissions will be necessary at later stages in the process of accessing and utilizing genetic resources," IUCN-Canada, 2005.
} 
In this sense, any attempt to control post-access activities relating to the genetic resources can be seen as a way of applying "property-like" rights to those resources, with-

\subsubsection{Recommendations}

It appears that all countries have the need to address property rights issues in some way. ${ }^{148}$ While no external source can provide a model or complete guide to a country in this very individualized issue, a few clear recommendations arise:

- First, the countries should recognize the difficulties inherent in any attempt to establish property rights over genetic information, but should also be aware of the problems that arise from trying to apply traditional property regimes in this context. Obstacles such as the difficulty in identifying the property, and in exercising physical control over it, as well as its transnational character, have proven insurmountable, up to now. The exercise of traditional attributes of property rights is not always effectively applicable in the case of genetic resources. out (or in support of) creating new property rights. Table 3 provides a few examples of this type of provisions.

- Second, in spite of the difficulty, it seems clear that property rights to genetic material should be specified in each country in conformity with the legal system established by its Constitution. The clarification of the relation between property rights over biological resources and genetic resources would contribute to greater legal certainty in all transactions relating to both kinds of resources.

- Finally, the rights granted to the applicant and the reach of the concept of public domain, should be clarified to avoid uncertainty regarding prohibitions and restrictions on future uses to be carried out by users.

\subsection{Differentiating between basic and commercial research}

One of the harshest criticisms of the legal systems of ABS comes from the sectors of basic research (universities and other research centers). From the earliest days of the $\mathrm{CBD}$, these have considered that the regulations of $\mathrm{ABS}$ tend to impose requisites difficult to fulfill; they do not distinguish clearly between research done with commercial intentions and that without commercial purposes. They have complained that the Convention does not adequately recognize the intrinsic advantages of basic research and its contribution to the conservation and the sustainable use of biodiversity. ${ }^{149}$

A study undertaken by Columbia University, ${ }^{150}$ concludes that:
... hindrance to access to genetic resources is the use of same standards in commercial and non-commercial research.... access regulations have become increasingly restrictive and commercially-oriented. Hence a cumbersome, unnecessarily strict application process is imposed on what is considered basic, not for profit research. This basic scientific investigation is required to understand natural processes and almost invariably precedes commercial research ....

\footnotetext{
148 This book does not consider the impact of variations among national decisions on this point. (See, Book 6 of this Series, Young et al., Covering Access.)

149 See Grajal, 1999.

150 Columbia University, op. cit.
} 
Several laws have sought to address these concerns, by establishing different regulations for research-related access, than for other types of use. ${ }^{151}$ For purposes of legal certainty, however, it is important to note several key concerns for countries seeking to make this distinction. First, the flexibility that some countries have established for basic research requires the designation of clear limits between the cases of access for commercial gain, and access for basic non-commercial purposes. Second, however, it is necessary to guarantee that the rights of the provider will be protected in the case that a commercially valuable result is obtained from an activity initially considered as basic research. Additionally, the user should have certainty that eventually it will be possible to seek commercial results. ${ }^{152}$
There is significant agreement in many countries and institutions that the process of access for basic research should be simpler, but subject to later negotiations in the case of the commercialization of the results of the research based on the genetic resources. ${ }^{153}$ This concept of subsequent negotiation is needed to balance past experience, where basic research has resulted in products on the market, without any $\mathrm{ABS}$ compliance or benefit sharing. This is especially so in the case of biotechnology research that requires a strong component of basic science. Both researchers and source countries share an important consensus with respect to the difficulties in establishing a clear frontier in this area. ${ }^{154}$

151 Correa (2000) on a broader comment on ABS laws mentions: "The Convention applies to all types of genetic resources, including food and agriculture. No difference is made with respect to the treatment to be given to different sectors of biodiversity. The broad scope and the generality of the regulation on genetic resources is problematic. The conditions and use of animal, plant, microbial, aquatic or marine resources vary considerably. As a result, the practices of exchange and appropriation of such resources also differ, depending on the distribution and availability of the resources, the difficulty or ease to reproduce them, and the existence or not of markets for their exchange, among other factors."

152 Rosenthal (unpublished) indicates: "It may also be useful to consider a two phase approach to preserve elements of both the freedom to academic research and the flexibility to pursue industrial development of potential discoveries, while offering security to providers."

153 Fernández (2005) comments: "A basic implication of the valuation problem is that any effort to fully contract the terms and conditions of benefit sharing is likely to be faced with a wide variety of difficulties, from non-commercial projects that will unexpected turn commercial at an unknown point in the future to commercial ventures in which it will be extremely difficult to assess the value of the collection of species to be prospected. Therefore, there is a need for better information on the actual potential of genetic resources. If contracting is forced to take place fully at the outset, the value negotiated will be highly speculative and could end up being too low or the contract will not be signed."

154 Cf. Carrizosa et al., (eds) 2004. Dross and Wolff (2005) indicate: "A more general question is whether scientific and commercial research should be differentiated. While this is desirable to foster scientific research, the differentiation is not always obvious. Often scientific research later leads to commercialisation." 


\subsubsection{Legislative approaches}

This flexibility of regulation for non-commercial activities has been considered in the legislation in draft laws of various countries, ${ }^{155}$ as presented in the following chart. ${ }^{156}$

\section{Table 4. Select countries which differentiate commercial and basic ABS research}

\begin{tabular}{|c|c|}
\hline Country $^{157}$ & Provision \\
\hline Philippines & $\begin{array}{l}\text { In accordance to the Wildlife Law, bioprospecting is limited to research with commercial purposes. Research with } \\
\text { non-commercial purposes does not require the signature of a Commercial Research Agreement (CRADA). The } \\
\text { authorization of scientific research is done by means of a gratuitous (no fee) permit. "Scientific research" is not defined } \\
\text { but "bioprospecting" is defined as research, collection and utilization of biological and genetic resources for purpose } \\
\text { of applying knowledge derived solely for commercial purposes. }\end{array}$ \\
\hline Costa Rica & $\begin{array}{l}\text { Access for basic research is defined as "Activities directed at investigation, examination, classification or increase of } \\
\text { existing knowledge over biological resources or their genetic or biochemical characteristics without immediate } \\
\text { interest in commercializing its results." Some (few) requisites do not apply for basic research (e.g., unlike in other } \\
\text { ABS situations, in the case of basic research, it is not mandatory to share up to } 10 \% \text { of the research budget with } \\
\text { the providers of the genetic resources). }\end{array}$ \\
\hline Brazil & $\begin{array}{l}\text { The Council of Genetic Patrimony dispenses with some requirements (no contract for utilization of genetic } \\
\text { resources is signed) and undergoes fast tracking, in which special authorizations are issued to domestic academic } \\
\text { institutions that encompass a group of projects. Scientific Research is defined as using genetic resources with no eco- } \\
\text { nomic purpose. Access for non-commercial purposes is considered to "contribute to the advance of knowledge of } \\
\text { biodiversity of the country and not present previously identified potential for economic use as with the activities of } \\
\text { bioprospecting or technological development." }\end{array}$ \\
\hline Australia & $\begin{array}{l}\text { The relevant law covers both commercial and non-commercial access. However, a benefit-sharing } \\
\text { agreement is required for any applicant for a permit for access to biological resources for commercial purposes } \\
\text { or potential commercial purposes. }\end{array}$ \\
\hline $\begin{array}{l}\text { Malaysia } \\
\text { (Sarawak) }\end{array}$ & $\begin{array}{l}\text { According to the amended regulations of the Sarawak Access, Collection and Research, the regulations exclude a } \\
\text { study, experiment, test or examination carried out within Sarawak, of biological resources in connection with any } \\
\text { educational course or syllabus conducted by an approved institution which does not or is not intended to lead to } \\
\text { development and commercialization of the aforesaid properties, values and qualities. }\end{array}$ \\
\hline
\end{tabular}

Note: Other countries or regions have intentionally decided not to make any distinction between non-commercial and commercial research (e.g., Andean Countries, Venezuela, India).

A broader analysis of "research exceptions" provisions suggests a few common characteristics. For example, they define in a general manner, usually negatively (e.g., activities without commercial intent), the meaning they attach to basic research, and so far, they do not include criteria that would permit the user to know what actions, conditions or situations cause the (non-commercial) character of the investigation to change.

\footnotetext{
155 See Chile, ABS Draft Law which would be applicable only to commercial research.

156 See Carrizosa et al., 2004; Dross and Wolff, "New Elements," op. cit; and Columbia University, 1999.

157 Names and citations of relevant laws are available in Cabrera Medaglia, 2004, A Comparative Analysis... .
} 
To facilitate access to genetic resources for basic research, it has been suggested ${ }^{158}$ that countries establish a "two track" application process, wherein any access applicant would be able to choose between either one of the two tracks. Under this system, the user/applicant would define his own intentions, avoiding the need to infer them from the project description or other criteria. Some criteria that can be utilized to differentiate between both types of research could include: ${ }^{159}$

- Whether an initial direct and immediate purpose exists to take to the market a resultant product of the research; ${ }^{160}$

\subsubsection{Recommendations}

A few recommendations can be drawn from this analysis, to aid countries that have decided to include a research/non-commercial use distinction:

- Countries should establish a list of criteria that, prima facie, permits the differentiation between basic and commercial research, recognizing that it is not always easy to establish the boundary between the two.

- Criteria should be established to provide a basis for determining when "basic research" turns into
- Whether research results will be transferred to third parties for a price;

- Whether the researcher or related entity applies for intellectual property rights (demonstrating an intention to commercialize the results).

In any case, the design of the legal framework will be functional if accompanied by mechanisms that allow the source country:

a) to control the use (in the country where the research and development will take place);

b) to verify the later commercial use; and

c) to claim benefits, including the possibility of gaining access to justice in the user country.

commercial research or utilization.

- Flexibility in the treatment of access that is sought for scientific ends has to be seen also in the context of an integral regulatory system of $\mathrm{ABS}$ where the user countries establish measures for the later control of the commercial use of the genetic resources which allows the country of origin to know if commercial use exists and to proceed to exercise the rights in the foreign jurisdiction, in the case that the commercialization does not comply with the conditions of access.

\footnotetext{
158 Columbia University, 1999.

159 The principles for accessing genetic resources, the treatment of intellectual property and the sharing of benefits associated with International Cooperative Biodiversity Groups-sponsored research indicate: "Where national governments do not have clear regulations to guide informed consent procedures, activities should follow a two phase approach to distinguish basic and commercial research. Research intended primarily for publication including collecting and analyzing biodiversity, as well as bioassay and chemistry work, may be considered basic research. If at any time, researchers intend to file a patent application based on this work or send a sample for testing to an industrial partner, the research enters the commercial realm and must follow all the requisites," available in www.fic.nih.gov

160 The Principles on Access to Genetic Resources of the Botanical Gardens, defines commercialization as "applying for, obtaining or transferring intellectual property rights or other tangible or intangible rights by the sale or licence or in any other manner commencement of product development, conducting market research, and seeking pre-market approval and/or the sale of any resulting product."
} 


\subsection{Prior informed consent (PIC): making it operative and certain}

From the viewpoint of legal certainty, it is indispensable to address the issue of Prior Informed Consent (PIC). Despite its very simple description, PIC has been identified as one of the most complex and difficult aspects for the user seeking to obtain access to genetic resources. In fact, some of the strongest criticisms of the ABS systems have related to the difficulties of obtaining the PIC in practice. ${ }^{161}$ In its practical analysis of national implementation, the study on the Pacific Rim Countries identified the PIC procedures as one of the major shortcomings. ${ }^{162}$

As noted above, despite all of the attention, PIC is not a new concept. Not only does the concept of

\subsubsection{National PIC measures}

Administrative procedures relating to PIC in the ABS context vary from country to country. Based on analysis of these, several principal difficulties can be cited: ${ }^{164}$

- Lack of clarity regarding legislation and applicable procedures. When the legislation exists, it is not clear what is the participation of the different departments and who has the right to finally authorize the access request.

- Insufficient information about who should solicit the PIC and regarding when the access procedure has included all interested parties. ${ }^{165}$

- Lack of institutional and technical capacity for resolving the request for PIC at the legal, administrative and technical levels. This lack of capacity on occasion translates into lack of confidence. "informed consent" form the basis of all contract law, it is also specifically included in several international instruments. In contrast to other convention-based applications of PIC (medical treatment, transboundary movements of chemicals or toxic wastes), the prior informed consent within the context of the CBD is also intended to act as a guarantee of equitable benefit sharing and therefore plays a contractual as well as regulatory role. ${ }^{163}$ PIC difficulties, like most other issues in this book, find their basis in the basic functionality problems of the ABS concept, rather than in the national legislation itself.

- Conflicts between stakeholders' interests and expectations. Effective implementation of PIC can be hampered by different and, at times, incompatible interests and expectations amongst various stakeholders.

A recent study ${ }^{166}$ indicates that "questions frequently exist about how to convey the information needed to make informed decisions and about how, when and from whom consent should be obtained. The answers to these critical questions often differ according to the precise ABS issue and community involved."167 Problems relating to PIC have been identified across a wide range of parties and stakeholders whose concerns can probably best be satisfied by cooperation. The next section describes work by a user-oriented association, suggesting some issues which can be addressed, at least in part, by national legislation of the source country.

161 See Lange, 2005; and Rosenthal, unpublished.

162 Carrizosa et al., 2004.

163 Cf. Hirakuri and Toben, 2005.

164 See cases studies on PIC in Perault, 2006.

165 For example, Decision 16/V of the V COP indicated that access to traditional knowledge should be subject to prior informed consent or prior approval from the holders of such knowledge.

166 See Perault, 2006.

167 In this connection, the IUCN-Canada study concludes that to “... enhance user certainty appears to be through clarity, including clarification of key elements of the application process such as: (i) the rights and duties of National Competent Authorities, (ii) the relationship between ABS applications and other approval processes, (iii) milestones and the timing of the various steps in the process, (iv) the extent to which the CND may request additional information and performances, (v) the bases on which the decision will be made, (vi) rights of appeal, and (vii) the objective factor that will determine whether an applicant is exempt from the need to obtain ABS permits. Perhaps the most important way to maximize certainty is to clarify the legal status of the rights granted whether it is a property right or vested interest. A user can determine what it can legitimately expect, whether it is worth his investment and what procedures and protections of law apply." IUCN-Canada, 2005. 


\subsubsection{Insight into PIC from user countries}

Recently, the government of Japan, in the course of developing guidelines for its users of genetic resources, ${ }^{168}$ identified several practical issues of concern, which are usually not easily answered under the PIC laws and practices of source countries:

- Whether it is necessary to obtain PIC once again for those genetic resources that had been obtained before the CBD entered into force (29 December 1993);

- What rights, if any, the user has when a number of months have passed since a PIC application was made, but the authorities have not informed whether or not the permission has been granted;

- How to verify that PIC has been obtained in a case where the genetic resources are provided indirectly via a commercial intermediary;

- Whether it is necessary to obtain PIC when acquiring genetic resources from culture collections (exsitu collections of microbial resources, for example);

- What rules apply in the case of acquisition for nongenetic-resource purposes (for example: plants obtained for ornamental purposes), which are later found to possess some molecule of commercial interest (i.e., is it mandatory to obtain PIC from the country where the species have been taken?) ${ }^{169}$

Some of these points may not be answerable or resolvable through source-country legislation at all, but many of them may be.

\subsubsection{Bonn Guidelines: recommendations for PIC implementation}

Likewise, the Bonn Guidelines recognize PIC as an important element through which the $\mathrm{ABS}$ process can be catalyzed and legitimized. ${ }^{170}$ As noted by IUCN, it provides "a first step in promoting effectiveness and efficiency in the application of laws and regulations governing access and use of genetic resources in identifying and assigning clear functions, competences and roles to the National Competent Authority on access to genetic resources and benefit sharing;"171 however, choosing a focal point is a relatively simple action (unless it has political implications) and offers no expectation of a solution to the problems of national implementation or user certainty. In any case, PIC procedures must be clearly outlined in a way that reduces time and transaction costs for bioprospectors.

\subsection{Conclusions: pathways to effective legislation in source countries}

Obviously, the problem of source-country legislation is far from solved, even though source countries have been attempting to develop effective ABS regimes since 1992.

The case of the Philippines is quite illustrative of the issues being addressed in this paper. The Philippines has been a pioneer in ABS. In 1995, it was the first country after the entry into force of the CBD to regulate $\mathrm{ABS}$ in great detail with the development and implementation of Executive Order $247 .{ }^{172}$ At the

\footnotetext{
${ }^{168}$ Ministry of Trade and Industry (METI), 2005. The Japanese Guidelines present principles set forth in the CBD for PIC; explanatory notes on the meaning of them; "points to note" including information on entities issuing PIC, procedures for obtaining PIC; etc.. Other Guideline documents have been put forward. See also Bioprospecting Guidelines for BIO members, developed by the Biotechnology Industry Association of the USA (see www.bio.org) and the approach found in the Access and Benefit Sharing. Good Practice for Academic Research on Genetic Resources, Swiss Academy of Sciences, Switzerland, 2006.

169 Similarly, Perault (2006) mentions five enabling conditions for PIC at the international, national, local and project levels, including: understanding and recognition of property rights, including community based property rights; community participation in decision making; building capacities for local communities to engage efficiently in PIC processes, including legal and technical capacities; effective mechanisms for resolving disputes and promoting compliance, etc.

170 See Bonn Guidelines, para. 24-40.

${ }^{171}$ Cfr IUCN, position paper on Access to Genetic Resources and Benefit Sharing, submitted at the Seventh Meeting of the Conference of the Parties to the Convention on Biological Diversity, Curitiba, Brazil, 20-31March 2006 (contact, Rojas, M.).

172 Executive Order 247 on Access to Genetic Resources is entitled "Prescribing Guidelines and Establishing a Regulatory Framework for the Prospecting of Biological and Genetic Resources, their By-products and Derivatives, for Scientific and Commercial Purposes and for Other Purposes.”
} 
same time, it has been one of the few countries to carry out a full review and modification of its legal framework. It adopted new legislation (the Wildlife Resources Conservation and Protection Act) in 2001, which contains a few general provisions on $A B S$ and has developed new implementing guidelines on bioprospecting. ${ }^{173}$ This means that it has taken more than 10 years $^{174}$ to revise a regulation that was widely considered as complex, bureaucratic and restrictive. This is not an isolated case; in the Mexican context (where the author has direct experience), consensus building in the Congress is very difficult to achieve. This means that once a problematic law is passed, it will be very difficult to change, especially if that change implies a full review or a whole change of direction.

173 Benavidez, 2004, “The Challenges...”.

174 This figure should not be dramatically surprising. In a related documented case of capacity development in a developing country, it took more than 10 years for Mexico to fully understand its obligations and to play a full role in the workings of CITES. See Arroyo-Quiroz, 2005. 


\section{Enforcement, Tracking, and the Need for Incentives and Other Approaches}

This chapter seeks to address the legal problems for source countries, regarding the enforcement of their laws on ABS. These problems have been noted across a wide range of commentators, with varying suggestions, ranging from increasing penalties and controls on specimen collection to mandating greater involvement by user countries, to developing incentives which are sufficient to promote compliance without major enforcement actions. This chapter also raises another possible avenue for improving enforcement altering the legal basis of the user's action through "reciprocity" provisions. This idea links to the discussion of incentives, under which more favorable (streamlined or less expensive) procedures would be available to users who make such a commitment. As noted below, this idea may have some limited implications from international trade.

\subsection{Preliminary considerations - inefficacy of mandatory measures}

Before analyzing the issue of incentives to promote compliance with the $\mathrm{ABS}$ procedures, some preliminary considerations are necessary. It has been noted that the current $A B S$ situation often penalizes those who want to comply with ABS laws. ${ }^{175} \mathrm{ABS}$ initiatives that have become known to the public have come under the attack of different groups that have been opposed to them, under the concept of biopiracy, even where the applicant took every available measure to comply with national $\mathrm{ABS}$ requirements. ${ }^{176}$
Detection of non-compliance is also difficult, but for different reasons. Monitoring and enforcement, for example, are problematic because the material in question can often be difficult to identify, consisting of things such as seeds, water samples or micro-organisms. Authorities have no means of assessing what the samples might contain and what uses they might be put to. Even when identified their provenance cannot often be proven. Compounding this problem is the fact that the collection of material for one purpose might be quite legitimate while collection of the same material for a different purpose might be an offence.

\subsection{Controlling and monitoring the utilization of genetic resources}

Even the most basic elements of the national access legislation frameworks present difficult challenges. Access legislation embodies many kinds of action and awareness, most especially awareness of what is done with resources once they have been accessed (obtained with permission to use). According to Carrizosa et al., the monitoring of bioprospecting agreements is one of the most difficult, expensive and resource consuming tasks currently undertaken in ABS. Currently, none of the countries studied has created an effective and functional monitoring system, whether applicable at national level or as applied to users outside of the source country's borders, given the jurisdictional and other problems with any attempt to follow the uses of genetic resources, or to exchange information about them. ${ }^{177}$

The problem with monitoring and compliance is considered to exist on two levels: ${ }^{178}$ direct monitoring (the technical problems relating to all monitoring, inspection and verification at national levels) and transboundary monitoring after the genetic resources

\footnotetext{
175 Young, 2006.

176 Id. and see Rosenthal, unpublished.

177 Carrizosa et al., 2004.

178 Cf. Ogolla, 2005.
} 
have left the country (where users' facilities are located in other countries). This section will begin by addressing direct monitoring and oversight provisions, and then consider what provisions and processes source countries may use to maximize oversight,

\subsubsection{Direct national monitoring and oversight}

Even in areas where territorial jurisdiction is clear, experience has generally shown that governments have difficulty in monitoring bioprospecting activities, due to the limited resources available. Under article 15, source country monitoring, oversight and enforcement are all seen to arise out of two sources:

(i) legal compliance with the procedures for obtaining a right of access (discussed above under the heading "Prior Informed Consent"), and

(ii) the terms of the access agreement or permit (Mutually Agreed Terms) and/or national legislation regarding the activities, standards and limitations relevant to obtaining and using genetic resources of the source country. awareness and legal authority when the genetic resources are outside of their borders. The next section (4.3) will discuss particular approaches and case examples in greater detail.

In addition, of course, all countries have broader rights to adopt legislation, and compliance with national legislation itself (both ABS and other legislation) is really the primary rule of ABS oversight. This section, however, focuses only on ABS laws and their implementation.

In most national access laws the primary oversight measures are based on periodic reporting, to evaluate compliance with access conditions. This is the main mechanism used to verify compliance, but its effectiveness is limited. Other schemes such as the use of identification codes for samples, access to research lab notes, etc., have been used, for example, by the National Biodiversity Institute in Costa Rica, as discussed below. ${ }^{179}$

\subsubsection{Facilitating/mandating transboundary monitoring and oversight}

The main enforcement problems with observance of ABS regulations are posed by the possibility of noncompliance with the provider countries' legislative provisions or with provisions in access contracts. In large measure, these issues arise outside of the source country's territorial jurisdiction.

Obviously, in a transboundary system ${ }^{180}$ the most significant problems arise where both countries are involved on the administrative and/or legal levels. Numerous authors have noted that the near total lack of measures by user countries may have had the greatest influence on the decision to commence the negotiations for an International Regime. In this regard, it has been said that:

\begin{abstract}
In effect, any international regime will require a cooperative effort between the providers and users of genetic resources and traditional knowledge and will require that both take actions to mutually support the common objectives of the CBD relating to fair and equitable benefit-sharing. ${ }^{181}$
\end{abstract}

The ability of the provider countries to enforce their legal requirements will largely depend on legal mechanisms in foreign jurisdictions. The source country, however, is not released from the need to adopt both primary measures and enforcement-based mechanisms such as reporting and rights to annul or terminate the contract. Thus, although there is a strong impetus to compel developed countries to adopt "user measures," there is also a need for source countries'

\footnotetext{
179 Cfr Cabrera Medaglia, 2004, A Comparative Analysis.... Cfr Cabrera Medaglia, 2004, "Access and Benefit Sharing in Costa Rica...".

180 As noted above, the CBD concept of ABS is based on the situation of a user from one country who utilizes genetic resources from another country.

181 Barber et al., 2003.
} 
access legislation to be designed to provide that "mutual support."

There are numerous provisions that appear to be necessary at the source-country level, to strengthen the country's position with regard to enforcement outside its territorial boundaries. In general, these provisions include clear statements about what may or may not be done with resources that have originated from the country, regardless of where those activities take place. In addition, the country should adopt legislation stating that the terms of any access arrangement (or of utilization of genetic resources without ABS compliance) shall require regular reporting and milestones (as noted in chapter 3, above). Most important, however, the law must authorize the national government to take whatever measures possible to oversee, inspect and confirm that utilization of genetic resources complies with national ABS law. This should include giving the government the power to call on officials from other countries, and other individuals, to take these actions, if necessary.

In the majority of $\mathrm{ABS}$ contracts, periodic reports form the primary tool to secure the correct use of the resources provided. Casas suggests other mechanisms that could be developed including: ${ }^{182}$

\subsubsection{Contractual mechanisms}

Up to now, discussion of oversight and enforcement has generally focused on the contents of ABS contracts. They assume that if the contracts exist and are agreed by user and provider, enforcement under contract law is inevitable. The primary challenge, and principal problem, for source countries is rooted in the difficulties of using contractual instruments as enforcement tools, where the basic rules and subject of the contract are unclear. ${ }^{184}$ In essence, the objective in these negotiations is to obtain sufficient guarantees on
Administrative and legal mechanisms to fully investigate demands for violation of $A B S$..., in particular, facilitating access to justice for developing Countries of Origin [where resources were] acquired by deception or through a failure to fully disclose the commercial motive behind the acquisition or based upon a transaction deemed to be exploitative.

In this connection, it is important to remember that monitoring and oversight apply far beyond the stage of commercial development. Provider countries must also seek mechanisms to tie access to user standards and measures during the phases of use, research and development, patenting of products and processes, etc. - that is, all stages after initial acquisition of the resource. ${ }^{183}$

The legal need for both the power and the ability to oversee and monitor may tie in with the idea of a "certificate of origin/source/legal provenance," which has been raised in international ABS discussions. Such an instrument would be of interest, providing that it is able to improve transparency and traceability. It has also been suggested that such a mechanism might simplify user-country measures, if it can provide guarantees that the provider country's legal requirements have been complied with.

the use of the genetic resources, and compliance with reporting and data-sharing requirements, that the country's interest will be protected. ${ }^{185}$

This suggests that further development of ABS legislation (including development at the international level) will need to focus on those points of ABS implementation that are not enforceable under contract law whether they are unclear, ambiguous, unfair, ineffective or impractical. In the long run, mechanisms, measures

\footnotetext{
182 Casas, 2005.

183 Fernandez Ugalde, 2005.

${ }^{184}$ However, as mentioned earlier, the assumption that ABS (creation, execution, implementation, oversight and compliance with ABS agreements) would be addressed by contracts and governed by national contract law is not necessarily correct. This statement is also valid for the assumption that ABS contracts can provide the legal means to monitor the use of the GR and to enforce the terms and conditions of the permits, see Young, 2004, "Legal Issues...."

185 Many issues relating to the negotiation of ABS contracts are addressed in Book 4 of this Series, Bhatti et al., Contracting for ABS.
} 
and instruments that are negotiated and developed at the national level, but relate to transboundary situations, provide a clear indication of some areas in which cross border cooperation and legislative support are essential.

\subsubsection{Case study: tracking and monitoring at INBio}

In the majority of cases, the only mechanisms available to provider countries for monitoring the utilization of genetic resources are the reports of the user. Experience has indicated some good practices and case studies which have proven effective. ${ }^{186}$

One useful case study is the manner in which Costa Rico's INBio addresses the transfer of resources for bioprospecting. In general, material is collected in the field under a permit system with separate permits for export and domestic use. A standard agreement applies to taxonomic research while unique legal agreements are developed for bioprospecting research.

\subsubsection{External transfers for bioprospecting}

All material leaving INBio's Bioprospecting Unit is labeled with a barcode and identification number. INBio uses legal and contractual mechanisms for the tracking of the genetic resources as follows:

1. Access is limited in time and quantity. Any transfer to a third party of sample is made using a material transfer agreement (MTA) or under a collaborative research agreement (with companies, research institutions, etc.). INBio agrees to transfer the materials specified in detail in the annex of the MTA or the contract.

2. The recipient may transfer the material only with prior written authorization. The terms and conditions of the original MTA shall apply equally to these third parties. A letter with the following wording is usually required to accompany all transfers: This material has been received under a Material Transfer Agreement which includes terms and conditions for use by Third Parties.

3. The recipient shall assign a unique identification number to each of the materials obtained and to the resulting materials from the research that will ensure traceability.

4. Usually the recipient is obligated by the contract to maintain complete and accurate internal written records and reporting systems so as to keep track of all the materials and any research and/or development activities.

5. The recipient has the duty to allow INBio upon request to audit and/or inspect such records and reporting systems from time to time and to make such changes in such reporting systems as INBio may reasonably request to ensure the accurate tracking of all materials.

6. INBio may have access to the lab notes on INBio material.

7. The recipient shall submit periodical reports to INBio on materials, stage of the research, IPR, research results, etc.

8. The monitoring of uses is provided by the Bioprospecting Unit. There is no Department or special personnel dedicated to the monitoring of contracts; it is done by the current scientific and technical personnel in charge of other bioprospecting tasks.

\subsubsection{External transfers for biodiversity inventory}

In general, all the types of samples located in INBio's collection (existing inventory) can be transferred to a third party, using an MTA and only for basic noncommercial research. These transfers occur mostly in the context of taxonomic research which does not involve access to reproducible genetic resources. Transfers are made only to qualified collaborators. Each specimen has a bar code written in the sample

\footnotetext{
${ }^{186}$ For instance the agreement can make clear who will cover the cost. A specific contribution to the payment of the cost of the dispute mechanisms may be considered. Additional mechanisms such as insurance provisions in case of disputes may be explored, by which the insurance institution will pay for the cost of the process.
} 
form or MTA and monitoring is done through 1) reports from the recipient and 2) a requirement for the recipient to cite the barcode number of any specimens used in publications. ${ }^{187}$

\subsubsection{Costs of tracking resources through INBio}

One frequent concern is the cost of this kind of system. The facilities for bar-coding, and the time and expense necessary to create a collection/inventory of national specimens cannot be denied. However, these activities are useful far beyond the scope of ABS. For example, the database and barcode system can be thought to effectively enable tracking; however, the purpose of the system is not primarily for tracking, but rather to facilitate data-control - to associate taxonomic use and other information with the actual material in the collection, to facilitate biodiversity research. Hence, the costs associated with tracking are difficult to separate from the wider research information management system. No cost estimate is available for compiling or analyzing reports from recipients on material used in taxonomic or bioprospecting research projects.

\subsubsection{Overall analysis: practical aspects of INBio's tracking system}

INBio's practices for labeling biological material and tracking uses of the material within and outside Costa Rica show that it is feasible to label even individual insects given sufficient resources. INBio also databases agreements relating to collection and use of specimens including MAT.

\subsubsection{Legislation where there is less infrastructure} For many countries, the experience of Costa Rica, while useful and interesting, is not practical, given that they do not have the financial and technical resources to replicate it. Legislative efforts in these countries focus on facilitating compliance with contracts and the access to justice in their jurisdiction as demonstrated by a new draft ABS law, proposed in the Seychelles, ${ }^{188}$ one element of which is discussed in part 4.6, below.

\subsection{Source-based incentives for compliance}

As noted above, there are many virtually unsolvable problems that prevent source-country legislation - in the absence of necessary provisions in the user country from functioning to mandate, oversee and ensure benefit sharing. Even if sufficient provisions are adopted by the source country, the costs and demands of oversight of a mandatory system may prevent functionality.

Some commenters feel that this situation can only be addressed by focusing on the establishment of a regime that encourages compliance rather than one that seeks to force it through monitoring and enforcement actions. The relatively limited enforcement capacity of most source country $A B S$ authorities does not provide a sufficient threat of penalty. Consequently, the threat of being detected breaking the ABS laws does not constitute an incentive to comply. Similarly, the existing system's nonenforcement motivations are minimal. The threat of public exposure does not always have a sufficient impact to encourage compliance, and compliance does not always prevent claims of biopiracy. ${ }^{189}$ Consequently, it seems essential to develop incentives and other elements that give the user a motivation to comply with $\mathrm{ABS}$ requirements. ${ }^{190}$

As Tvedt ${ }^{191}$ pointed out:

One gap in the present benefit-sharing situation is the lack of clear incentives for researchers and industry to comply with the benefits-sharing obligation. Industry does not have much to achieve or gain by complying

\footnotetext{
187 In this connection, it is noted that researchers at INBio do not routinely record publications citing INBio specimen numbers.

188 The report of the consultants who wrote this draft law is available from IPGRI. See Lettington and Dogley, 2006. Note: as of last report, this bill has not been approved by the Government of the Seychelles. It is offered as an example of one approach to some of the issues discussed below, but not as a political statement, nor as a "best practice," nor as a recommendation that the draft be adopted.

189 See Young, 2006. See also Lettington and Dogley, 2006.

190 An additional discussion of this issue, from the perspective of user and user countries, is included in Book 2 of this Series, Tvedt and Young, Beyond Access.

191 Tvedt, 2006.
} 
with the benefit-sharing obligation in the $C B D$. The success of patent law partly rests in the fact that the patentee has the very clear interest in enforcing the patent upon all other commercial users of the invention. It is in the interest of the private party that the others comply with the regulations. Thus, the incentive structure in the patent system brings economic benefits to the patentee and thus captures the value of his contribution to the state of the art. Thus, one topic...... to address is how to establish a sufficient level of incentives for industry to share a fair and equitable part of the benefits arising from the use of genetic resources.

In a situation where there are no effective incentives in place, the need for effective enforcement mechanisms increases. If it is not in the interest of the private party to comply with a legal requirement, there is a need for legal tools to enforce that legislation. Due to the extra-territorial gap described above, there is a lack of effective enforcement mechanisms in the area of benefit-sharing. .... Certificates and disclosure requirements are often mentioned in the context of incentives and enforcement.

In summary, as Young suggests: ${ }^{192}$ "There are basic indicators of the need for this [to create incentives]. First is the pressure for enforcement and the difficulties in actually enforcing ABS. It is not simple for any country to oversee or even know about its ABS activities. Often the only way of knowing whether genetic resources are being used would be to have access to private laboratories and files. Second, it is generally noted that any formal negotiation of ABS agreements increases the user's risk of being sued. From this perspective there is a very strong disincentive to engage in formal ABS compliance. What is needed is a business case for ABS compliance - a carefully reasoned, commercially realistic evaluation of the reasons that $A B S$ is good for business. Presently there are relatively few such reasons."

The use of market mechanisms has been suggested as one way of promoting compliance with access requirements. For the most part, these measures are dependent on user country measures, which are strongly advocated by other authors. However, one critical question in these discussions will be how source countries' legislative systems can promote and integrate with such incentives. Measures such as Certification Systems and voluntary codes of conduct are important, but really only effective if they are adopted by user country first, rather than unilaterally by the provider. Hence only a brief summary of these issues is appropriate.

It has been suggested that a system for certification of bioprospecting activities could be a way of encouraging companies to comply with the laws of $\mathrm{ABS}$ and, in general, with better practices in this matter. Formal certification systems depend on the creation of clear, objective standards, and then the creation of administrative mechanisms for verification of the compliance with the standards. If the certification is sufficiently "leakproof" and accepted by consumers, it would allow the consumer to differentiate the final product and consequently to favor the product by means of his purchase. Currently, these types of systems are being developed and applied in cases of forest and organic products.

A study into the possibilities of establishing a system of certification for bioprospecting determined that "At least in theory a bioprospecting certification system would be feasible to create. This conclusion relies on the realization that certification is a tool that has already been applied to a wide range of situations. There is nothing to suggest that certification could not be applied to bioprospecting activities.... Notwithstanding this general conclusion, outstanding issues, such as cost and demand, make it difficult to definitely say whether a bioprospecting certification system would be feasible to create and operate in practice. These outstanding issues need to be reviewed more closely in any subsequent exploratory work undertaken in the future." 193 The study concluded that unlike other natural resources addressed by other certification systems, genetic resources do not circu-

\footnotetext{
192 Young, 2005.

193 Cfr Glowka, 2001.
} 
late in the consumer economy. Where they do, it is not necessarily in a way where consumers could easily distinguish whether the products embodying them are coming from a certified source without a label or logo. Furthermore, even with a label or logo, there may be no viable mechanism to pass on and capture the cost as with, for example, marine, ornamentals or fairly traded agricultural commodities. ${ }^{194}$ For these reasons, a market-based certification system appears difficult to develop. ${ }^{195}$

Another interesting development is the promotion of voluntary measures, ${ }^{196}$ such as Codes of Conduct, principles and guidelines that may be of value, at least in a relative sense, especially given the previously mentioned problems related to access to justice, monitoring and observance. Basically these codes seek to encourage adherents to comply with legal standards and good practices. However, these instruments can be ineffective if not accompanied by some incentive to use them.

For instance, the Japanese Guidelines (described above) offer a concrete first step toward effective user measures, by including a commitment from the Japanese Government, stating that if a user complies with all these guidelines and still encounters claims of misappropriation, unauthorized access or biopiracy, the Japanese Government will utilize diplomatic and informal means to seek a solution to the problem. This assurance of user-country assistance in resolving ABS-related claims offers real value to the user companies and may become a primary incentive encouraging companies to comply with these voluntary guidelines. Such examples are not common, however. Finally, incentives for compliance have not been iden- tified in any of the ABS legislation that has been adopted to date. For source countries, the issue of incentives must focus on matters within their control, and in which they can provide some benefit. As one example, ${ }^{197}$ the country might post the names of companies that have complied with good ABS practices and legislation.

Other benefits that the source country can offer as positive incentives to promote $\mathrm{ABS}$ compliance could include faster processes of approval, lower fees and other expedited administrative processes, where there is compliance with the ABS laws. Another possibility is the payment of reduced fees in IPR applications and approval processes if/when the user seeks to patent his innovation in the source country. This option might be applied to all users, even where their product is based on genetic resources acquired from some other source (another user, an ex-situ collection, a researcher, etc.), so long as their compliance with the ABS laws is proven. If it is enforceable, such an approach would constitute an incentive to good corporate citizenship and compliance with $\mathrm{ABS}$ around the world.

Another potential incentive would apply where the source country created streamlined access procedures for users who take certain actions (including potentially the certificate, certification or voluntary codes, as described above). ${ }^{198}$ The possibilities for such simplification are as diverse as the national circumstances. For instance, in Mexico, some national experts agree that having the State involved in all ABS activities might create excessive inefficiency in ABS management. ${ }^{199}$ Thus, an element of the expedited procedure could include an exemption, under which

\footnotetext{
194 Glowka, 2001.

195 The BioTrade Initiative is looking for the development of a verification system for the natural ingredients sector. See BioTrade Facilitation Programme, Framework for the verification of BioTrade companies of natural ingredients, Working Document, Geneva, March 2006.

196 The need for guidance and orientation is evidenced by the guidelines and principles, in either final or draft form, developed by biotechnological organizations in the USA, Europe and Japan (in the latter case, in conjunction with the Japanese Trade Ministry).

197 This book does not consider the legal implications of this kind of action, the listing and delisting process, and the potential for harm to innocent companies that are mistakenly removed from the list, even if only for a short time.

198 A somewhat similar measure was suggested at the First Panel of the Experts of the CBD. However, it focused on the conduct of persons, not State acts, it only referred to voluntary instruments, and it only suggested simplifying the PIC procedures. See Report of the Panel of Experts, op. cit., Annex V.

199 Larson et al., 2004.
} 
the State's involvement in some activities might be limited. (For example, where a series of Access events are planned, it may not be necessary for the State to be party to every single access agreement. ${ }^{200}$

\subsubsection{Role of incentives in source-country legislation}

For the source country, the most important question about measures such as guidelines and certification is how they should be applied legislatively. This raises a number of questions, including the following:

- How would the source country's access legislation incorporate these measures?

- Can national law give preference to users that commit to the standards of an "ABS Certification System" or specified/approved voluntary codes of conduct?

- What corresponding measures could the source country adopt, in the case of a code of conduct like the Japanese Guidelines described above, where the user country has made specific commitments, to help avoid lawsuits or claims for misappropriation or biopiracy?

- Can other steps be adopted to promote voluntary systems that recognize, in the market, users that have complied with ABS good practices?

Specific issues can be noted with regard to the exam- ples mentioned above. For example, the creation of a "voluntary certification" system can be confusing, when applied in source country legislation. In essence, such a system will not guarantee that anyone will comply with $A B S$ legislation, although it may create an incentive for some users to comply. At the same time, if the source country declares that certification will be mandatory for all users of the country's genetic resources, they may face problems under many other legal regimes (trade, contractual, enforcement, etc.) as well as objections from countries whose participation in the certification system was conditioned on the fact that it was "voluntary."

If the certification system is functional however (that is, if the system has found a mechanism that is highly effective and leakproof for confirming that the user has complied with the system standards, and for tracking products and controlling labeling), then the source country may be able to create a different incentive based on the certification system. Specifically, it can provide special streamlined procedures and other special arrangements for any applicant who is certified under the system, and who agrees that his actions will comply with that system.

\subsubsection{Recommendations regarding monitoring and oversight}

The first step in ensuring the $\mathrm{CBD}$ ABS principles can only be realized if Countries of Origin recognize their rights, powers and responsibilities, and clearly impose requirements on users through their own laws. Although only countries that are predominantly source countries have adopted $\mathrm{ABS}$ laws (giving them a strong position as compared with developed/user countries), the fact remains that fewer than 20 countries have adopted any functional or partly functional $\mathrm{ABS}$ regulatory provisions.

Clearly the problems inherent in ABS (definitions of genetic resources, problems of transboundary oversight) have prevented many countries from acting; ${ }^{201}$ however, it is not advisable for countries to simply wait for some external legislation to solve their problems. Despite the legislative problems, users con-

200 Allegedly, agreements are most likely to succeed when the number of parties is minimized. Particularly, some experts claim that having the State directly involved in the negotiation of benefit-sharing agreements results in bureaucratic hurdles that lead to inefficacies and high transaction costs, Larson et al., 2004.

${ }^{201}$ Alternatively, many countries that have no ABS legislation in place might choose to wait for the outcome of the negotiations. Something similar happened regarding the Cartagena Protocol on Biosafety, where controls were delayed pending completion of the negotiations, providing an opportunity for many companies which strongly requested that they be given permission to introduce their products before any new laws are adopted. Young, "Access and Benefit sharing: In Search of an 'International Regime,' " Environmental Law Programme Newsletter, IUCN, Bonn, 2004. 
tinue to obtain, research and utilize genetic resources on a regular basis. Unless those uses are bound by appropriate laws and contractual provisions requiring necessary actions at the source country level, those transactions may well be "lost to remedy" in the event that user measures or international provisions are later adopted. However, if properly written, these documents may provide some interim protection, as well as a basis for oversight and monitoring by new mechanisms, at that time.
These time concerns are not uncommon and are shared by other international agreements including, most relevantly, the International Treaty on Plant Genetic Resources for Food and Agriculture (ITPGRFA), and the Cartagena Protocol on Biosafety. Although there is strong national interest in both instruments, national implementation has either not started or has not been significant yet. Clearly, even if the international negotiations could be expected to completely replace the need for national legislation, it is not appropriate simply to wait for that day.

\subsection{Additional concerns: flexibility and law}

In ABS discussions at all levels, one common complaint voiced by user companies is the fact that $A B S$ regulations are very difficult to comply with, and that different situations require special treatment, in part because, as discussed above, there are many areas in which ABS law is unclear, unreliable or undeveloped. Normally, however, law is perceived as firmly fixed because it must give certainty to all different categories of individuals who are governed by or who rely on the law, and also provide a basis for non-biased governmental action. Increasingly, however, a need to provide some level of flexibility is asserted. This is a problem, given that the values of legal certainty and nonbiased application continue to apply.

This tension is very apparent in the history of the genetic resources issue. After the CBD created the concept of a property right called "genetic resources" and recognized it as (i) having value (see CBD Article 1 ), and (ii) being a sovereign right of the source coun- try (CBD Article 15.1), there was an initial rush among countries to establish highly restrictive regimes. Thereafter, although pressures for flexibility and streamlining are strongly asserted, ${ }^{202}$ concerns about legal certainty for the source country have tempered most subsequent legislative development. The Bonn Guidelines address these issues through a series of provisions which are entirely voluntary. If this "voluntary" nature means that no applicant may be required to comply, this would mean that the Guidelines are completely flexible, but also completely uncertain. It also does nothing to aid governments in their goal of ensuring that the ABS system gives fair treatment to all users (and providers). However, the Bonn Guidelines focus primarily on access issues, and do not address the serious governance problems described in Chapter 2,203 especially the need for enforcement and oversight of resource utilization outside the source country. ${ }^{204}$

\subsection{Flexibility through governmental reciprocality}

One step that source countries can consider, as a means of finding an appropriate standard of flexibility in addressing post-access monitoring and oversight, is through the concept of reciprocality. By nature, however, reciprocality is a "double-edged sword," since a reciprocality provision may require the user countries to provide only the level of oversight and protection that the source country provides. This might possibly mean that reciprocality would require source countries to adopt detailed and comprehensive

\footnotetext{
202 See, for example, the Bonn Guidelines and the documents that were provided during their negotiation.

203 Dross and Wolff, 2005.

204 Hodges and Daniel, 2005.
} 
oversight mechanisms, and then pray that none of their citizens decide to utilize any other country's genetic resources, triggering costly implementation.

However, a second option, without requiring mirroring, might be possible. A source country might consider adopting legislation under which special
ABS procedures are only available for users operating under the jurisdiction of a country that has adopted certain measures. This approach might eliminate a common problem where applications had been refused, because the authorities felt that they did not have adequate guarantees or were uncertain of how exported material might really be used.

\subsection{Case study: reciprocality in the Seychelles' draft ABS Law}

The Seychelles constitutes a good example of a country for which oversight and control of users will be nearly impossible. The Seychelles is not primarily a "user" of genetic resources, and will probably not be able to build the level of infrastructure to monitor, test, or take other actions that impose restrictions on users. Its draft law, however, attempts to remedy these deficiencies, through the use of two kinds of provisions, legal mandates (basic user measures) and reciprocity. These provisions were included to give users and user countries an idea of the minimum that is expected from other countries in return for access and the right to use genetic resources.

These user provisions are very basic statements, however. In general, they simply require Seychellois who are utilizing the genetic resources of other countries to:

- Comply with the laws of the source country (Article 32);

- Comply with the terms and conditions of any relevant permit or contract (Article 33); and

- Notify the source country when the resources have been accessed (Article 34).

So long as these activities are required under the source country law, it is probable that they would already be required under general laws in the Seychelles, however, this reaffirmation provides a demonstration of the drafters' view of the minimum that source countries should expect.
For the purposes of access legislation, however, a much more important provision is that which addresses questions of legal reciprocity and unconscionable terms and conditions. In this connection, Article 36 of the draft law states that:

The provisions of this Part shall only apply in respect of the laws or other terms and conditions of access or utilization of foreign jurisdictions providing equivalent or reciprocal protections to those contained in this Part, and shall not be enforceable where any relevant terms and conditions are declared unconscionable.

Both clauses of this provision are of interest legally. First, the reciprocity clause appears designed to create an incentive for user countries to adopt "user measures." In essence, it says that "if you don't protect our genetic resources from unauthorized exploitation, we won't do the same for you." Presuming that other source countries (with larger genetic-resource industry and research bases) follow this example, such an incentive might indeed develop. At the same time, that clause suggests that all that user countries must do is provide three or four unenforceable single sentence mandates, in order to meet their responsibility under Article 15.7.

In addition, the second clause might be interpreted to be an authority to declare foreign law invalid another provision that might have negative reciprocal impacts, if a user country were to adopt and enforce it. 


\subsection{Enforcement and guarantee}

In provisions of this type, however, it is important to have something more than a promise or expectation of compliance. Relatively few countries are able to demand and receive guarantees or security that can reliably protect their interest during the pendancy of the ABS agreement. ${ }^{205}$ Effective global governance of ABS, however, will clearly be dependent upon the adoption and implementation of relevant law and policy by national governments.

Ultimately, this issue will have to be supported by international action that provides source countries with reliable bases for monitoring, evaluation, determining where there is "complete non-compliance" (i.e., users who have not complied with ABS in any way), and taking action to promote compliance. In the meantime, reciprocity may be a useful first step. One of the primary advantages of this kind of simplic-

\subsection{Trade concerns}

In modern legislative practice, any provision that limits commercial relationships across national boundaries should consider the possibility of trade-related concerns. Generally, a provision that does not restrict trade (that is, importation of commercial goods and services), but only places limits on foreign persons who want to buy a country's resources does not run afoul of the international trade regime (for practical reasons relating to each country's own interest in the sovereign/personal power to decide whether to sell and to whom) ${ }^{206}$ However, it is useful to briefly consider the possibility that a special privilege for some buyers ity is that it can be accepted by courts in user countries relatively quickly. If that happens it will enable source countries to build confidence in the overall system. Over time, as legislative reciprocity provisions become common and are proven to work, many of the more stringent and immovable source country provisions will be dispensed with. In essence, reciprocality would transform the implementation of the regime into a dynamic system where access would be further facilitated through a legal evolution. Obviously, such a provision should not overrule the authority to determine access.

Traditionally, it has been held that there is little provider countries can do to influence compliance outside their jurisdiction. The use of reciprocity measures may challenge this assumption.

could raise trade concerns.

This need is underscored, for example, by recent political negotiations in Mexico. The idea of introducing, in addition to the standard access procedure, certain expedited/simplified access procedures for nationals of jurisdiction where user measures have been adopted, was discussed within the environmental public sector in Mexico, during the deliberation of the Draft National ABS Law. ${ }^{207}$ In the end the Ministry of Environment was not persuaded due to misunderstandings over the exact limitations posed by interna-

\footnotetext{
205 See Lettington and Dogley, 2006.

206 The often misunderstood relationship between the rules of the WTO (World Trade Organization) and MEAs has been on the international agenda for more than a decade. It arose out of a fear in the environmental policy community that the reasoning of a GATT (General Agreement on Trade and Tariffs) panel, in the infamous Tuna-Dolphin case (1991), threatened the rapidly developing international architecture of environmental protection. However, despite a considerable amount of attention in official intergovernmental processes - including, inter alia, the World Trade Organization, the Organisation for Economic Cooperation and Development, the United Nations Conference on Trade and Development and the World Summit on Sustainable Development - the debate about the appropriate parameters of this relationship persists without resolution. Cfr Tarasofsky, 2004. There has been no indication, however, that it will impose a duty to sell natural sovereign resources against national desires or interests.

207 C. López (one co-author of this book) led the legal position for the National Commission on Biodiversity, which regularly provides technical advice to the Ministry of Environment. The position of the Commission was coordinated with the National Institute of Ecology (through José Carlos Fernández). This coordination led to the common conclusion that there was a need to develop much simpler procedures that the ones being advanced in the Draft Law, which later derived in the proposed measure.
} 
tional trade obligations and an over-dimensioning of the issue of discrimination.

Probably the most important trade provisions for ABS purposes are contained in the ITPGRFA, which establishes in Article 11 that:

\subsection{Contracting Parties also agree to take} appropriate measures to encourage natural and legal persons within their jurisdiction who hold plant genetic resources for food and agriculture listed in Annex I to include such plant genetic resources for food and agriculture in the Multilateral System.

\subsection{Within two years of the entry into force} of the Treaty, ${ }^{208}$ the Governing Body shall assess the progress in including the plant genetic resources for food and agriculture referred to in paragraph 11.3 in the Multilateral System. Following this assess- ment, the Governing Body shall decide whether access shall continue to be facilitated to those natural and legal persons referred to in paragraph 11.3 that have not included these plant genetic resources for food and agriculture in the Multilateral System, or take such other measures as it deems appropriate.

These provisions essentially threaten to impose a multilateral system if national efforts to increase access to ITPGRFA listed species are not sufficient. In effect, this is a reverse trade sanction, requiring countries to give access, even if this is not possible or desirable from their point of view.

A significant amount of interpretation will be required from the Governing Body since many aspects of the functioning of this mechanism are still unclear. ${ }^{209}$ Thus a full comparative analysis cannot be concluded at this point.

208 The Treaty came into force on 29 June 2004. Therefore, the review should take place before 29 June 2006 in theory. However, so far, this aspect has not been addressed.

${ }^{209}$ For instance, it is not clear whether it is the State conduct or the private individual conduct what is subject to the review. Traditionally, only States acquire directly rights and obligations in international treaties. However, many recent treaties, including the ITPGRFA in other provisions, transcend and affect rights and obligations within the private sphere of individuals. 


\section{Conclusions}

Inevitably, although this book is intended to address national implementation rather than simply adding another to the huge volume of expert opinions on what should be done in the international regime negotiations, in the end our conclusions necessarily focus on some issues which appear to be resolvable only through those negotiations.

National ABS legal systems need to restate some conceptual basic aspects to be consistent and functional. The lack of reflection on the scope of certain concepts or on the need to consider the effectiveness of applying the contract and property rights law, consequently hinder the implementation of ABS systems. To date, the studies on this matter are scarce, as are the legislative attempts to tackle these conceptual aspects. Among the conceptual elements to be studied, those of genetic resources, derivatives, biological resources and utilization stand out. One key conclusion is the need for an integrated approach to these concepts and a reconsideration of the use of conventional mechanisms (property, contracts) to put into effect $\mathrm{ABS}$ regimes.

Although these topics must be dealt with at a national level, it is necessary to give legal consistency to the ABS systems, international understandings in these matters, in order to support the national efforts. In this sense, the negotiations of the IR are a framework to resolve and to find solutions to some of these problems.

It should be indicated that although resolving these aspects is critical, for the operation of a system of ABS, there exist other operative basic problems that are equally important. Among them: the capacity to negotiate; political will; and the lack of confidence between different stakeholders.

Despite the lack of understanding of some basic topics, some countries have started implementing their national laws. This demonstrates that national measures need to be strengthened.
The efforts of provider countries will probably continue to reflect the insufficiency of unilateral national legislation to regulate $A B S$, until countries have adopted user measures under which they commit to require and promote their own companies and ex-situ collections to engage in benefit sharing with source countries, and apply those provisions, including access to justice, in the cases of non-compliance of contracts or illegal access.

Clear criteria should be established with regard to the differences between access for basic research and for commercial purposes.

With regard to property rights over genetic resources it is necessary that these are addressed at the national level and, at the same time, that the difficulties to apply traditional concepts of control and exclusion in the case of the genetic information contained in the samples are recognized. The clarification of the implications of the public domain concept in relation to the rights granted to the bioprospector is also a key aspect to provide legal certainty.

Providing countries should establish clear, simple and transparent systems of ABS, including those relative to the PIC. Any flexibility in the ABS process can be conditioned to the existence of user measures which would be compatible with the international trade system.

The incentives which provider countries can reasonably give to encourage compliance, such as faster approval procedures, reduced application fees and special status for those who demonstrate compliance with $\mathrm{ABS}$ regimes, must be explored.

Finally, although legal studies and analyses are necessary for this to happen, we feel that the most important objective is that the result should focus on practical solutions that offer legal certainty while protect the rights of the providers. 



\section{References}

Aguilar, D. 2004. "El Lado Oculto de los recursos genéticos; su carácter compartido o transfronterizo." Unpublished paper.

Arroyo-Quiroz, I., R. Perez-Gil and N. LeaderWilliams. 2005. "Developing Countries and the Implementation of CITES: The Mexican Experience." Journal of Wildlife Law and Policy 8(13).

Australian Government Department of Environmental Heritage. 2005. "Genetic Resources Management in the Commonwealth Areas." In: Sustainable Access and Benefit Sharing. Canberra, Australia: Australian Government.

Barber, C., L. Glowka and A. La Vina. 2002. "Developing and implementing national measures for genetic resources regulation and benefit sharing." In: Laird, S. (ed.) Biodiversity and Traditional Knowledge. Equitable partnerships in practice. Earthscan.

Barber, C. 2002. "Developing and Implementing National Measures for Genetic Resources, Access Regulation and Benefit Sharing." In: Laird, S. (ed.) Biodiversity and Traditional Knowledge: Equitable Partnerships in Practice. Earthscan.

Barber, C. et al. 2003. User Measures: Options for Developing Measures in User Countries to Implement the Access and Benefit-sharing Provisions of the Convention on Biological Diversity. Japan: UNU/IAS.

Bass, S. and M. Ruiz, eds. 2000. Protecting Biodiversity in the Americas. National laws regulating access to genetic resources in the Americas. Ottawa, Canada: IDRC.

Benavidez, P. 2004. "Philippines: evolving Access and Benefit Sharing Regulations." In: Carrizosa, S., Brush, S., Wright, B. and McGuire, P. Accessing Biodiversity and Sharing the Benefits: Lessons from Implementing the Convention on Biological Diversity. Environmental Policy and Law Paper No. 54. IUCN-ELP.
Benavidez, P. 2004. "The Challenges in the Implementation of the Philippine ABS Regulations: Monitoring and Enforcement of Bioprospecting Activities in the Philippines," document presented in the International Expert Workshop on ABS, hosted by the governments of Canada and Mexico, held in Cuernavaca, Mexico, October 2004.

Cabrera Medaglia, J. 2004. A Comparative Analysis of the Implementation of Access and Benefit-sharing Regulations in Selected Countries. ABS Project. Bonn, IUCN-ELP. (may be accessed from the IUCN-Environmental Law Centre's website at www.iucn.org/themes/law).

Cabrera Medaglia, J. 2004. "Costa Rica: Legal Framework and Public Policy." In: Carrizosa S., Brush, S., Wright, B. and McGuire, P. Accessing Biodiversity and Sharing the Benefits: Lessons from Implementing the Convention on Biological Diversity. IUCN Environmental Policy and Law Paper No. 54. IUCN-ELP.

Cabrera Medaglia, J. 2004. "Elementos básicos para la negociación de contratos de bioprospección." Unpublished paper.

Cabrera Medaglia, J. 2004. "Access and Benefit Sharing in Costa Rica: Lessons Learned from the Monitoring and Tracking of Genetic Resources in Access Contracts." Research document prepared for the Centre for International Sustainable Development Law, Montreal, Canada.

Cabrera Medaglia, J. 2004. "Biodiversity Prospecting in Practice." IP Strategy Today 11. Biodevelopments. New York, USA.

Caillaux, J. and M. Ruiz, "Legislative Experiences on Access to Genetic Resources and Options for Megadiverse Countries." In: Report of the First Ministerial Meeting of the Like-Minded Megadiverse Countries on Conservation and Sustainable Use of Biological Diversity. SEMARNAT, México. 
Carrizosa S., S. Brush, B. Wright and P. McGuire, eds. 2004. Accessing Biodiversity and Sharing the Benefits: Lessons from Implementing the Convention on Biological Diversity. IUCN Environmental Policy and Law Paper No. 54, IUCN-ELP.

Carrizosa, S. 2004. "Developing and Implementing ABS Regulations in the Pacific Region: Issues and Challenges," paper presented to the International Expert Workshop on Access to Genetic Resources and Benefit Sharing, Cuernavaca, Mexico, October 2004.

Casas, F. (2004). "Derechos de propiedad sobre los recursos genéticos: El asunto de los derivados. Derechos de propiedad tangible e intangible. Notas preliminares," document presented at the International Expert Workshop on Access to Genetic Resources and Benefit Sharing, Cuernavaca, Mexico, October 2004.

Columbia University School of International Affairs, Environmental Policy Studies Workshop (1999). Access to Genetic Resources: an evaluation of the development and implementation of recent regulation on access agreements. New York, USA: Columbia University.

Convention on Biological Diversity. 1998. "Case Studies on Benefit Sharing Arrangements," distributed to the Fourth Conference of the Parties, Bratislava, Slovakia, 4-15 May 1998.

Convention on Biological Diversity. 2004. "An Analysis of Existing National, Regional and International Legal Instruments Relating to Access and Benefit Sharing and Experience Gained in their Implementation, including Identification of Gaps." Doc. UNEP/CBD/WGABS/3/2, November 2004.

Correa, C. 2000. "Implications for National Access Legislation for Germplasm Flows," background paper prepared for the Global Forum on Agricultural Research, Dresden, Germany, May 2000.
Crucible Group. 2001. Seeding Solutions. Options for National Laws Governing Access to Genetic Resources and Control over Genetic Resources. Canada: IPGRI, IDRC and the Dag Hammarskjold Foundation.

Downes, D. et al. 1994. "A Biodiversity Prospecting Contract." In: Reid, W. et al. (eds.), Biodiversity Prospecting. Sustainable Use of Genetic Resources. San José: World Resources Institute. 1st edition.

Dross, M. and Wolff, F. 2005. New Elements of the International Regime on Access and Benefit-Sharing of Genetic Resources - the Role of Certificates of Origin, Federal Agency for Nature Conservation, Germany.

Dutfield, G. 2004. "What is Biopiracy?" Document presented at the Expert Workshop on Access and Benefit-sharing, Cuernavaca, Mexico, October 2004.

Edmond Institute and the African Centre for Biosafety. (Undated). "Out of Africa: Mysteries of Access and Benefit Sharing." Available at www.edmonds-institute.org

Febres, M.E. 2003. "Avances Normativos de Venezuela en material de acceso a recursos filogenéticos," document prepared for the Seminario Regional on Acceso a Recursos Fitogenéticos en la Región Andina, Lima, 2003.

Febres, M.E. 2002. La regulación del acceso a los recursos genéticos, Venezuela. Centro de Estudios del Desarrollo, Caracas, Venezuela: Universidad Central de Venezuela.

Fernández Ugalde, J.C. 2005. "The Feasibility, Practicality and Cost of a Certificate of Origin System for Genetic Resources: Economic Considerations." In: Towards a fair and equitable benefit-sharing instrument for effective implementation of the Bonn Guidelines under the Convention on Biological Diversity. Yokohama, Japan: UNU/IAS and JBA. 
Gartforth, K. et al. 2005. Overview of the National and Regional Implementation of Access to Genetic Resources and Benefit Sharing. Montreal, Canada: Centre for International Sustainable Development Law.

Glowka, L. et al. 1994. A Guide to the Convention on Biological Diversity. Environmental Policy and Law Paper No. 30, IUCN-ELC.

Glowka, L. 1998. A Guide to Designing Legal Frameworks to Determine Access to Genetic Resources. Environmental Policy and Law Paper No. 34, IUCNELC.

Glowka, L. 2001. Towards a Certification System for Bioprospecting Activities, study commissioned by the Swiss State Secretariat for Economic Affairs (SECO), Bern.

Gollin, M. 2002. "Elements of Commercial Biodiversity Prospecting Contracts." In: Laird, S. (ed.) Biodiversity and Traditional Knowledge. Equitable partnerships in practice, UK and USA: Earthscan.

Grajal, A. 1999. "Biodiversity and the Nation State: Regulating Access to Genetic Resources Limits Biodiversity Research In: Developing Countries," Conservation Biology, Vol. 13, No. 1. Feb 1999, pp. 6-10.

Hernández, A.M. 2000. Biodiversidad y Variedades Vegetales, Instituto de Investigación en Recursos Biológicos Alexander Von Humboldt, Colombia.

Hirakuri, S. and B. Toben. 2005. "Prior Informed Consent and Access to Genetic Resources and Benefit sharing: paralysis or prudence?" In: UNU, Work in Progress, Vol 17.

Hodges, T. and A. Daniel. 2005. "Promises and Pitfalls: First Steps on the Road to the International ABS Regime." RECIEL 14(2).
ICTSD and UNCTAD. 2003. "Intellectual Property Rights: Implications for Development." Policy discussion paper, Geneva.

International Institute for Sustainable Development (IISD), Stratos and J. Cabrera Medaglia. 2005. A Guide to Using the Working Draft ABS Management Tool. State Secretariat for Economic Affairs (SECO), Switzerland, Berne.

IUCN-Canada (principal author: T.R. Young). 2005. "Summary Analysis: Legal Certainty for Users of Genetic Resources under Existing Access and Benefitsharing (ABS) Legislation and Policy," document UNEP/CBD/WG-ABS/3/INF/10 February 2005. (This study was undertaken under the ABS Project (sponsor of this book) and will be published in one of the later books in this series, entitled Covering Access: Addressing the Need for Sectoral, Geographical, Legal and International Integration in the ABS Regime, expected 2007.)

Laird, S. (ed.). 2002. Biodiversity and Traditional Knowledge. Equitable partnerships in practice. Earthscan.

Laird, S. 1994. "Biodiversity Prospecting Contracts." In: Reid, W. et al. (eds.), Biodiversity Prospecting. Sustainable Use of Genetic Resources. San José: World Resources Institute. 1st edition.

Lange, L. 2005. "CBD: Status, Pitfalls, Actions Needed and Perspectives" In: JBA-UNU/IAS Symposium on Access to and benefit sharing of genetic resources How industry and Government are coping with the current situation, Proceedings Update, Tokyo, 2005.

Larson, J., C. López-Silva, J. Chaela, J.C. Fernández Ugalde, and J. Soberon. 2004. "Mexico: Between Legality and Legitimacy." In: Carrizosa S., S. Brush, B. Wright, and P. McGuire. Accessing Biodiversity and Sharing the Benefits: Lessons from Implementing the Convention on Biological Diversity. Environmental Law and Policy Paper No. 54, IUCN-ELP. 
Lettington, R. and D. Dogley. 2006. Commentary on the Development of the Republic of Seychelles Access to Genetic Resources and Benefit Sharing Bill. (NOTE: As of this writing, this bill has not been adopted.)

Lettington, R. 2004. "Vision and Nature of an International Regime: Minimum Requirements and Options from a Practical Developing Country Perspective," document presented at the Expert Workshop on Access and Benefit-sharing, Cuernavaca, Mexico, October 2004.

Loufi, S. and B. Toben. 2006. "User Measures to Resolve Potential Conflicts Between the WTO and the CBD." In: Disclosure Requirements: Ensuring Mutual Supportiveness Between the WTO TRIPs Agreement and the CBD, IUCN (Gland) and ICTSD.

Ministry for Sustainable Development, Access to Genetic Resources. 2004. "The Bolivian Experience In: Applying Decision 391: The Common Regime on Access to Genetic Resources," Bolivia.

Mugabe, J. et al. "Managing Access to Genetic Resources," In: Mugabe, John et al. eds. 1997. Access to Genetic Resources. Strategies For Sharing Benefits, ACTS Press, Kenya.

Nnadozie, K. et al. eds. 2003. African Perspective on Genetic Resources, Environmental Law Institute, Washington, 2003.

Nnadozie, K. et al. 2003. "Needs and Options for ABS Implementation," in Africa; Recommendations for the Regional ABS Capacity Building Workshop for Eastern and Southern Africa."

Normand, V. 2004. "Level of National Implementation of ABS," paper presented to the International Expert Workshop on Access to Genetic Resources and Benefit Sharing," Cuernavaca, Mexico, October, 2004.
Ogolla, D. 2005. "Legislative Regimes on Access and Benefit Sharing: Issues in National Implementation," In: Report International Expert Workshop on Access to Genetic Resources and Benefit Sharing, Cape Town, Norway and South Africa, September, 2005.

Oldam, P. 2005. "Global Status and Trends in Intellectual Property Claims," In: Genomics, Proteonomics and Biotechnology, CESAGEN, United Kingdom.

Osama, M. 2002. "Malaysia: Recent initiatives to develop access and benefit sharing regulations," In: Carrizosa S., S. Brush, B. Wright and P. McGuire, Accessing Biodiversity and Sharing the Benefits: Lessons from Implementing the Convention on Biological Diversity. IUCN Environmental Law and Policy Paper No. 54, IUCN-ELP, 2004.

Oxley, A. and B. Bowen. 2006. Developing an Effective International Regime for Access and Benefit Sharing for Genetic Resources using Market-based Incentives, Australian APEC Study Centre/Monash University, Melbourne.

Pérez, E. 1997. "Access in Roman-Napoleonic Legal Systems," In: Access to Genetic Resources. Strategies for Sharing Benefits, Mugabe, John et al. (eds.), ACTS Press, Kenya.

Perault, A. 2006. "Prior Informed Consent and Access and Benefit Sharing: Recognition and Implementation, Prior Informed Consent from Theory to Practices," In: Disclosure Requirements: Ensuring Mutual Supportiveness Between the WTO TRIPs Agreement and the CBD, 2006, IUCN (Gland) and ICTSD.

Petit, M., et al. 2001. Why Goverments Can't Make Policy. The Case of Plant Genetic Resources in the International Arena, International Potato Center, Lima. 
Report of the Commission on Intellectual Property Rights. 2002. Integrating Intellectual Property Rights and Development Policy, London.

Rosenthal, J. 2003. "Equitable Sharing of Biodiversity Benefits: Agreements on Genetic Resources, in International Cooperative Biodiversity Groups (ICBG)," Workshop Developing Research Access and Benefit Sharing Agreements, Fogarty International Center, Bethesda, Maryland, 2003.

Rosenthal, J., undated. "Politics, Culture and Governance in the Development of Prior Informed Consent and Negotiated Agreements with Indigenous Communities," unpublished, contact the author.

Ruiz, M. 2000. "Regulating Bioprospecting and Protecting Indigenous Knowledge in the Andean Community. Decision 391 and its overall impacts in the Region," document submitted to the UNCTAD Expert Meeting on National Experiences for protecting Traditional Knowledge, innovations and practices, Geneva.

Ruiz, M. and I. Lapeña (expected 2007). A Moving Target: Genetic Resources and Options for Tracking and Monitoring their International Flows. IUCN Environmental Law and Policy Paper No. 67/3, ABS Series, IUCN-ELP.

Sampath, P. 2005. Regulating Bioprospecting: institutions for drug research, access and benefit sharing, UNU, The Netherlands.

Seiler, A. and G. Dutfield. 2001. Regulating Access and Benefit Sharing. Basic Issues, Legal Instruments and Policy Proposals, BfN, Germany.

Suzuki K. 2005. "Access and Benefit Sharing of Genetic Resources: A case for the pharmaceutical industry," In: UNU/IAS and JBA Symposium Proceedings Access and Benefit Sharing of Genetic Resources: How Industry and Governments are Coping with the Current Situation, Tokyo.
Svarstad, H., and S. Dhillion, eds. 2000. Responding Bioprospecting: from biodiversity in the South to Medicines in the North, Oslo, Spartacus Forlag.

Swiderska, K. 2001. Stakeholder Participation in Policy on Access to Genetic Resources, Traditional Knowledge and Benefit-Sharing. Case Studies and Recommendations. Biodiversity and Livelihoods Issues No 4, IIED, London.

Tarasofsky, R. 2004. "The Relationship between MEAs and WTO rules," presentation in a seminar to raise awareness of trade issues in civil society, Szentendre, May 2004.

Ten Kate, K. and S. Laird. 1999. The Commercial Use of Biodiversity, Earthscan.

Tvedt, M.W. and T. Young, (expected 2007). Beyond Access: Exploring Implementation of the Fair and Equitable Sharing Commitment in the CBD. IUCN Environmental Law and Policy Paper No. 67/2, ABS Series; IUCN-ELP.

Tvedt, M.W. 2006. "Elements for Legislation in User Countries to Meet the Fair and Equitable Benefit Sharing Commitment," In: Journal of World Intellectual Property, 2006, Vol. 9 No 2.

UNEP-WIPO 2000. Case Studies on the role of IPR in sharing the Benefits arising from the use of biological resources and associated traditional knowledge, Geneva.

Vogel, J. 1998. El Cartel de la Biodiversidad, Care, Ecuador.

Young, T. 2006. An Analysis of Claims of Unauthorized Access and Misappropriation of Genetic Resources and Associated Traditional Knowledge, report prepared for IUCN-Canada and distributed at the Fourth Meeting of the ABS Working Group, Granada, document UNEP/CBD/WG-ABS/4/INF/6, SCBD. 
Young, T. 2004. Legal Issues regarding the International Regime: Objectives, Options and Outlook, In: Carrizosa S., S. Brush, B. Wright and P. McGuire, Accessing Biodiversity and Sharing the Benefits: Lessons from Implementing the Convention on Biological Diversity. IUCN Environmental Law and Policy Paper No. 54, IUCN-ELP.

Young, T. 2004. "The International Regime from an Implementation Perspective: What Legislation Can (and Can Not) Do... and How This Affects the Vision and Nature of the Regime", paper presented at the International Expert Workshop on Access to Genetic Resources and Benefit Sharing, Cuernavaca, México, September, 2004.

Young, T. 2004. "Genetic Resources and Utilisation of Genetic Resources: a Legislative View," document presented to the International Expert Workshop on Access to Genetic Resources and Benefit Sharing, Cuernavaca, Mexico, October, 2004.
Young, T. 2005. "Gaps and Obstacles in Developing/Implementing National ABS Legislation, in Report of the International Expert Workshop on Access to Genetic Resources and Benefit Sharing, Cape Town, South Africa, co-hosted by Norway and South Africa, September, 2005.

Young, T. 2006. "An Implementation Perspective on International Law of Genetic Resources: Incentive, Consistency and Effective Operation," In: Yearbook of International Environmental Law, Oxford Press, Volume 15. 


\section{About the Authors}

\section{Jorge Cabrera Medaglia}

Jorge Cabrera Medaglia is a lawyer, with honors degrees (Bachelor's and Juris Doctor) from the University of Costa Rica, Faculty of Law, supplemented by postgraduate studies on environmental and agricultural law, commercial law and economic law. He is now a professor of environmental law at the University of Costa Rica.

He currently serves as legal adviser of the National Biodiversity Institute (INBio) and international consultant in the area of intellectual property and biodiversity, biotechnology and biosafety, and access to genetic resources and benefit sharing. He served for more than four years as a member of the National Biodiversity Commission of Costa Rica and a negotiator of the CBD on behalf of the government (Head of the Delegation in the First Conference of the Parties (Nassau 1994) and Member of the Delegation in the COP V (Kenya), VI (Holland), VII (Malaysia) and VIII (Brazil)). Between 1999 and 2001, he served as a co-chairman of the Expert Panel on Access and Benefit Sharing of the CBD and chairman of the Sub-working Group on IPR and Capacity Building during the Second Meeting of the Working Group on Access and Benefit Sharing. He has also participated in the CBD's Technical Expert Group on Certificates of Origin-Legal Provenance-Source, WIPO's Committee on Genetic
Resources and Traditional Knowledge, and the deliberations of the Group of Like-minded Megadiverse Countries.

As a consultant, he has worked on IPR, biotechnology, biosafety and ABS for a variety of national and international institutions (including UNCTAD, ECLAC, IICA, SICA, CCAD, IPGRI, CYMMIT, REMERFI, CATIE, IUCN, COSUDE, EU, IISD, CAF, USAID, FAO, TNC, IDB, ICTSD, PNUMA). He has advised in drafting the Biodiversity Laws of Costa Rica (1998), Bhutan, Honduras, Seychelles and Nicaragua, the draft access regulations and ABS policy guidelines of El Salvador, and participated in regional negotiations on IPR and agriculture for the Eastern Caribbean Countries Association. He has advised the governments of Panama, Chile, and Paraguay. $\mathrm{He}$ served as Adviser to the process of drafting ABS regulations in Dominica and on their ABS practices and instruments. He drafted the Draft Central American Protocol on ABS, the Draft Central American Protocol on Biosafety and the Model Law on Safety in Biotechnology for Central American Countries. He has served as a trainer on ABS issues in Africa, and has written numerous books and articles in the area of IPR, $\mathrm{ABS}$, biosafety, trade and environment. 



\section{About the Authors}

\section{Christian López Silva}

Christian López Silva is a lawyer specialized in biotechnological law. He has worked for the Mexican Government as a legal adviser/consultant in biotech regulation in the areas of access and benefit sharing, traditional knowledge, intellectual property and biosafety. He co-authored and coordinated the legal aspects of the Mexican chapter on ABS in Accessing Biodiversity and Sharing the Benefits: Lessons from Implementing the Convention on Biological Diversity (EPLP 54), Carrizosa, Brush, Wright and McGuire, eds. (November 2004). He has contributed to capacity building projects on biotechnology in the Latin American region for a variety of international bodies including UNEP-GEF, UNDP-GEF, UNU-BIOLAC and ICGEB. He has participated in various capacities in CBD and WIPO meetings and has collaborated with international non-governmental organizations, including the IUCN and the Foundation for Public Research and Regulation, as research fellow and legal adviser, respectively. He has taught biotech regulation in several postgraduate and accredited courses, including the University of Sheffield (UK) and the ICGEB (Italy). He has a Master's degree in Biotechnological Law and Ethics (Chevening Scholar) and is currently at Sheffield, finishing his Doctoral thesis on the WTO EC-Biotech dispute and its impact for developing countries. 



\title{
Publications of the ABS Project
}

\section{EPLP No. 54}

Accessing Biodiversity and Sharing the Benefits: Lessons from Implementing the Convention on Biological Diversity Edited by Santiago Carrizosa, Stephen B. Brush, Brian D. Wright, Patrick E. McGuire, 2004

Also available in Chinese (2006)

\section{EPLP No. 57}

Explanatory Guide to the International Treaty on Plant Genetic Resources for Food and Agriculture Gerald Moore and Witold Tymowski, 2005

Also available in French (2007) and Spanish (2007)

\section{The ABS Series}

\section{EPLP 67, No. 1}

Addressing the Problems of Access: Protecting Sources, While Giving Users Certainty

Jorge Cabrera Medaglia and Christian López Silva, 2007

\section{EPLP 67, No. 2}

Beyond Access: Exploring Implementation of the Fair and Equitable Sharing Commitment in the CBD

Morten Walløe Tvedt and Tomme Young, 2007

EPLP 67, No. 3

A Moving Target: Genetic Resources and Options for Tracking and Monitoring their International Flows Manuel Ruiz and Isabel Lapeña, editors, 2007

\section{EPLP 67, No. 4}

Contracting for ABS: The Legal and Scientific Implications of Bioprospecting Contracts

Shakeel Bhatti, Santiago Carrizosa, Patrick McGuire, Tomme Young, editors, 2007

\section{EPLP 67, No. 5}

Covering ABS: Addressing the Need for Sectoral, Geographical, Legal and International Integration in the ABS Regime Tomme Young, editor, 2007

Translations of The ABS Series into French and Spanish are forthcoming. The project continues to seek funds and other support for translation of the books into other languages. Interested persons and organizations may contact the Environmental Law Centre for more information:

\author{
Daniel Klein, Legal Officer \\ IUCN Environmental Law Centre \\ Godesberger Allee 108-112 \\ 53175 Bonn \\ Germany \\ E-mail: daniel.klein@iucn.org
}

A wider range of publications from the Environmental Law Centre can be found online: http://www.iucn.org/themes/law/info04.html 

IUCN Environmental Law Programme

Environmental Law Centre

Godesberger Allee 108-112

53175 Bonn

Germany

Email: elcsecretariat@iucn.org

Phone: ++49 2282692231

Fax: ++49 2282692250 